\title{
Scale-dependent management of biodiversity and ecosystem processes in fragmented landscapes
}

\author{
Dissertation \\ zur Erlangung des mathematisch-naturwissenschaftlichen \\ Doktorgrades \\ "Doctor rerum naturalium" \\ der GeorgAugustUniversität \\ Göttingen
}

\author{
vorgelegt von \\ Urs Gabriel Kormann
}

aus Bern, Schweiz

Göttingen, Oktober 2014 
Mitglieder des Betreuungsausschusses:

Referent: Prof. Dr. Teja Tscharntke

Koreferent: PD Dr. Christoph Scherber

Tag der mündlichen Prüfung: 22. 10. 2014 

To Grosi, Lotti \& Fredi,

and those who apply the knowledge we generate 


\section{TABLE OF CONTENTS}

$\begin{array}{ll}\text { Summary } & 7\end{array}$

$\begin{array}{ll}\text { Chapter } 1 & 11\end{array}$

General Introduction $\quad 11$

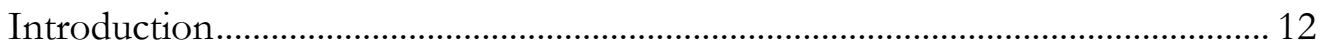

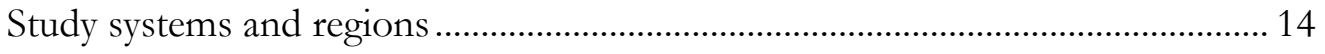

Research aims and methods .................................................................................... 21

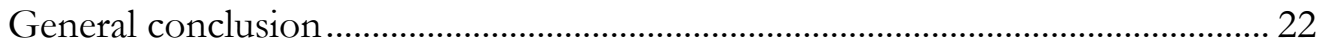

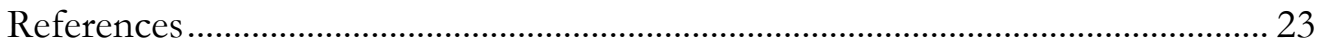

Chapter 2

Local and landscape management drive trait-mediated biodiversity of nine taxa on $\begin{array}{ll}\text { small grassland fragments } & 27\end{array}$

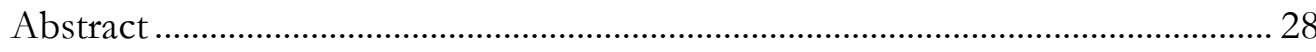

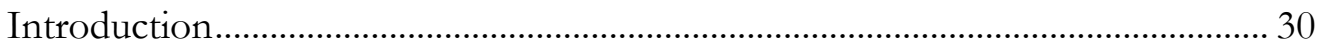

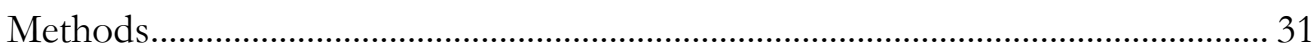

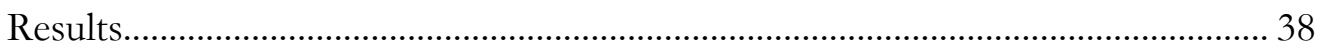

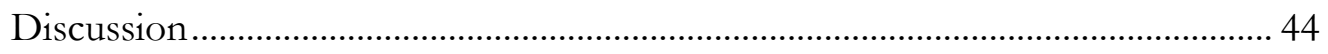

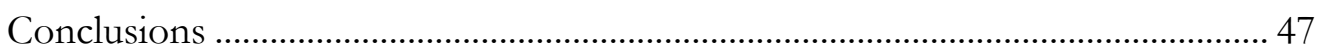

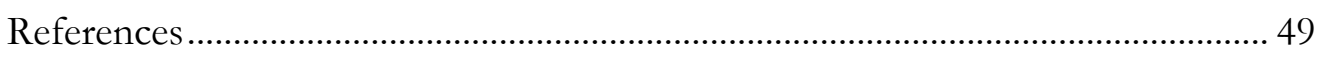

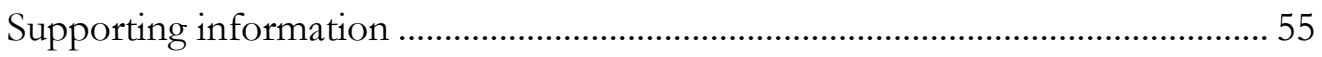

$\begin{array}{ll}\text { Chapter } 3 & 64\end{array}$

Corridors restore animal-mediated pollination in fragmented tropical forest $\begin{array}{ll}\text { landscapes } & 64\end{array}$

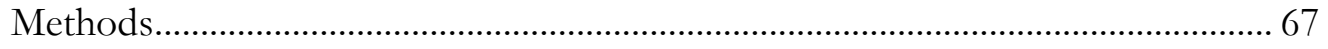

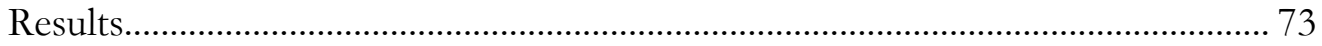

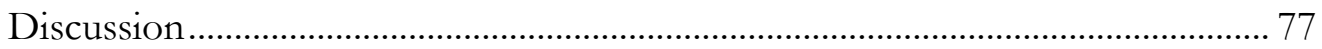

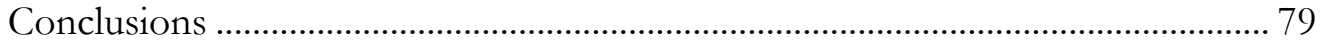

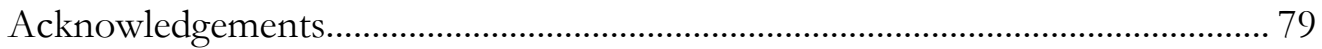

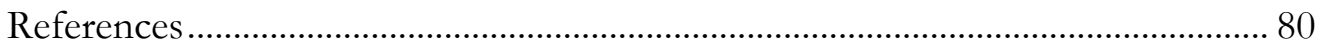

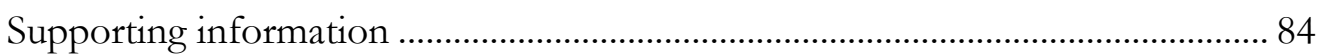


Old growth forest mitigates the erosion of tropical bird communities in human modified landscapes

Abstract 105

Introduction 106

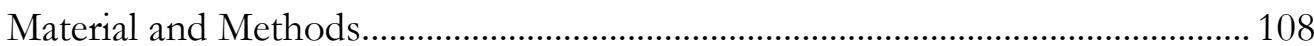

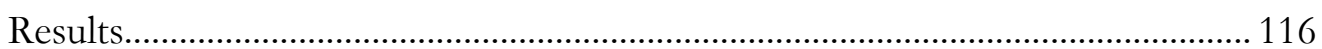

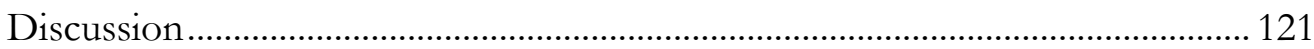

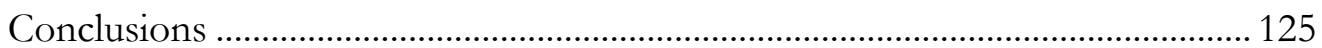

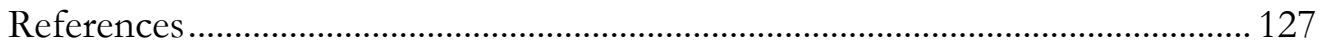

Supporting Information .......................................................................................... 134

$\begin{array}{ll}\text { Acknowledgements } & 138\end{array}$

$\begin{array}{ll}\text { Curriculum vitae } & 140\end{array}$

$\begin{array}{ll}\text { Publications } & 143\end{array}$ 


\section{SUMMARY}

Global biodiversity is increasingly found in fragmented landscapes and populations due to altered human land use. Expansion of agricultural land and changed agricultural practices to the detriment of natural and semi-natural habitats are the most important drivers of this process, caused by the rocketing human demand for agricultural products. Ensuring the persistence of biodiversity and the services it provides to humanity (management of biodiversity and ecosystem services) will require a sound understanding about how biological communities and ecological processes in fragmented landscapes are affected by potentially interacting factors at different spatial scales. However, it remains unclear how properties of fragmented landscapes (landscape composition, landscape configuration, local habitat quality) interact across spatial scales in shaping community structure and ecological processes.

In this thesis I assess the relative role of landscape composition, landscape configuration and local habitat quality at different spatial scales for the conservation of biodiversity and ecosystem processes in fragmented human modified landscapes. My research had two geographical foci: In the first part, I capitalized on the well-known fauna and flora of a traditional, highly fragmented central European agro-ecosystem, to investigate general and trait-mediated patterns across a wide taxonomic range. In the second and third part, I studied bird communities and animal-mediated pollination in the tropics of Central America, which are highly biodiverse but currently sufferan intensive period of human modification.

In the first paper of this study (chapter 2), I used small calcareous grasslands in Germany as our model system, a highly biodiverse, but threatened habitat. Using a large dataset with more than 600 species of nine taxa (bees, butterflies, grasshoppers, hoverflies, leafhoppers, rove beetles, spiders, true bugs, and plants), I tested the separate effects of habitat connectivity, landscape complexity and local management across taxa. In particular, we assessed species richness, community composition and universal, trait-mediated responses. While a high proportion of arable land resulted in a $29 \%$ loss of species richness, increasing connectivity generally enhanced species richness across taxa. Only the large species per taxon, assumed to be more dispersive, profited from increased connectivity. 
While all three management types led to distinct communities, prolonged grazing reduced species richness and abundance, in particular so for red-listed species. In conclusion, we suggest a strategy of alternating mowing and short-term abandonment, focusing on connected sites in diverse landscapes for the conservation of small calcareous grasslands.

The second paper (chapter 3) focuses on the effect of habitat configuration on animal-mediated pollination in tropical fragmented forest landscapes. In Costa Rica, I combined manipulative experiments and field observations to test if narrow woody strips (living fencerows and narrow riparian strips) enhanced pollinator movement, pollen transfer, pollinator availability and pollination success. Using experimental flowers and live plants, I show that such corridors consistently enhance functional connectivity for forestassociated hummingbirds, and in turn pollen transfer between neighboring forest fragments. Corridors drastically increased forest-associated pollinator availability in small fragments, which approached zero in equally sized patches lacking such connections. In parallel, corridors not only substantially increased pollination success of an ornithophilous keystone herb, but averted complete pollination breakdown in small forest fragments. Overall, these results suggest that simple corridors elements can maintain pollination mutualisms and plant gene in tropical forest fragments through increased functional connectivity and pollinator availability.

In the third paper (chapter 4), I evaluated the effect of landscape composition (landscape wide amount and type of forest) and configuration (fragment size and edge proximity) on bird communities, disentangling the effect of old growth forest from secondary forest in a human-modified landscape of southern Costa Rica. I characterized the entire bird community in 49 forest fragments, representing independent variation of patch size and landscape wide forest amount, and found that $\alpha$-diversity and abundance at the plot scale varied little between fragments. In contrast, $\alpha$ - diversity and abundance of forest birds at the plot scale, in particular insectivores, was nearly halved in edges and secondary forest compared to core areas of primary forest. The same was found in small fragments, but only below a critical threshold of old growth forest within the landscape (22.6\%). Similarly, $\beta$ - diversity of the entire bird community was strongly reduced among small fragments, but only at low landscape-level percentage of oldgrowth forest. Finally, bird communities were similar to primary forest only in fragments surrounded by a high proportion of old growth forest. Overall, the minimum local area (fragment size) required to support substantial levels of $\alpha$ - and $\beta$ - diversity is lowered in landscapes with a high proportion of old growth forest. Thus, the benefits of old growth not only manifest locally 
but extend into the landscape scale - not the local fragment area, but the percentage of oldgrowth forest within a landscape drives biodiversity conservation success. Given that human land use is driving landscape structure, there is a need to keep a minimum amount of primary forest - thus, the conservation of old growth forest should remain a key conservation priority.

In conclusion, the results of my dissertation show that biodiversity patterns areshaped by local habitat characteristics, and habitat composition and configuration at the landscape scale. Landscape configuration (corridors) strongly influenced movement between fragments, which in turn affected an ecosystem process (pollination). While small fragments can contribute significantly to conservation in the tropics, there is a need to keep old growth forest above a critical landscape-level threshold. Myresults emphasize that future conservation of biodiversity and ecosystem services in fragmented landscapes should not only aim to improve local habitat quality, but additionally improve habitat quality and configuration at an appropriate landscape scale. Conservation schemes lacking such a landscape perspective will likely fail to achieve an optimum conservation outcome and thus waste the limited resources available. 


\section{Chapter 1}

\section{GENERAL INTRODUCTION}




\section{INTRODUCTION}

Human modification of ecosystems is irrefutably the major threat to biodiversity and ecosystem services worldwide (Sala et al. 2000, Tilman et al. 2001, Dirzo et al. 2014). This modification is mainly fuelled by increasing human demand for agricultural products, which causes (i) large scale-conversion of native habitat into farmland and (ii) changes in agricultural intensity on existing agricultural land, i.e. intensification (e.g. increased nitrogen input, irrigation, landscape homogenisation) or abandonment of unproductive marginal areas.

Although agricultural expansion and changes to management intensity are predicted to increase at a global scale, the geographical importance of both processes for biodiversity conservation varies (Queiroz et al. 2014). In many high-income countries, particularly in Central Europe, a large proportion of biodiversity occurs in low-intensity agricultural systems (e.g. extensive grasslands and traditional orchards) and thus explicitly requires agricultural land use (WallisDeVries et al. 2002, Tscharntke et al. 2005). Nevertheless, much of this biodiversity has been lost during the second half of the last century, which was characterized by the conversion of traditional, low-intensity agro-ecosystems into homogenized, intensive landscapes (Tscharntke et al. 2005). Therefore, an important focus of conservation in Europe is the maintenance of traditional and extensive agricultural processes to protect semi-natural habitats.

In contrast, tropical regions contain the majority of biodiversity hotspots worldwide (Myers et al. 2003), with most biodiversity persisting in relatively undisturbed, forested areas (Gibson et al. 2012, Laurance et al. 2012). As large-scale agriculture and the accompanying deforestation have only begun recently, many species are poorly adapted to agricultural land-use and require forested areas to prosper (Gibson et al. 2012, Frishkoff et al. 2014). This is particularly worrisome, as the majority of new croplands globally replace tropical forests (Gibbs et al. 2010), causing an annual forest loss of 5-10 million hectares (Mayaux et al. 2005, FAO 2011). Consequently, conservation efforts in the terrestrial tropics often focus on forest ecosystems (Gibson et al. 2012).

Despite the different starting points, highly biodiverse habitats in the tropics and central Europe share a common feature: they are increasingly restricted to fragmented systems. In the tropics, $\sim 25 \%$ of the existing rainforest already persists in fragments surrounded by agriculture (Wade et al. 2003). Similarly, many biodiverse grassland habitats in central European only persist in scattered remnants embedded in intensive agriculture (Tscharntke et al. 2005). 
For sound biodiversity management, the (i) patterns of biodiversity and (ii) the processes determining these patterns have to be identified. In fragmented landscapes, biodiversity patterns and ecological processes occur at several spatial scales. The most intuitive spatial scale is the local (fragment) scale, which has been the focus of most ecological research (Tscharntke et al. 2012). Given that fragments often represent a biologically significant unit, i.e. the "local population" within which genetic exchange occurs (Slatkin 1977, Fahrig \& Merriam 1994), they have been the traditional unit for conservation research and management (i.e. 1 fragment $=1$ landowner). Thus, traditional management strategies often tried to maximize biodiversity at the fragment scale (Tscharntke et al. 2012). Previously studied local factors that shape biodiversity within a fragment include management-mediated habitat quality (e.g. Bailey et al. 2010, chapters 2 and chapter 4 of this thesis), edge effects (e.g. Malcolm 2014, chapter 4 of this thesis) or fragment size (SteffanDewenter \& Tscharntke 2000, chapter 4 this thesis).

However, biodiversity patterns in fragmented landscapes are also determined by processes acting at the landscape scale. First, habitat fragments are linked to additional areas of habitat in the landscape by dispersal. Several theoretical frameworks describe this link, the two most important being island biogeography (MacArthur \& Wilson 1967) and metapopulation theory (Levins 1970, Hanski 1998). Island-biogeography describes species richness of isolated islands as a function of island area, the extinction rate of populations and importantly, immigration of species from a mainland-source. Similarly, metapopulation theory describes the occurrence of species in habitat fragments as a function of dispersal processes between fragments, the available habitat in the landscape, and lacks the assumption of a mainland source. So far, both theories have had a fundamental influence on the conservation planning of fragmented landscapes. Following Fischer \& Lindenmayer (2007), this conservation concept may be approximated as "the more, the better", both in terms of the size of neighbouring fragments and the connectivity to them. That is, the persistence of species in a fragment is enhanced through immigration from nearby, preferentially large fragments (MacArthur \& Wilson 1967, Hanski 1998). Importantly, movement between fragments can be influenced by the intervening landcover type, the "matrix" (Ricketts et al. 1993, Dricsoll 2013). In addition to this, more recent research has demonstrated strong effects of the matrix, which are not directly linked to movement (reviewed in Driscoll et al. 2013): These include spillover processes from populations in adjacent habitats (Rand et al. 2007), input of matter (fertilizer, pesticides, Tilman 2001), or provision of alternative resources in the neighbouring landscape (Holzschuh et al. 2011). 
Despite the traditional focus on fragment-scale conservation, policy makers increasingly acknowledge the importance of a holistic landscape perspective for optimized conservation outcomes. In parallel, research increasingly focuses on determining relevant spatial scales driving conservation outcomes, however large knowledge gaps remain (summarized in Tscharntke et al. 2012), that this thesis aims to explore. A large research gap exists regarding the relative importance and potential interactions of factors across spatial scales: For example, when are local scale management regimes more important than landscape factors in determining the results of conservation efforts (chapter 2, chapter 4)? That is, can labour intensive management (e.g. manual mowing) provide high conservation outcomes in landscapes dominated by intensive farming? Similarly, the relative roles of local habitat amount vs. landscape scale habitat availability on biodiversity need to be clarified (chapter 4). In particular, more knowledge is needed with respect to critical thresholds, below or above which biodiversity collapses (chapter 4). A further research gap is the separate impact of landscape composition and configuration on metacommunity dynamics and biodiversity functions (Fahrig 2003, Fahrig 2013, chapter 3, chapter 4), particularly regarding ecosystem services in the tropical systems (Hadley and Betts 2012). For example, which factors influence the transfer of individuals and genes between fragments (chapter 3)? In addition, many studies in fragmented landscapes restrict their analyses to species richness and abundance, but disregard completely species identities (chapter 4), conservation relevant characteristics such as red list status (chapter 2), or the contribution of species to ecosystem services (chapter 3). Finally, researchers increasingly investigate which factors drive the similarity of fragmented local communities at a landscape scale, and thus their potential to mutually complement the landscape wide species pool $(\beta-$ and $\gamma$ - diversity, Tscharntke et al. 2012, chapter 4).

\section{STUDY SYSTEMS AND REGIONS}

\section{Calcareous grasslands in central Germany}

The first part of this thesis focuses on the conservation management of invertebrates and plants in European calcareous grasslands. These grasslands are one of the most species rich habitat types in Central Europe, hosting an extraordinarily diverse assemblage of thermophilic and specialised invertebrates and plants, many of which are red-listed (van Swaay 2002, Stoll et al. 2009, chapter 2, Fig. 1). Calcareous grasslands are a semi-natural habitat that developed through traditional, low intensity grazing (predominantly by sheep) and mowing on rocky outcrops and shallow soils (Wilmanns 1993). This habitat has faced massive losses in area of up to $90 \%$ during the agricultural intensification of the last century (WallisDeVries et al. 2002). The major causes for this loss were changes in management, such as fertilisation, conversion to arable land or 
abandonment and subsequent shrub encroachment (Poschlod \& WallisDeVries 2002). In previous centuries, calcareous grasslands were also connected through the transport of diaspores by transhumance shepherding, but the cessation of this management practice has additionally contributed to the breakdown of dispersal processes between fragments (Wagner et al. 2013).

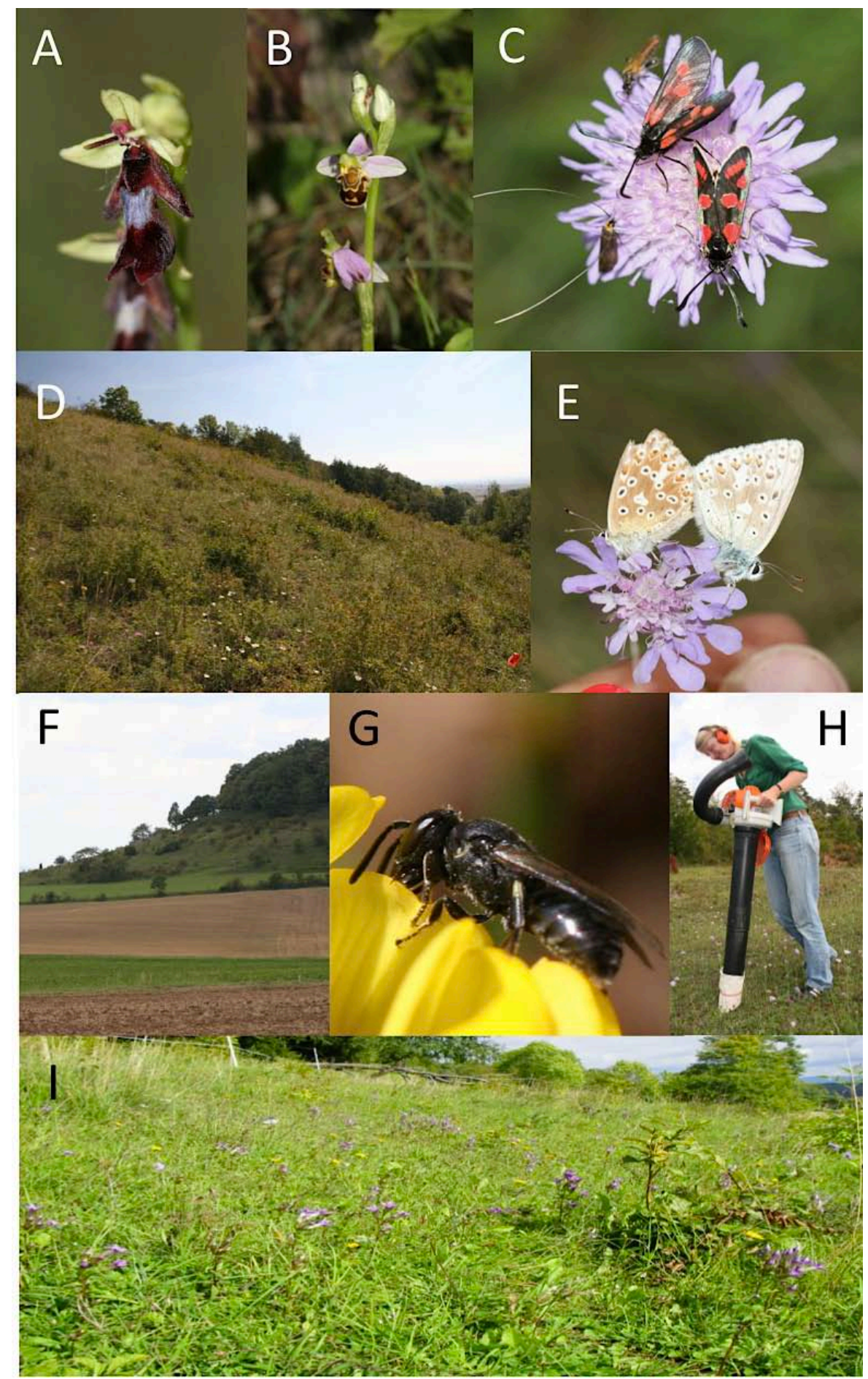

Fig. 1: Calcareous grasslands around Göttingen. A) Ophrys insectifera. B) Ophrys apifera C) Zygaena carniolica and Zygaena cf. filipendulae on Scabiosa columbaria. D) An abandoned grassland with Prunus spinosa. E) Mating Polymmatus icarus. F) Calcareous grassland (background) surrounded by intense agriculture (to the front). G) Small wild bee (cf. Hylaeus) visiting Hippocrepis comosa. H) Verena Rösch doing suction sampling. I) Extensively grazed grassland. Photo I) by Verena Rösch, all others by U. Kormann. 
Here, we studied calcareous grasslands in southern Lower Saxony, Central Germany, situated in the districts of Göttingen and Northeim $\left(51.5^{\circ} \mathrm{N}, 9.9^{\circ} \mathrm{E}\right)$. This region is characterized by intensive agriculture (cereals, oil seed rape and fertile meadows), but there are still $\sim 220$ fragments of calcareous grassland in the region. Most of these fragments are small (<1ha, Fig. 2), and increasingly threatened by shrub encroachment resulting from management cessation. Previous studies on these grasslands have reported reduced species richness and turnover for butterflies with decreasing fragment size, and a positive influence of landscape complexity on bees, syrphids and leafhoppers (e.g. Krauss et al. 2003; Meyer et al. 2007, Rösch et al. 2013).

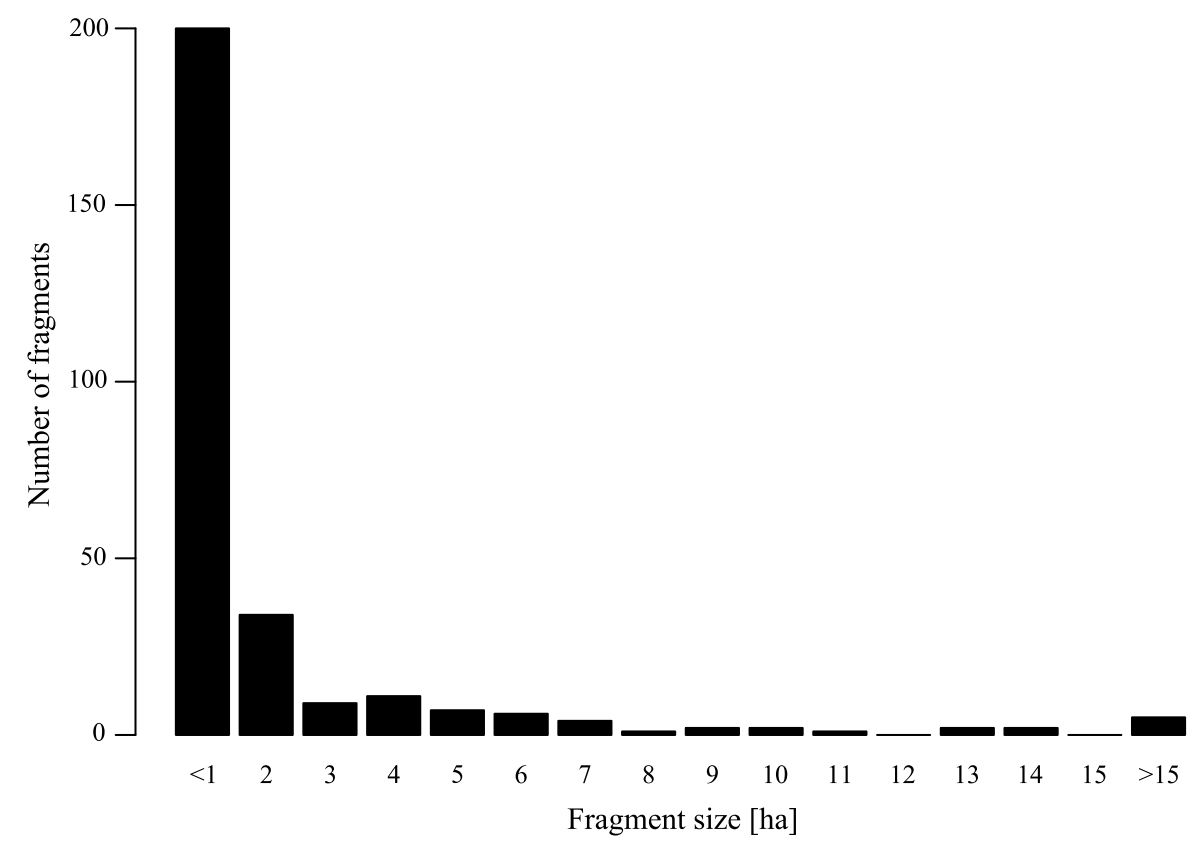

Fig. 2. Fragment size distribution in the study area of the districts of Göttingen and Northeim.

\section{Forest fragments in Southern Costa Rica}

The second and third papers in this thesis focus on the conservation management of animal-mediated pollination and bird communities in tropical forest fragment of Central America. This region is part of the Central American biodiversity hotspots (Myers 2003), and hosts a high density of endemic species (Myers 2003, Fig.3 and Fig. 4).

We worked in the human-modified landscape of the Coto Brus region, Southern Costa Rica, around the Las Cruces Biological Station ( $8^{\circ} 47 \mathrm{~N}, 82^{\circ} 57 \mathrm{~W}$, Fig. 5.). The study area ranges from $850-1^{\prime} 500 \mathrm{~m}$ a.s.l. and covers an area of $\sim 30$ 000ha. Originally, this landscape was covered by contiguous Pacific pre-montane humid forest, but massive deforestation since the 1950s reduced the original forest cover to $\sim 30 \%\left(\sim 8^{\prime} 844 \mathrm{ha}\right)$ of its former extent (Zahavi, Duran 
\&Kormann in prep., Fig. 5). Most deforestation occurred between 1960 and 1980 (annual deforestation rate $\sim-3.81 \%$, Zahavi, Duran \& Kormann in prep.). Forest loss slowed strongly during the period 1980-1997 (annual deforestation $\sim-0.58 \%$ ) and was relatively constant thereafter (annual deforestation 1999-2014 -0.66\%), despite a country-wide logging - ban after 1996 (Steed 2003). Concomitantly, remaining forest shifted from a predominantly large single forested area to c. 2000 smaller forest patches, the majority of which range between 1-10ha in size (Fig.3A \& 3D). With the fragmentation of forest into progressively smaller patches, the area of forest exposed to edge effects increased: The area of forest closer than $100 \mathrm{~m}$ to the nearest edge has risen from 1,000ha to almost 1,400hasince 1960. Further disturbance is generated by frequent selective illegal logging and poaching (Fig. 4).

Today, approximately $70 \%$ of the current forest cover originates from before 1960 , while most of the remaining $30 \%$ has to be considered secondary forest. This forest patchwork is largely embedded in an agricultural matrix of pasture $(>90 \%)$, coffee plantations $(\sim 5 \%)$ and to a lesser extent human settlements (Hadley et al. 2014). Despite the increased degree of forest fragmentation, an extensive network of linear strips of woody vegetation remains in the landscape (Zahavi, Duran \& Kormann subm., chapter 3). Previous studies in the region documented depauperated species communities in small forest fragments for a broad variety of taxonomic groups (e.g. birds Sekercioglu et al. 2002, orchid bees Brosi 2009, hummingbirds Hadley \& Betts 2014). Further, breakdown of pollination mutualism in small forest fragments has been reported (Hadley \& Betts 2014). In addition, small forest fragments have been identified as crucial elements to maintain bird-mediated pest control for coffee plantations in the region (Karp et al. 2013). 

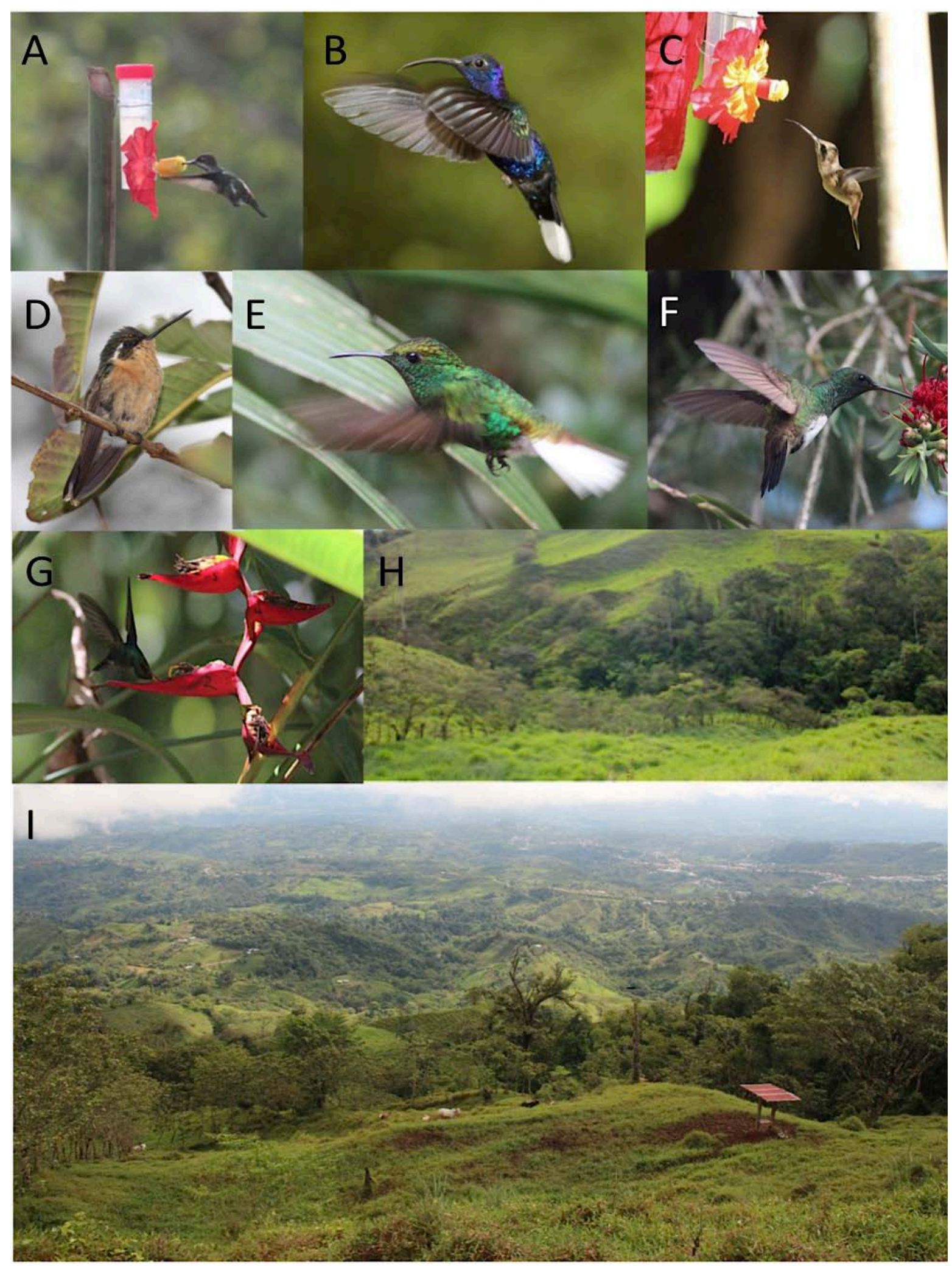

Fig. 3: Coto Brus study region and hummingbird community. A) Heliomaster longirostris at experimental feeder. B) Male Campylopterus hemileucurus. C)Phaethornis striigularis inspecting a feeder prototype.D)Female Lampornis castaneoventris (endemic). E) Elvira chionura (endemic).F) Amarilia edward (endemic). G) Phaethornis guy pollinating Heliconia tortuosa in an experiment. H) Living fencerow. I) Typical land use in the region. All photos by U. Kormann. 


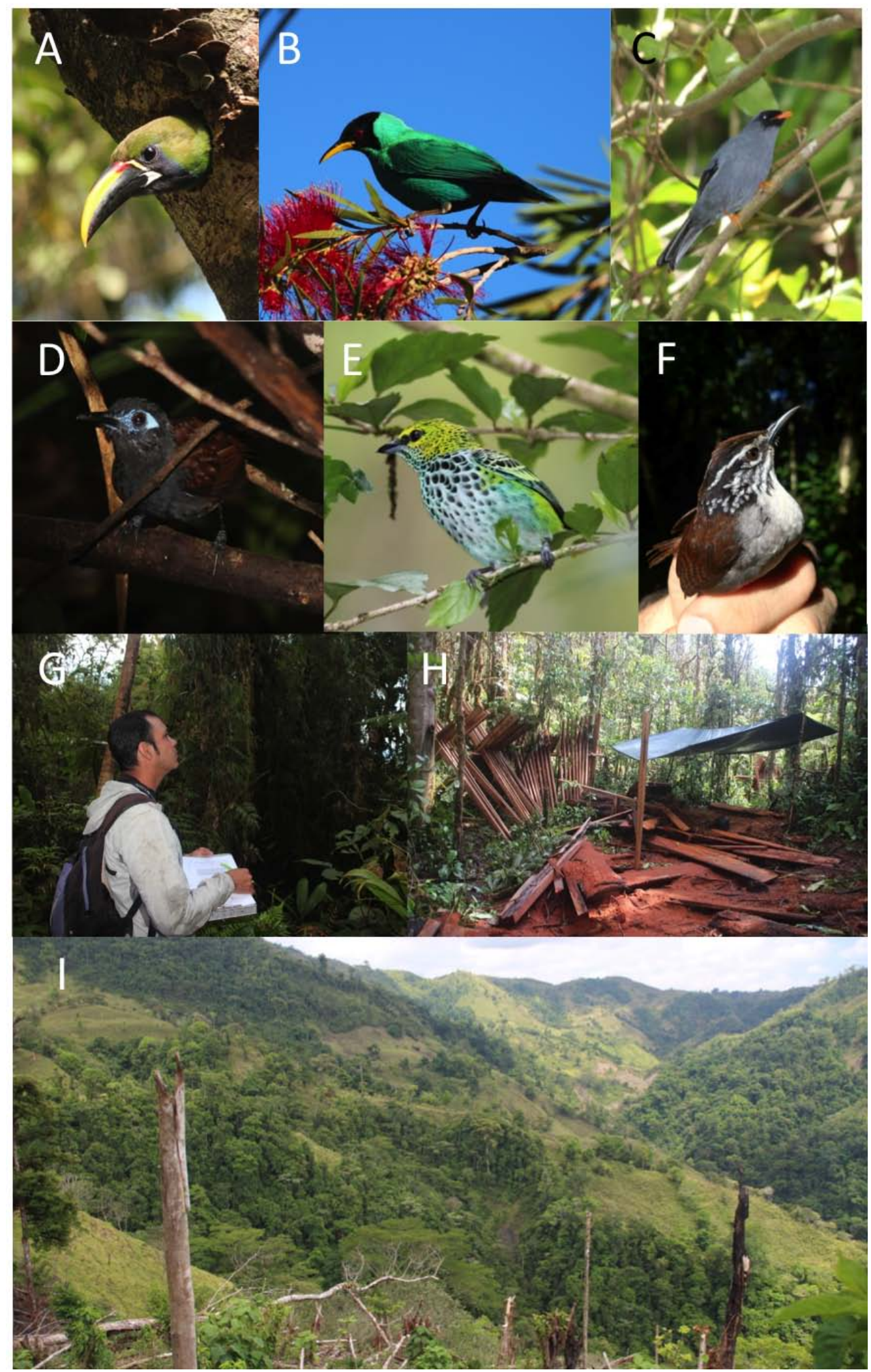

Fig.4: Bird communities in forest fragments of the Coto Brus region. A) Aulacorbynchus prasinus at its nest. B) Chlorophanes spiza. C)Myadestesmelanops, a species commonly trapped for pet trade.D)Myrmecizaexsul, a forest insectivore. E) Tangaraguttata, afrugivore. F) Henicorbinaleucophrys, a forest insectivore. G) Jeisson Figueroa duringa point count. H) Illegal logging camp. I) Land clearing tothe front, forest fragments to the back. All photos by U. Kormann. 

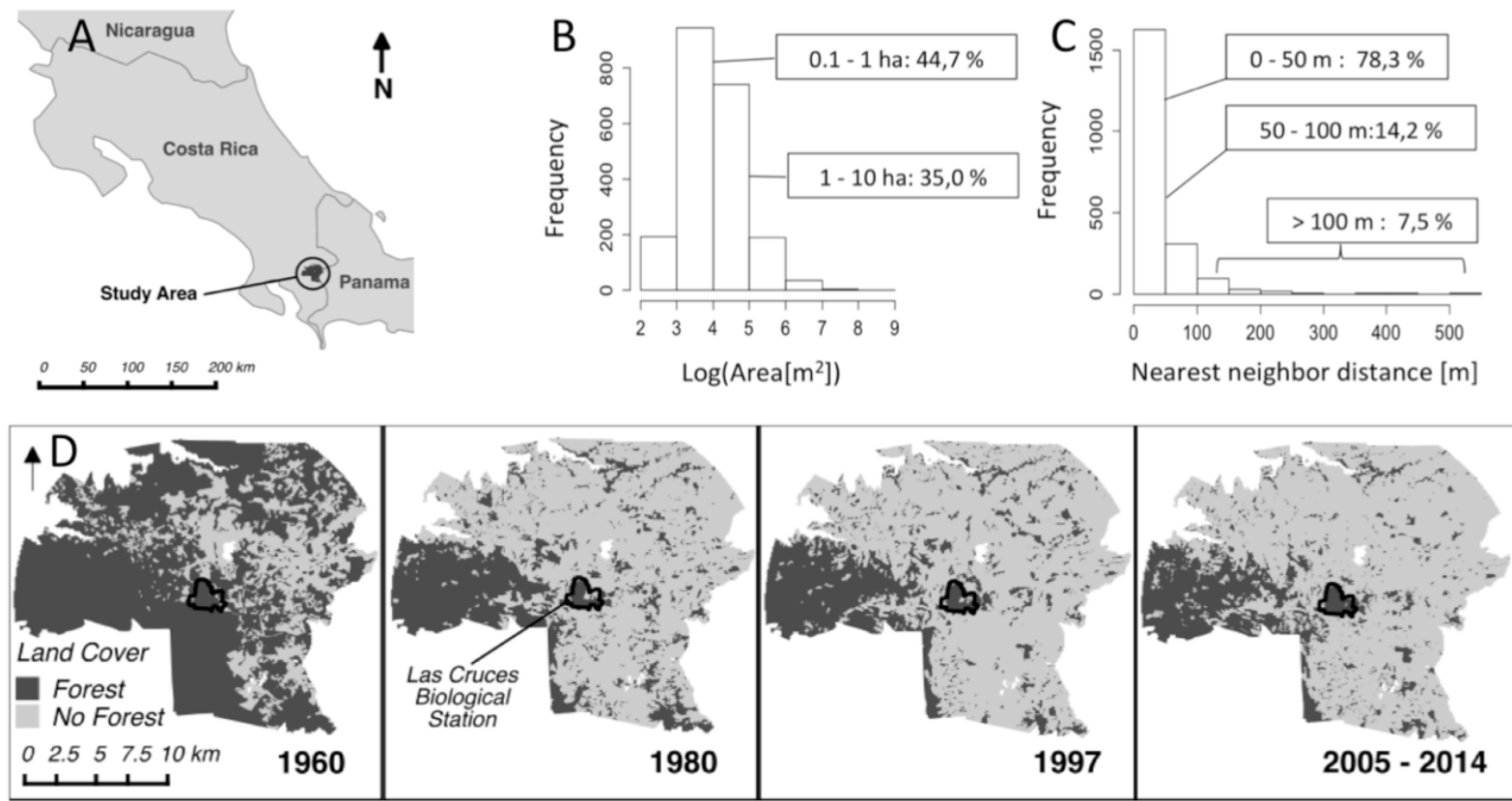

Fig. 5: Characteristics of the Costa Rican study area. A) Geographic location. B)Size distribution of the current forest fragments in the study region. Included are old growth and secondary forest. C) Nearest neighbor distances between forest fragments. D) Regional deforestation history. Shown are forest cover maps for four points of time (1960, 1980, 1997 and 2005-14). Maps are based or orthorectified, digitized aerial photos (Zahavi, Duran \& Kormann submitted). 


\section{RESEARCH AIMS AND METHODS}

In this thesis, we investigate the importance of landscape composition, landscape configuration and local habitat quality at different spatial scales to inform appropriate biodiversity management in fragmented, human modified landscapes.This thesis comprises one observational landscape scale study on calcareous grassland communities in Central Europe (chapter 2). The second and the third studies focus on a fragmented neotropical forest landscape, where we studied corridor effects on hummingbird-pollination (chapter 3) and effects of forest composition and configuration on neotropical bird communities (chapter 4).

In chapter 2, we tested the independent effects of habitat connectivity, landscape complexity (arable land within a $1 \mathrm{~km}$ ) and local management on species richness, community composition and trait-based responses (body size and Red List status) of nine taxa (butterflies, bees, grasshoppers, hoverflies, leafhoppers, rove beetles, spiders, true bugs, plants) in small calcareous grasslands in Central Germany. We used a large dataset ( 20000 specimens, 600 species) to test (i) if local management, habitat connectivity and landscape complexity consistently shape species richness, abundance and community composition across taxonomic group (ii) if body size (as a proxy for dispersal capacity) indicates the sensitivity to landscape scale factors, i.e. if the larger-sized species of a taxon can benefit more from connectivity than the smaller ones and (iii) if negative effects of management cessation, decreasing connectivity and landscape simplification are more pronounced in Red-Listed species.

In chapter 3, we evaluated the effect of an abundant landscape element, i.e. narrow wooded corridors, on animal-mediated pollination in a tropical human-modified landscape. In particular, we were interested if narrow woody strips (living fencerows and narrow riparian strips) can increase (i) pollinator movement, (ii) pollen transfer between forest fragments, (iii) pollinator availability and (iv) pollination success in a forest dependent, fragmented hummingbird-plant study system in Southern Costa Rica. To assess this, we combined manipulative experiments, observational data and novel statistical approaches.We collaborated with the Oregon State University (USA) and the statistical department at Gottingen University.

In chapter 4, we assessed the effects of landscape composition and configuration and their potential interaction on bird communities in fragmented forest remnants of the Coto Brus study system, Costa Rica. For this, we characterized bird communities in forest fragments, which represented independent gradients in patch size and amount of forest in the surrounding landscape (forest cover within $1000 \mathrm{~m}$ radius). We were interested if landscape wide forest amount, fragment size, old growth and secondary forest drive patterns of (i) $\alpha$ - diversity (ii) $\beta$ - 
diversity and (iii) community shift after deforestation. This chapter also emphasizes the question of whether high landscape-wide forest amount has the capacity to mitigate negative effects of small patch size. This part of the thesis was also a collaboration with the Oregon State University (USA) and the Organisation for Tropical Studies OTS, Costa Rica.

\section{GENERAL CONCLUSION}

The aim of this thesis was to investigate the relative role of landscape composition, landscape configuration and local habitat quality at different spatial scales for the conservation of biodiversity and ecosystem processes in fragmented human modified landscapes. Seeking generalizability, we performed studies in two systems with contrasting biogeography, human land use history and conservation relevant vegetation type (i.e. forest vs. grassland).

These studies provided the following new key insights:

First, while connectivity generally enhanced species richness on calcareous grasslands, arable land-use in the matrix was detrimental. Connectivity was especially important for the large species per taxon. Communities changed with management type, and grazing was detrimental for red-listed species. Thus, conservation of small calcareous grasslands should focus on connected sites in diverse landscapes, potentially with an alternating strategy of mowing and short-term abandonment.

Second, narrow woody corridors consistently enhanced all aspects of pollination by forest dependent hummingbirds. Importantly, increased connectivity by corridors averted complete pollination breakdown in small forest fragments. This highlights the importance of maintaining connectivity between small forest remnants, which are among the most common landscape elements throughout the tropics. Our results suggest that this can be done for some species by simple woody corridors that are widely accepted by farmers.

Third, while $\alpha$-diversity and abundance of non-forest specialist birds remained stable, forest specialists depended strongly on primary forest, both at the local and at the landscape scale. The minimal local area (fragment size) required to maintain high levels of $\alpha$ - and $\beta$ - diversity decreased if landscape-level amount old forest remains above a critical threshold ( $25 \%)$. Thus, benefitsof old forest not only manifest locally but extend to the landscape scale - not local fragment area, but the percentage of old growth forest within a landscape drives biodiversity conservation success. Since human land use drives landscape structure, there is a need to maintain a minimum amount of primary forest - the conservation of old growth forest should remain a key conservation priority. 
Despite the stark contrasts between the two study systems, our results support the idea that biodiversity patterns in both regions are not only determined by local habitat quality (management type, forest type), but to a large extent also by landscape composition (landscape level habitat amount, proportion of arable land) and landscape configuration (fragment size, corridors and edge effects). Importantly, we showed that adequate management of landscape configuration, i.e. increasing connectivity with simple corridors, not benefit biodiversity beyond species richness, but promotes ecosystem functioning.

In conclusion, this thesisstrongly suggests that future conservation of biodiversity and ecosystem services in fragmented landscapes should not be restricted to habitat improvement at the local scale, but additionally improve habitat quality and configuration at an appropriate landscape scale. This will not only require a change of mind for local conservation practitioners but importantly, of policy makers to preferentially channel available conservation funds to projects that take into account a landscape perspective. Further, our results emphasize that complementary to large scale conservation areas (e.g. nature reserves), small fragments and smallscale improvements of landscape connectivity constitute a highly valuable contribution to conserve biodiversity and ecosystem processes in both temperate and tropical ecosystems. To inform adequate implementation, future research will have to identify critical compositional and configurational habitat thresholds, above which biodiversity, species interactions and ecosystem functions in human-modified landscapes can persist.

\section{REFERENCES}

Bailey, D., et al. (2010) Effects of habitat amount and isolation on biodiversity in fragmented traditional orchards. Journal of applied ecology, 47(5), 1003-1013.

Brosi, B. J. (2009) The effects of forest fragmentation on euglossine bee communities (Hymenoptera: Apidae: Euglossini). Biological Conservation, 142(2), 414-423.

Dirzo, R., Young, H. S., Galetti, M., Ceballos, G., Isaac, N. J., \& Collen, B. (2014) Defaunation in the Anthropocene. Science, 345(6195), 401-406.

Driscoll, D. A., Banks, S. C., Barton, P. S., Lindenmayer, D. B., \& Smith, A. L. (2013) Conceptual domain of the matrix in fragmented landscapes. Trends in ecology \& evolution, 28(10), 605613.

Fischer, J. \& Lindenmayer, D.B. (2007) Landscape modification and habitat fragmentation: a synthesis. Global Ecology and Biogeography, 16 (3), 265-280.

Fahrig, L., \& Merriam, G. (1994) Conservation of fragmented populations. Conservation biology, $8(1), 50-59$. 
Fahrig, L. (2003) Effects of habitat fragmentation on biodiversity. Annual review of ecology, evolution, and systematics, 34: 487-515.

Fahrig, L. (2013) Rethinking patch size and isolation effects: the habitat amount hypothesis. Journal of Biogeography, 40(9), 1649-1663.

Foley J, et al. (2011) Solutions for a cultivated planet. Nature 478: 337-42.

Food and Agriculture Organization of the United Nations (FAOSTAT) http://faostat3.fao.org/faostat-gateway/go/to/home/E (accessed, October 2014).

Frishkoff, L. O., et al. (2014) Loss of avian phylogenetic diversity in neotropical agricultural systems. Science, 345(6202), 1343-1346.

Gibbs, H. K., et al. (2010) Tropical forests were the primary sources of new agricultural land in the 1980s and 1990s. Proceedings of the National Academy of Sciences, 107(38), 16732-16737.

Gibson, L., et al. (2011) Primary forests are irreplaceable for sustaining tropical biodiversity. Nature, 478(7369), 378-381.

Hadley, A. S., \& Betts, M. G. (2012) The effects of landscape fragmentation on pollination dynamics: absence of evidence not evidence of absence. Biological Reviews, 87(3), 526-544.

Hadley, A. S., Frey, S. J., Robinson, W. D., Kress, W. J., \& Betts, M. G. (2014) Tropical forest fragmentation limits pollination of a keystone understory herb. Ecology (in press).

Hanski, I. (1998) Metapopulation dynamics. Nature, 396, 41-49.

Hanski, I., Alho, J., \& Moilanen, A. (2000) Estimating the parameters of survival andmigration of individuals in metapopulations. Ecology, 81, 239-251.

Holzschuh, A., Dormann, C. F., Tscharntke, T., \& Steffan-Dewenter, I. (2011) Expansion of mass-flowering crops leads to transient pollinator dilution and reduced wild plant pollination. Proceedings of the Royal Society B: Biological Sciences, rspb20110268 (online only)

Holzschuh, A., Dudenhöffer, J. H., \& Tscharntke, T. (2012) Landscapes with wild bee habitats enhance pollination, fruit set and yield of sweet cherry. Biological Conservation, 153, 101-107.

Karp, D. S., et al. (2013) Forest bolsters bird abundance, pest control and coffee yield. Ecology letters, 16(11), 1339-1347.

Krauss, J., Steffan-Dewenter, I., \& Tscharntke, T. (2003) How does landscape context contribute to effects of habitat fragmentation on diversity and population density of butterflies? Journal of Biogeography(online only), 30(6), 889-900.

Laurance, W. F., et al. (2012) Averting biodiversity collapse in tropical forest protected areas. Nature, 489(7415), 290-294.

Levins, R. (1970) Extinction. Lectures Notes in Mathematics and Life Sciences, 2, 75-107.

MacArthur, R.H. \& Wilson, E.O. (1967) The Theory of Island Biogeography. Princeton University Press, Princeton, New Jersey. 
Malcolm, J. R. (1994) Edge effects in central Amazonian forest fragments. Ecology, 75(8), 24382445.

Mayaux, P., et al. (2005) Tropical forest cover change in the 1990s and options for future monitoring. Philosophical Transactions of the Royal Society B: Biological Sciences, 360(1454), 373 384.

Meyer, B., Gaebele, V., \& Steffan-Dewenter, I.D. (2007) Patch Size and Landscape Effects on Pollinators an Seed Set of the Horseshoe Vetch, Hippocrepis comosa, in an Agricultural Landscape of Central Europe. Entomologia Generalis, 30(2), 173-185.

Myers, N. (2003). Biodiversity hotspots revisited. BioScience, 53(10), 916-917.

Poschlod, P. \& WallisDeVries, M.F. (2002) The historical and socioeconomic perspective of calcareous grasslands - lessons from the distant and recent past. Biological Conservation, 104(3), 361-376.

Queiroz, C., Beilin, R., Folke, C., \& Lindborg, R. (2014) Farmland abandonment: threat or opportunity for biodiversity conservation? A global review. Frontiers in Ecology and the Environment, 12(5), 288-296.

Rand, T. A., Tylianakis, J. M., \& Tscharntke, T. (2006) Spillover edge effects: the dispersal of agriculturally subsidized insect natural enemies into adjacent natural habitats. Ecology Letters, 9(5), 603-614.

Rösch, V., Tscharntke, T., Scherber, C., \& Batáry, P. (2013) Landscape composition, connectivity and fragment size drive effects of grassland fragmentation on insect communities. Journal of Applied Ecology, 50 (2), 387-394.

Sala, O. E., et al. (2000) Global biodiversity scenarios for the year 2100. Science, 287(5459), 1770 1774.

Şekercioglu, C.. H., et al. (2002) Disappearance of insectivorous birds from tropical forest fragments. Proceedings of the National Academy of Sciences, 99(1), 263-267.

Slatkin, M. (1977). Gene flow and genetic drift in a species subject to frequent local extinctions. Theoretical population biology, 12(3), 253-262.

Steed, B.(2003) Completing the Mosaic: the conservation of private lands in Costa Rica.Journal of Land Use\&Environmental Law,23 173-218.

Steffan-Dewenter, I., \& Tscharntke, T. (2000) Butterfly community structure in fragmented habitats. Ecology Letters, 3(5), 449-456.

Stoll, P., Oggier, P., \& Baur, B. (2009) Population dynamics of six land snail species in experimentally fragmented grassland. The Journal of Animal Ecology, 78(1), 236-246.

Taylor, P. D., Fahrig, L., Henein, K., \& Merriam, G. (1993) Connectivity is a vital element of landscape structure. Oikos 68 (3), 571-573. 
Tilman, D., et al. (2001) Forecasting agriculturally driven global environmental change. Science, 292(5515), 281-284.

Tscharntke, T., Klein, A. M., Kruess, A., Steffan-Dewenter, I., \& Thies, C. (2005) Landscape perspectives on agricultural intensification and biodiversity-ecosystem service management. Ecology Letters, 8(8), 857-874.

Tscharntke, T., et al. (2012) Landscape moderation of biodiversity patterns and processes-eight hypotheses. Biological Reviews, 87(3), 661-685.

Van Swaay, C.A.M. (2002) The importance of calcareous grasslands for butterflies in Europe. BiologicalConservation, 104(3), 315-318.

Wade, T. G., Riitters, K. H., Wickham, J. D., \& Jones, K. B. (2003) Distribution and causes of global forest fragmentation. Conservation Ecology, 7(2), 7.

Wagner, H.H., Rico, Y., Lehnert, H., \& Boehmer, H.J. (2013) Process-based long-term evaluation of an ecological network of calcareous grasslands connected by sheep herding. Ecography, 36(3), 374-382.

WallisDeVries, M.F., Poschlod, P., \& Willems, J.H. (2002) Challenges for the conservation of calcareous grasslands in northwestern Europe: integrating the requirements of flora and fauna. BiologicalConservation, 104(3), 265-273.

Wilmanns, O. (1993) Ökologische Pflanzensoziologie, Eine Einführung in die Vegetation Mitteleuropas. Quelle und Meyer, Heidelberg \& Wiesbaden. 


\title{
Chapter 2
}

\author{
LOCAL AND LANDSCAPE MANAGEMENT \\ DRIVE TRAIT-MEDIATED BIODIVERSITY OF \\ NINE TAXA ON SMALL GRASSLAND
}

FRAGMENTS

Urs Kormann', Verena Rösch ${ }^{1}$, Péter Batáry, Teja Tscharntke, Kirill Márk Orci, Ferenc Samu \& Christoph Scherber

${ }^{1}$ Equally contributing authors

published in Diversity \& Distributions 2015 1(14) 


\section{Abstract}

Aim: Biodiversity across the globe is heavily eroded by intensified management at local and landscape scales. Species communities of calcareous grasslands, which are among Europe's most diverse habitats, are severely threatened by the cessation of appropriate traditional management, loss of habitat connectivity and simplification of the surrounding landscape. However, our understanding of these often interrelated factors remains limited, in particular for trait-mediated responses across taxa. Here, we test the independent effects of local management (grazing, mowing and abandonment), habitat connectivity (measured by a connectivity index) and landscape complexity (indicated by the percentage of arable land) on nine taxa: plants, butterflies, bees, grasshoppers, hoverflies, spiders, true bugs, rove beetles and leafhoppers on small semi-natural calcareous grassland remnants $(<1 \mathrm{ha})$.

\section{Location: Central Germany.}

Methods: We use a joint analysis across taxa to identify general and trait-mediated responses (body size and Red List status) in species richness, abundance and community composition. Results: We identified three key drivers of local diversity patterns: First, an increasing proportion of arable land from 10 to $80 \%$ led to a $29 \%$ loss of overall species richness. Second, despite differences between taxa, increasing habitat connectivity generally enhanced species richness. Connectivity effects were more accentuated in the large species per taxon, which can be expected to be good dispersers. Finally, grazing reduced species richness and abundance much more than annual mowing or short term abandonment (5-15 years), in particular for red-listed species. We attribute this to of plant resource removal through overgrazing and trampling.

Main conclusions: For the conservation management of small calcareous grasslands, we advocate an alternating strategy of mowing or lenient grazing and short-term abandonment, prioritising connected fragments surrounded by diverse landscapes. Despite taxon-specific responses, our study across nine taxa demonstrates universal, trait-mediated 
effects of management, landscape complexity and connectivity on local biodiversity in fragmented communities.

Keywords: community dissimilarity, calcareous grasslands, connectivity, habitatfragmentation, landscape composition, multi-taxon approach 


\section{INTRODUCTION}

Habitat fragmentation, habitat loss and agricultural intensification are major reasons for biodiversity decline worldwide (Sala et al., 2000; Fahrig, 2003; Fischer \& Lindenmayer, 2007), causing reductions in habitat area and connectivity. Small or isolated fragments are reached by fewer immigrants than large or connected ones (MacArthur \& Wilson, 1967; Losos \& Ricklefs, 2010). Furthermore, small fragments may experience higher extinction rates. The type of land use between fragments (matrix) also affects dispersal and persistence of species in fragmented landscapes. Simple landscapes with high proportions of arable land are a hostile matrix for many organisms (Ewers \& Didham, 2006; Prugh et al., 2008). However, matrix types may influence permeability (Eycott et al., 2012; Öckinger et al., 2012), as shown e.g. for mass flowering crops (Holzschuh et al., 2013).

In fragmented landscapes, surprisingly little is known about the effects of landscape factors like habitat connectivity and matrix complexity on invertebrate communities across taxa (Prugh et al., 2008). Previous studies focussed on few taxa with a bias on butterflies and bees (e.g. van Swaay, 2002; Krauss et al., 2003; Brückmann et al., 2010, but see Zulka et al., 2013) and were rarely designed to distinguish between local management, connectivity and landscape complexity (but see Sjödin et al., 2007; Pöyry et al., 2009). This lack of knowledge is particularly accentuated for trait-mediated patterns across taxa (Öckinger et al., 2010). These may be life history traits like body size or conservationrelevant characteristics such as Red List status. Body size can mediate the response of species to habitat loss, predicting dispersal capability in many taxa (Jenkins et al., 2007; Öckinger et al., 2010; Sekar, 2012).

In Central Europe, calcareous grasslands are among the most species-rich habitat types for both plants and invertebrates. Over centuries, calcareous grasslands have been maintained through traditional extensive (sheep) grazing and, less frequently, by mowing (Wilmanns, 1993). With increasing agricultural intensification, management has become progressively uneconomical for farmers. Therefore, up to $90 \%$ of calcareous grasslands have been lost over the past decades due to changed management (Poschlod \& WallisDeVries, 2002). As a result, the distribution of the remaining habitat patches is nowadays highly fragmented. Accordingly, many species occurring on these grasslands have been categorised as threatened in Red Lists (Binot-Hafke et al., 2011). The current conservation of calcareous grasslands primarily focuses on local habitat management, 
aimed at mimicking traditional management. As rotational shepherding has become scarce, the remnants are often kept open by grazing, mowing or shrub removal. Contrastingly, the composition of the landscape surrounding a habitat fragment is often disregarded (Zulka et al., 2013).

In the study area (southern Lower Saxony, Central Germany) the landscape surrounding calcareous grasslands is intensively managed. More than $70 \%$ of all fragments are small ( $<1$ ha, Fig. S1), yet of high conservation value due to their high biodiversity (Tscharntke et al., 2002; Rösch et al., 2013) and their potential role as stepping stones (Saura et al., 2014). Therefore, in order to avoid the confounding influence of differences in fragment size, we here focus on small fragments ( $<1 \mathrm{ha})$. We set up a landscape-scale mensurative experiment to disentangle the effects of local management, landscape complexity and connectivity on nine taxa (plants, butterflies, bees, grasshoppers, hoverflies, spiders, true bugs, rove beetles and leafhoppers).

In particular, we test the following hypotheses:

1) Species richness, abundance and community composition change with the composition and connectivity of the surrounding landscape and depend on the type of local management.

2) Body size (as a proxy for dispersal capacity) indicates the sensitivity to landscape scale factors, i.e. the larger species of a taxon can benefit more from connectivity than the smaller ones.

3) Negative effects of management cessation, decreasing connectivity and landscape simplification are more pronounced in red-listed species.

\section{METHODS}

\section{Study area}

The study area was situated in Central Germany, southern Lower Saxony $\left(51.5^{\circ} \mathrm{N}\right.$, $9.9^{\circ} \mathrm{E}$, see Map S1 in Supporting Information) in the districts of Göttingen and Northeim.

About $30 \%$ of the area is intensively managed arable land, with wheat, maize, sugar beet and oilseed rape grown in crop rotation. Forest fragments and grasslands make up another $40 \%$ of the landscape. For the present study, we focused on fragments of calcareous grasslands (Mesobrometum erecti Koch 1926 (Ellenberg \& Leuschner, 2010)) that are patchily distributed across the landscape (mainly on South-facing slopes). These grasslands are either mown or extensively grazed, or management has been abandoned. 
Mowing occurs once a year, usually in autumn or winter to ensure successful ripening of plant seeds. Grasslands are grazed predominantly by ruminants such as sheep and goats, but to a lesser extent also by horses or cattle, starting in the middle of June at the earliest. Grazing frequently results in trampling, areas of open soil and in the removal of a large proportion of the available plant material. Management of abandoned fragments used in our study ceased between five and 15 years ago. We did not include fragments that had been abandoned for longer, since they did not display the characteristics of calcareous grasslands anymore.

\section{Study design}

The study was conducted between April and September 2011. A total of 30 small fragments of calcareous grasslands $(0.045-0.69 \mathrm{ha}$, mean $=0.3 \mathrm{ha})$ were selected from a total pool of about 200 potential fragments usingdigital maps (ATKIS-DLM 25/1 Landesvermessung und Geobasisinformationen Niedersachsen 1991-1996, Hanover, Germany) in ArcGIS 10.0 (ESRI Geoinformatik GmbH, Hanover, Germany) and extensive field surveys in the study area. Sites were selected to be either grazed, mown or abandoned (10 each). Fragments were grazed by single species (sheep, goats, cows, highland cattle, ponies or horses). For the type of livestock used on the grazed fragments see Table S3. Grazing intensity varied greatly from a few days to months.

The fragments were selected with randomization along two orthogonal gradients (Fig. 1, Fig. S2, Table S3): (1) A landscape composition gradient, i.e. increasing percentage of arable land within a radius of $1000 \mathrm{~m}$ around fragments $(9-78 \%$, mean $=44 \%)$. We chose a radius of $1000 \mathrm{~m}$ since we expected some taxa to be dispersal limited (e.g. leafhoppers, plants, true bugs) so that the close surroundings of the fragments would be most important for them. Several previous studies have shown that the percentage of arable land (used here) is highly correlated with landscape Shannon diversity in the study region (e.g. Thies et al., 2003; Roschewitz et al., 2005). (2) A gradient in habitat connectivity, measured by a connectivity index (CI) as described in Hanski et al. (2000):

$$
\mathrm{CI}_{\mathrm{i}}=\Sigma \exp \left(-\alpha \mathrm{d}_{\mathrm{ij}}\right) \mathrm{A}_{\mathrm{i}}^{\beta}
$$

where $A_{j}$ is the area (in $\mathrm{m}^{2}$ ) of the $j^{\text {th }}$ neighbouring fragment and $d_{i j}$ is the edge-toedge distance (in $\mathrm{m}$ ) between focal fragment $i$ and neighbouring fragment $j . \alpha$ is a speciesspecific parameter describing species' dispersal ability and $\beta$ is a parameter describing the scaling of immigration. Since we applied the connectivity index to entire communities 
containing many taxa, both scaling parameters $\alpha$ and $\beta$ were set to the commonly used value of 0.5 (e.g. Brückmann et al., 2010). Connectivity indices calculated with $\alpha=0.5$ or $\alpha$ $=1$ were highly correlated (Spearman's rho $=0.997, \mathrm{p}=<0.001$ ). We included all fragments of calcareous grassland that were located a radius of $1000 \mathrm{~m}$ around the focal fragment. If only part of a fragment was inside the $100 \mathrm{~m}$ buffer and it continued outside it, we included the whole fragment area, weighted by the shortest distance to the central fragment. Roadsides and field margins with plant species typical for calcareous grasslands (Krauss et al., 2003) were uncommon and were not taken into account. To ensure that fragments exhibited the characteristics of calcareous grasslands, we only included fragments that harboured more than five of the plant species that are characteristic for calcareous grasslands in the study area (Krauss et al., 2003). The values of the connectivity index ranged between 0 and 443 (mean $=121$ ) with larger values indicating higher levels of connectivity.

The explanatory variables habitat connectivity and landscape complexity were weakly, but non-significantly correlated (following Dancey and Reidy (2004), Pearson correlation, $\mathrm{r}$ $=-0.19, \mathrm{t}=-1.05$, d.f. $=28, P=0.303$, Fig. S2).

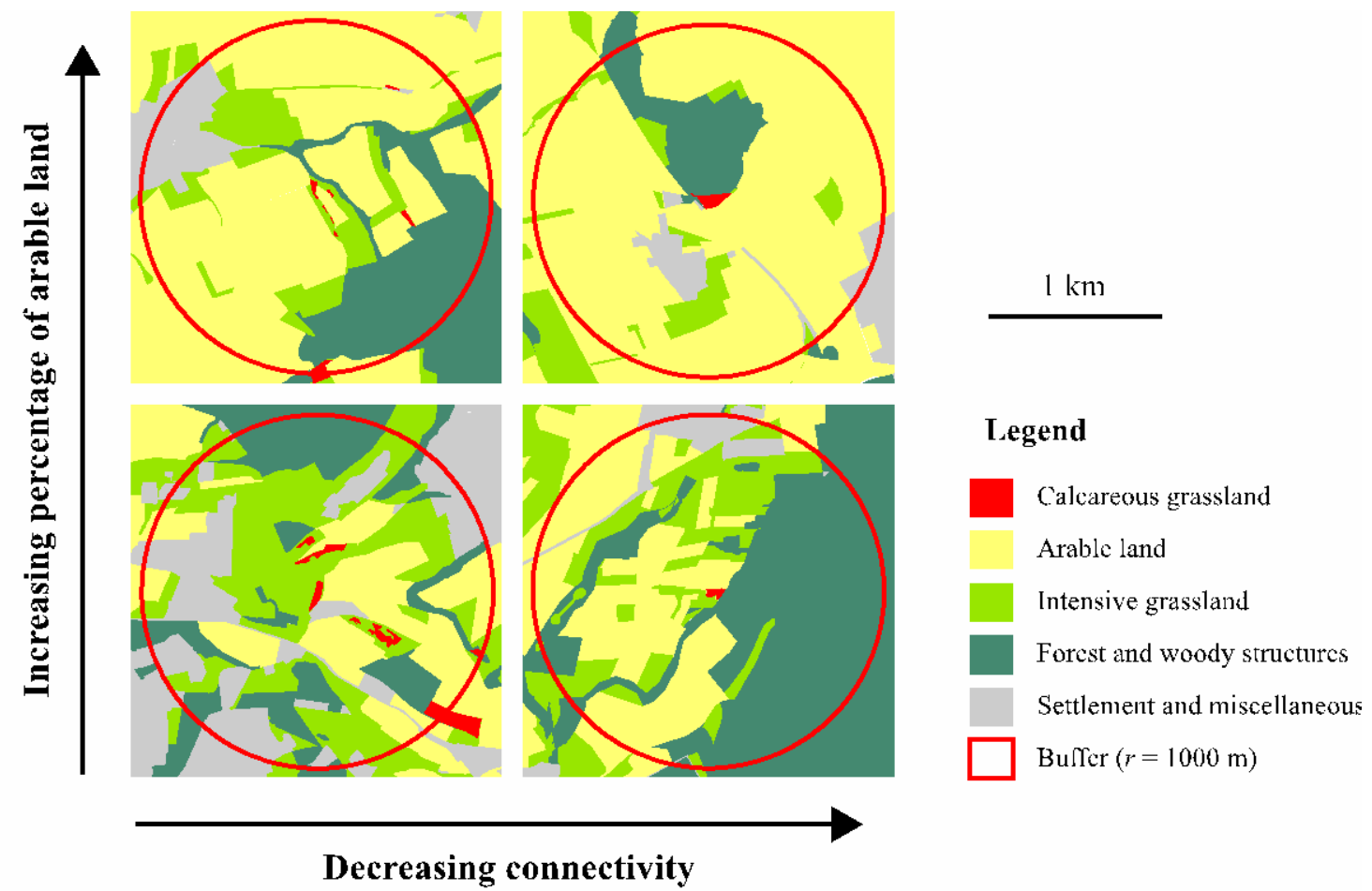

Fig. 1. Illustration of the study design, showing calcareous grasslands with high (left) and low (right) levels of habitat connectivity and high (above) and low (below) levels of landscape complexity (measured as percentage of arable land). 


\section{Sampling methods}

At the beginning of June 2011, we recorded the vegetation (only vascular plants) in four botanical plots per fragment $(1 \times 5 \mathrm{~m})$. The plots were well spread across the fragments, about 10-15 maway from each other within a fragment (minimum distance $3 \mathrm{~m}$ ); fragment edges were avoided.

Leafhoppers (Hemiptera: Auchenorrhyncha), true bugs (Hemiptera: Heteroptera) and spiders (Arachnida) were sampled by suction sampling (modified SH 56 leaf blower, Stihl, Waiblingen, Germany) on the botanical plots (20 suction pulses per plot, i.e. 80 pulses per fragment) in dry weather on three occasions in 2011 (early June, late July, early September). Transects were located on the botanical plots but exceeded them (length approximately $10 \mathrm{~m}$ ). Spiders were sampled by both suction sampling and pitfall trapping (see below) to improve coverage of species sampled (Standen, 2000).

Hoverflies (Diptera: Syrphidae) and bees (Hymenoptera: Apiformes) were surveyed with three pan traps per fragment during two three-day rounds (mid June, mid July). Each trap consisted of a yellow plastic cup ( $23 \mathrm{~cm}$ diameter, filled with salt water), treated with UV-reflecting paint and mounted at vegetation height to maximize trapping efficiency (Stephen \& Rao, 2005; Westphal et al., 2008). Traps were separated by at least $15 \mathrm{~m}$ from the next trap and from the fragment edge (Westphal et al., 2008), to minimize potential interactions between traps and edge effects.

We sampled butterflies (Lepidoptera: Hesperioidea, Papilionidea and Zygaenidae) using standardized visual transect walks (Krauss et al., 2003). Fragments were visited four times (late May - early September) under suitable weather (temperature $>18^{\circ} \mathrm{C}$, wind speed $<4$ Beaufort, $<50 \%$ cloud cover, 10:00 - 17:30). Transects on each fragment were $180 \mathrm{~m}$ long and divided into three non-overlapping 60-m subtransects. Butterflies were sampled during four minutes per subtransect using a butterfly net within a $5 \mathrm{~m}$ wide band, identified and released immediately or collected for genitalisation.

We recorded grasshoppers (Orthoptera: Caelifera, Ensifera) during their peak density in late summer. Each fragment was sampled on two occasions (late July, late August) under dry and warm conditions $\left(>22^{\circ} \mathrm{C}\right.$, cloud cover $\left.<50 \%, 10: 00-18: 00\right)$. We applied a boxquadrat procedure for sampling, using a foldable wooden construction (1 x $1 \mathrm{~m})$ with gauze sides (70 cm high) that was repeatedly placed onto the vegetation. This method yields more consistent and unbiased abundance estimates than sweep netting (Gardiner et al., 2005; Gardiner \& Hill, 2006). Grasshoppers were collected in five $1 \times 1 \mathrm{~m}$ squares near each botanical plot, resulting in $401 \times 1 \mathrm{~m}$ squares per fragment in total. Only adult specimens 
were determined to species level and incorporated into further analyses.

Rove beetles (Coleoptera: Staphylinidae) and spiders were sampled twice with pitfall traps for seven days each, in warly August and in late August/early September. We employed three pitfall traps per fragment (plastic cups filled with salt water \& detergent, 12 $\mathrm{cm}$ diameter, plastic roof) with $>15 \mathrm{~m}$ distance from each other and $>15 \mathrm{~m}$ away from the fragment edge.

All specimens caught (except butterflies released after identification) were transferred into ethanol (70\% vol.) and identified to species level. Only adult specimens were determined and used for later analyses.

For leafhoppers and true bugs, species feeding on woody host plants were excluded, except if host tree saplings were present in botanical plots. Species feeding on woody plants whose larvae fed on herbs or grasses were included in the analysis.

For species with morphologically similar female specimens (e.g. Ribantodelphax, Anaceratagallia, Psammotettix) (Biedermann \& Niedringhaus, 2004),species identity was inferred from male specimens; if this was not possible, identification stopped at genus level. If males of more than one species of a genus were present, the number of females was assumed to mirror that of males.

\section{Specification of traits}

All taxa were subdivided into habitat specialists and generalists, except for rove beetles for which no suitable literature was available. Plant habitat specialization was defined following Krauss et al. (2003). Arthropod habitat specialization was derived from (i) habitat requirements typical for calcareous grasslands (i.e. warm, dry habitat conditions; short, grazed swards; open soil) and (ii) diet preferences (i.e. host plants occurring exclusively on calcareous grasslands), based on published work and expert opinions (see References S1). Species were classified as habitat specialists if conditions (i) and/or (ii) were fulfilled, whereas it was classified as a generalist if neither (i), nor (ii) were fulfilled.

Body sizes of species was defined as body length (from head to end of abdomen) taken from published literature (Supplementary References S1). For species with sexually dimorphic body sizes, we used mean body size of both sexes. For butterflies, we used median forewing length as this was a better indicator of dispersal ability. Species larger than the taxon-specific median body size were considered large; all others were considered small. Taxon's Red List was based on the most recent and regional Red List available (Remane et al., 1997; Melber, 1999; Garve, 2004; Binot-Hafke et al., 2011; Westrich et al., 2011). 


\section{Statistical analyses}

Species richness and abundance of the nine taxa were summed over transects, vegetation plots and pan traps. Arthropod species richness and abundance were summed over the sampling occasions.

We performed four types of analyses: (1) Analysis of species richness and abundance for every taxon separately and cumulated over all taxa.(2) Redundancy analysis for all taxa separately to assess changes in community composition. (3) A hierarchical analysis including all taxa simultaneously to determine general trends in species richness and abundance. (4) Two hierarchical analyses including all taxa simultaneously to determine if richness patterns are generally modified by relative body size and Red List status, respectively.

(1) Species richness and abundance were analysed for every taxon separately and cumulated over all taxa (additive species richness). Depending on the distribution of the response variables (assessed using $\mathrm{R}$ package fitdistrplus, URL: http://cran.rproject.org/web/packages/fitdistrplus/index.html), we fitted either generalized linear models with negative binomial or Poisson errors (glm.nb or glm, R package MASS (Venables \& Ripley, 2002)) or linear models (see Table S1), starting with the following explanatory variables: (1) habitat connectivity, measured as described in Equation 1, (2) the percentage of arable land in a $1000 \mathrm{~m}$-buffer around each fragment and (3) habitat management (abandonment, grazing or mowing), including an interaction between connectivity and arable land. The families and link functions used in generalized linear models were selected based on residual deviance. In addition, we divided residual deviance by residual degrees of freedom to assess overdispersion. Model selection was then done using an automated stepwise selection procedure based on AICc (function stepAICc based on function step AIC (R package MASS (Venables \& Ripley, 2002), but corrected for small sample sizes, see URL: http://wwwuser.gwdg.de/ cscherb1/stepAICc.txt). Multiple comparisons between management types were conducted using the glht function in $\mathrm{R}$ package multcomp (Hothorn et al., 2008). Models showed no spatial autocorrelation of the residuals (i.e. Moran's I was $>0.05)$.

(2) For the nine taxa, partial redundancy analyses (RDAs) with all three explanatory variables (management, connectivity and percentage of arable land) were performed with function $r$ da from $\mathrm{R}$ package vegan (Oksanen et al., 2013). We performed four RDAs: one with each of the explanatory variables, with the two remaining ones as conditional variables, and an ordinary RDA including all three variables. Interactions between explanatory 
variables were not tested. Prior to analysis, community data matrices were Hellingertransformed, weigting rare species lower (Legendre \& Gallagher, 2001). A permutation test with 999 permutations with function permutest from R package vegan (Oksanen et al., 2013)was used to asses statistical significance.

(3) To identify general patterns of species richness across all taxa, we ran linear mixed models (Pinheiro et al., 2014) including all taxa simultaneously. In such a joint analysis, all taxa contribute equally to identify general responses, independent of overall species richness. This is in contrast to the analysis of cumulated species richness described above, which is strongly influenced by species-rich taxa.

We standardized species richness per taxon by dividing it by the taxon's mean species richness across all fragments. The resulting value reflects the relative increase in species richness, compared to the average species richness of the taxon, and can be compared between taxa. We fitted linear mixed-effects models to standardized species richness (function lme, R package nlme (Pinheiro et al., 2014)), using fragment as a random factor. Note that because taxon was the lowest level in the hierarchy, it was not included in the random-effects part of the model as this would have saturated the model with random effects. Taxon was included as a fixed factor into the maximal model. Heteroscedasticity was accounted for by an exponential variance function, where the variance was an exponential function of the fitted values (weights $=\operatorname{varexp}($ ). Models with and without variance function were fitted using restricted maximum likelihood; AICc values indicated that variance functions considerably improved model fit.

In the fixed-effects part of the models, we started model selection with the same set of explanatory variables as for the taxon-specific models, but included interactions with taxon. Model selection was done using step $A I C c$ for models fit by maximum likelihood.

(4) Finally, we fitted two linear mixed effects models to test if explanatory variables affected species richness differently for small vs. large species of a taxon, and red-listed vs. unthreatened species of a taxon. Standardisation of species richness per taxon and model selection were performed as described above. In addition to management, connectivity and proportion of arable land, we included interactions of size class (large/small) or Red List status (red-listed/unthreatened) with all other explanatory variablesand their interactions. Fragment was treated as a random factor. Taxon was included as a fixed and not as a random factor. We ran additional models including a spatial correlation structure of the form "correlation $=$ corCompSymm $($ form $=\sim \mathrm{X}+\mathrm{Y})$ ". However, these models showed similar 
parameter values to those without correlation structure. Further, models with spatial correlation had consistently higher AICc values than those without (deltaAICc $>2$ ).

For consistency, we opted to not include fragment area in any of our analyses, as some of the models did not converge when fragment area was included.

\section{RESULTS}

On the 30 calcareous grassland fragments we recorded 604 species (154 specialists, 360 generalists) with 19696 arthropod individuals (8016 specialists, 11680 generalists) within the nine taxa. The most species-rich taxon was plants with 148 species, followed by spiders ( 83 species), bees and true bugs (82 and 80 species, respectively). The least diverse taxon was grasshoppers with only 10 species (Table S2).

In the analysis of abundance and species richness of all taxa combined and of each of the nine taxa individually we found that increasing the percentage of arable land always tended to negatively affect species richness (all nine taxa) and in most cases abundance (all arthropod taxa except hoverflies and rove beetles) (Table 1, Fig. S3, Table S4).

Table 1. Generalized linear models and linear models on the effects of landscape context (\% arable land), connectivity (a connectivity index described in Hanski et al. (2000)) and management on the abundance and species richness of all species, specialists and generalists. For management, successive differences between treatment levels are shown (g: grazed, m: mown, a: abandoned). Only variables included in the final models are shown. P-values $<0.05$ are depicted in bold characters.

\begin{tabular}{|c|c|c|c|c|c|c|c|c|c|}
\hline & & \multicolumn{4}{|c|}{ Abundance } & \multicolumn{4}{|c|}{ Species richness } \\
\hline & & Estimate & SEM & $\mathrm{z}$ & $P$ & Estimate & SEM & $z$ & $P$ \\
\hline \multirow[t]{6}{*}{ All taxa } & Intercept & 6.49 & 0.06 & 110.00 & $<0.001$ & 5.15 & 0.07 & 68.75 & $<0.001$ \\
\hline & $\%$ Arable land & & & & & -0.01 & $<0.01$ & -3.08 & 0.002 \\
\hline & Connectivity & & & & & & & & \\
\hline & Management g-a & & & & & & & & \\
\hline & Management m-a & & & & & & & & \\
\hline & Management m-g & & & & & & & & \\
\hline \multirow[t]{6}{*}{ Specialists } & Intercept & 6.24 & 0.32 & 19.64 & $<0.001$ & 3.98 & 0.14 & 29.07 & $<0.001$ \\
\hline & $\%$ Arable land & -0.02 & 0.01 & -2.24 & 0.025 & $<-0.01$ & $<0.01$ & -1.65 & 0.099 \\
\hline & Connectivity & & & & & & & & \\
\hline & Management g-a & & & & & & & & \\
\hline & Management m-a & & & & & & & & \\
\hline & Management m-g & & & & & & & & \\
\hline \multirow[t]{6}{*}{ Generalists } & Intercept & 5.73 & 0.08 & 73.66 & $<0.001$ & 4.59 & 0.08 & 55.56 & $<0.001$ \\
\hline & $\%$ Arable land & & & & & -0.01 & $<0.01$ & -2.98 & 0.003 \\
\hline & Connectivity & & & & & & & & \\
\hline & Management g-a & -0.35 & 0.11 & -3.14 & 0.005 & & & & \\
\hline & Management m-a & -0.05 & 0.11 & -0.49 & 0.878 & & & & \\
\hline & Management $\mathrm{m}-\mathrm{g}$ & 0.29 & 0.11 & 2.65 & 0.022 & & & & \\
\hline
\end{tabular}


Management significantly changed community composition of all taxa combined as well as for most taxa individually (except for grasshoppers, rove beetles and hoverflies, Fig. 2, Table 2). In particular, the three management types harboured three distinct communities, both for habitat generalists and habitat specialists. Except for hoverflies, where the abundance of species with aphidophagous larvae was increased in landscapes with a high proportion of arable land, the surrounding landscape did not have an effect on community composition.

Among the three management types, grazing tended to reduce both species richness and abundance across arthropod taxa (Fig 3a, Table 3). The only case where grazing had a positive effect compared to abandonment was for bee species richness and abundance. In some arthropod taxa (butterflies, true bugs, spiders, leafhoppers), species richness and/or abundance were increased by abandonment (Table 1, Fig. S3, Table S4). Plant species richness was not affected by management.

Accumulated species richness was strongly reduced in simplified landscapes (-29\%, Table 1, Fig. S3). Similarly, standardized species richness per taxon decreased in simplified landscapes (Fig. 3b, Table 4). Furthermore, standardized species richness also generally increased with connectivity, but this effect depended on the taxon (Fig. 3c, Table 3). In contrast to all other taxa, species richness of hoverflies and leafhoppers slightly decreased with increasing connectivity (Fig. 3c). Furthermore, the connectivity effect was modified by body size: The number of large-bodied species within each taxon significantly increased with increasing connectivity, whereas the number of small-bodied species per taxon did not (Fig. 4a, Table 4). Finally, grazing had a much stronger negative effect on red-listed species than on unthreatened species (Fig. 4b, Table 5). Interactions between management, proportion of arable land and connectivity was never retained in the best models in any analysis. 
Table 2. Results of RDA analyses: influence landscape composition ( $\%$ arable land), connectivity and management type on the community composition of all species, specialists, generalists, bees, butterflies, grasshoppers, true bugs, plants, spiders, rove beetles, syrphid flies and leafhoppers. P-values $<0.05$ are depicted in bold characters.

\begin{tabular}{|c|c|c|c|c|c|c|c|}
\hline & & $\begin{array}{l}\text { partial RDA } \\
\% \text { of variation }\end{array}$ & $P$ & & & $\begin{array}{c}\text { partial RDA \% } \\
\text { of variation }\end{array}$ & $P$ \\
\hline \multirow[t]{5}{*}{ All taxa } & $\%$ Arable & & & \multicolumn{3}{|c|}{ True bugs \% Arable } & \\
\hline & land & 3.2 & 0.980 .500 & & land & 3.1 & 0.950 .537 \\
\hline & Connectivity & 3.2 & 0.980 .517 & & Connectivity & 2.3 & 0.660 .706 \\
\hline & Management & 11.6 & 1.770 .001 & & Management & 11.5 & $1.76 \mathbf{0 . 0 0 1}$ \\
\hline & Total & 18.4 & 1.410 .001 & & Total & 14.4 & 1.050 .374 \\
\hline \multirow[t]{5}{*}{ Generalists } & $\%$ Arable & & & \multirow[t]{5}{*}{ Plants } & $\%$ Arable & & \\
\hline & land & 3.4 & 1.020 .430 & & land & 3.1 & 0.930 .560 \\
\hline & Connectivity & 3.1 & 0.930 .609 & & Connectivity & 4.0 & 1.210 .215 \\
\hline & Management & 11.1 & 1.670 .001 & & Management & 9.0 & $1.34 \mathbf{0 . 0 4 8}$ \\
\hline & Total & 17.4 & $1.32 \mathbf{0 . 0 0 3}$ & & Total & 16.6 & $1.25 \mathbf{0 . 0 5 0}$ \\
\hline \multirow[t]{5}{*}{ Specialists } & $\%$ Arable & & & \multirow[t]{5}{*}{ Spiders } & $\%$ Arable & & \\
\hline & land & 2.6 & 0.810 .792 & & land & 2.3 & 0.670 .937 \\
\hline & Connectivity & 3.5 & 1.090 .307 & & Connectivity & 2.5 & 0.750 .870 \\
\hline & Management & 13.5 & $2.12 \mathbf{0 . 0 0 1}$ & & Management & 11.9 & $1.77 \mathbf{0 . 0 0 1}$ \\
\hline & Total & 20.8 & 1.640 .001 & & Total & 16.4 & $1.23 \mathbf{0 . 0 4 9}$ \\
\hline \multirow[t]{5}{*}{ Bees } & $\%$ Arable & & & \multirow{5}{*}{$\begin{array}{l}\text { Rove } \\
\text { beetles }\end{array}$} & $\%$ Arable & & \\
\hline & land & 3.6 & 1.110 .292 & & land & 1.8 & 0.530 .882 \\
\hline & Connectivity & 2.7 & 0.830 .723 & & Connectivity & 3.8 & 1.110 .326 \\
\hline & Management & 11.4 & 1.740 .007 & & Management & 9.3 & 1.360 .151 \\
\hline & Total & 17.7 & $1.34 \mathbf{0 . 0 1 9}$ & & Total & 14.1 & 1.020 .401 \\
\hline \multirow[t]{5}{*}{ Butterflies } & $\%$ Arable & & & \multicolumn{3}{|c|}{ Hoverflies \% Arable } & \\
\hline & land & 3.4 & 1.050 .362 & & land & 6.0 & 1.790 .012 \\
\hline & Connectivity & 3.8 & 1.190 .234 & & Connectivity & 2.6 & 0.780 .786 \\
\hline & Management & 12.4 & 1.930 .006 & & Management & 7.7 & 1.150 .236 \\
\hline & Total & 19.8 & 1.540 .008 & & Total & 16.6 & 1.240 .089 \\
\hline \multirow{4}{*}{$\begin{array}{l}\text { Grass- } \\
\text { hoppers }\end{array}$} & $\%$ Arable & & & \multirow[t]{4}{*}{$\begin{array}{l}\text { Leaf- } \\
\text { hoppers }\end{array}$} & $\%$ Arable & & 0850637 \\
\hline & Connectivity & 2.3 & $\begin{array}{ll}1.55 & 0.200 \\
0.66 & 0.746\end{array}$ & & Connectivity & $\begin{array}{l}2.0 \\
3.0\end{array}$ & $\begin{array}{lll}0.05 & 0.057 \\
0.95 & 0.540\end{array}$ \\
\hline & Management & 7.2 & 1.060 .431 & & Management & 15.5 & $2.49 \mathbf{0 . 0 0 1}$ \\
\hline & Total & 14.4 & 1.050 .406 & & Total & 22.5 & $1.81 \mathbf{0 . 0 0 2}$ \\
\hline
\end{tabular}


Table 3. Effects of landscape context (\% arable land), connectivity and local management on overall standardized species richness per taxon. Shown is a sequential analysis of variance table for terms retained in the best linear mixed-effects model showing effects of. Only variables included in the final model are shown. Variables significant at $P \leq 0.05$ are printed bold. numDF, denDF: numerator and denominator degrees of freedom.

\begin{tabular}{lcccc} 
& numDF & denDF & F & $P$ \\
\hline Intercept & 1 & 208 & 1467.64 & $<\mathbf{0 . 0 0 1}$ \\
\% Arable land & 1 & 25 & 11.48 & $\mathbf{0 . 0 0 2}$ \\
Connectivity & 1 & 25 & 0.07 & 0.792 \\
Taxon & 8 & 208 & 1.00 & 0.368 \\
Management & 2 & 25 & 8.95 & $\mathbf{0 . 0 0 1}$ \\
Connectivity : Taxon & 8 & 208 & 2.41 & $\mathbf{0 . 0 1 6}$ \\
Management : Taxon & 16 & 208 & 2.96 & $<\mathbf{0 . 0 0 1}$ \\
\hline
\end{tabular}

Table 4. Anova summary of the best linear mixed model for the overall trend in species richness across taxa in large and small species. Only variables included in the final models are shown. Variables significant at $\alpha \leq$ 0.05 are depicted in bold characters.

\begin{tabular}{lcccc} 
& numDF & denDF & $F$ & $P$ \\
\hline Intercept & 1 & 434 & 1.52 & $<\mathbf{0 . 0 0 1}$ \\
\% Arable land & 1 & 25 & 11.00 & $\mathbf{0 . 0 0 3}$ \\
Connectivity & 1 & 25 & 2.00 & 0.217 \\
Size & 1 & 434 & 0.00 & 1.000 \\
Taxon & 7 & 434 & 0.00 & 1.000 \\
Management & 2 & 25 & 6.00 & $\mathbf{0 . 0 0 8}$ \\
Connectivity : Size & 1 & 434 & 6.00 & $\mathbf{0 . 0 1 4}$ \\
Connectivity : Taxon & 7 & 434 & 2.00 & $\mathbf{0 . 0 1 6}$ \\
\hline
\end{tabular}

Table 5. Anova summary of the best linear mixed model for the overall trend in species richness across taxa for red-listed and unthreatened species. Only variables included in the final models are shown. Variables significant at $\alpha \leq 0.05$ are depicted in bold characters.

\begin{tabular}{lcccc} 
& numDF & denDF & F & $P$ \\
\hline Intercept & 1 & 447 & 348.39 & $<0.001$ \\
\% Arable land & 1 & 26 & 2.29 & 0.142 \\
Connectivity & 1 & 447 & 0.00 & 1.000 \\
Management & 2 & 26 & 4.67 & $\mathbf{0 . 0 1 9}$ \\
RL status : Management & 2 & 447 & 4.24 & $\mathbf{0 . 0 1 5}$ \\
\hline
\end{tabular}



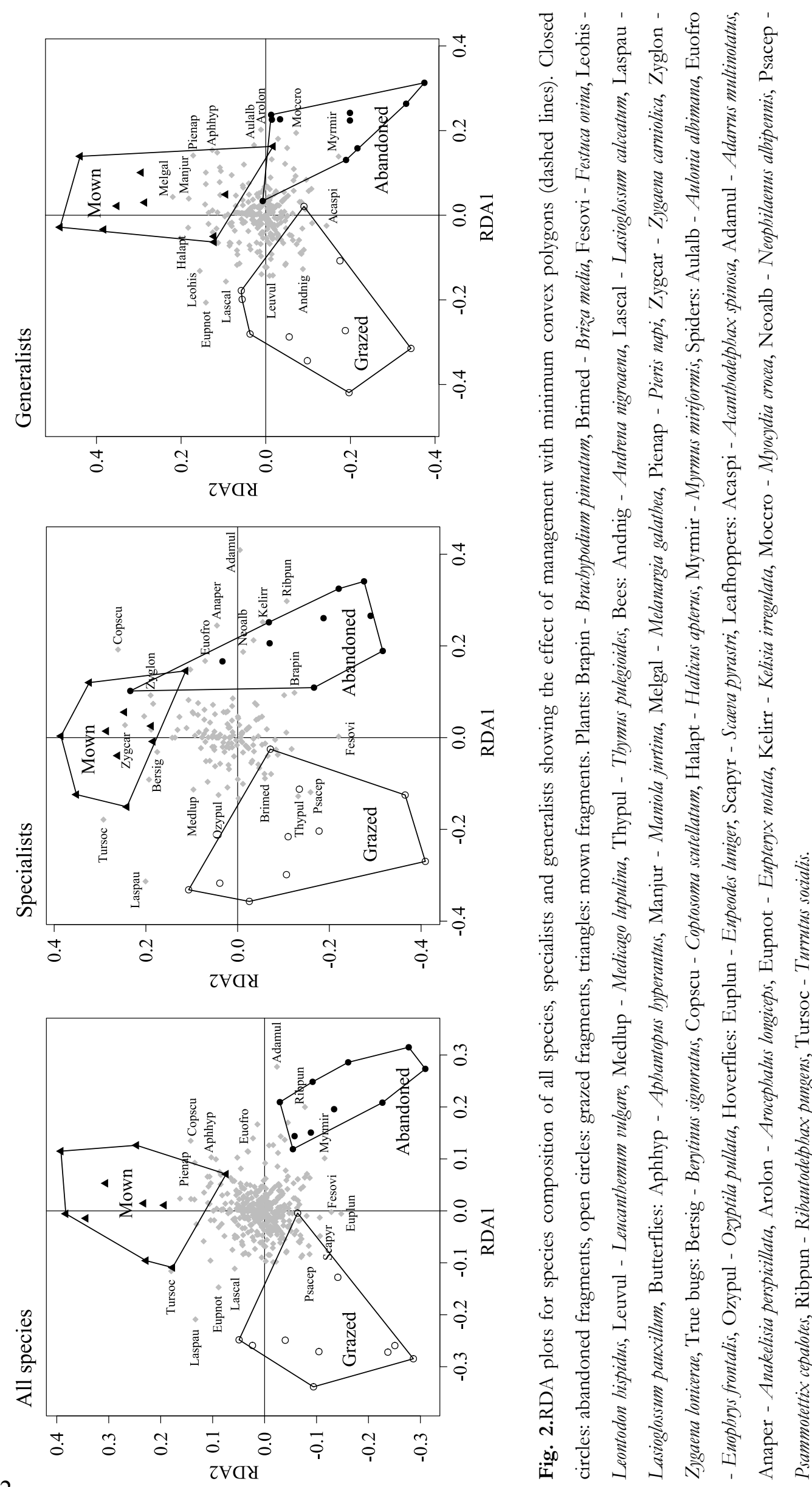

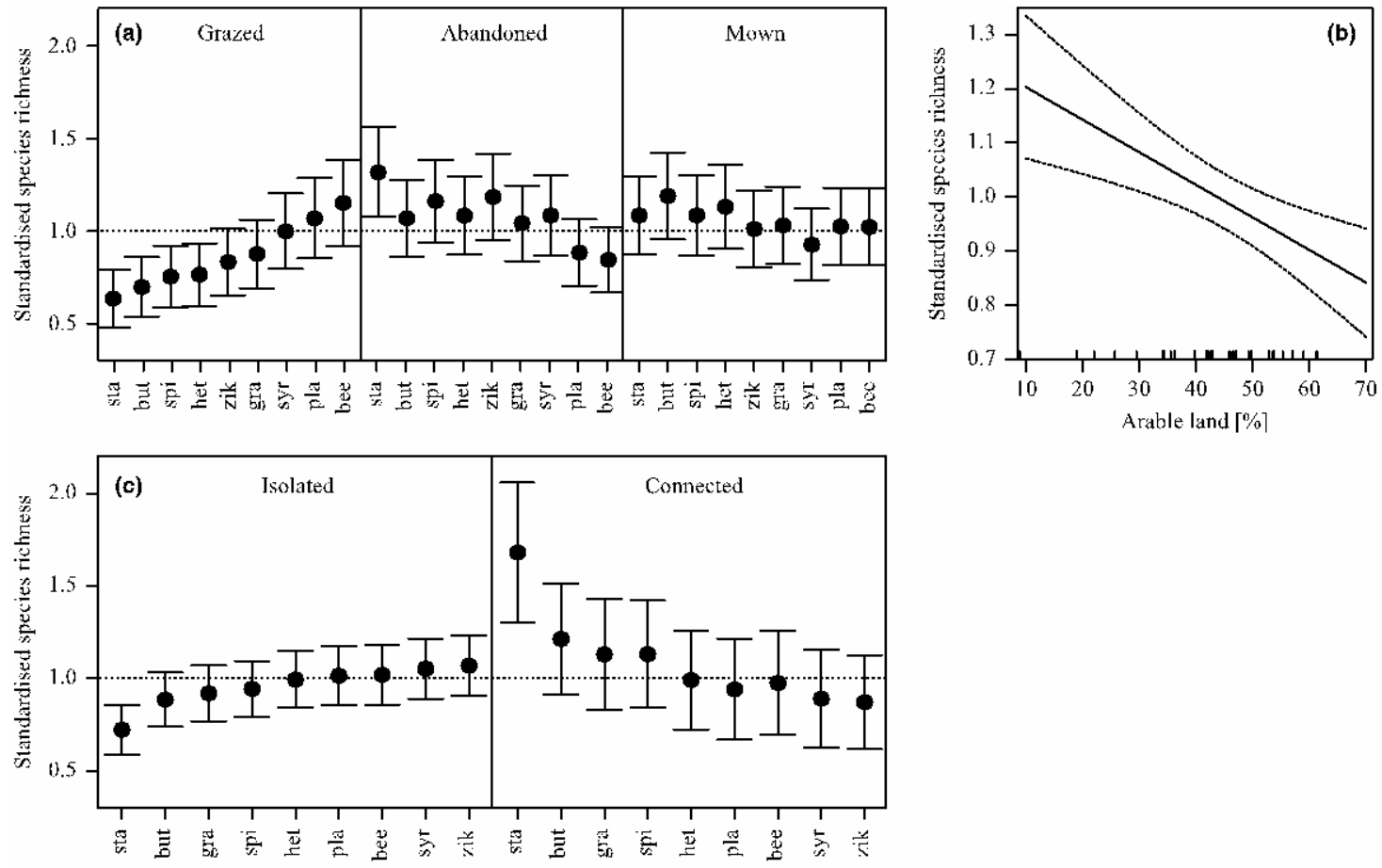

Fig. 3. Overall response of standardized species richness per taxon in relation to a) the significant interaction of management and taxon $($ sta $=$ rove beetles, but $=$ butterflies, spi $=$ spiders, het $=$ true bugs, zik $=$ leafhoppers, gra $=$ grasshoppers, syr $=$ hoverflies, pla $=$ plants, bee $=$ bees), b) the proportion of arable land and c) the significant interaction of connectivity and taxon. Shown is the predicted standardized species richness per taxon (yaxis) and $95 \%$ CIs, based on the best linear mixed model. Standardized species richness is calculated as species richness divided by the mean species richness of that taxon across the study. For improved visualisation, average species richness per taxon $(=1)$ is indicated by a horizontal dashed line.
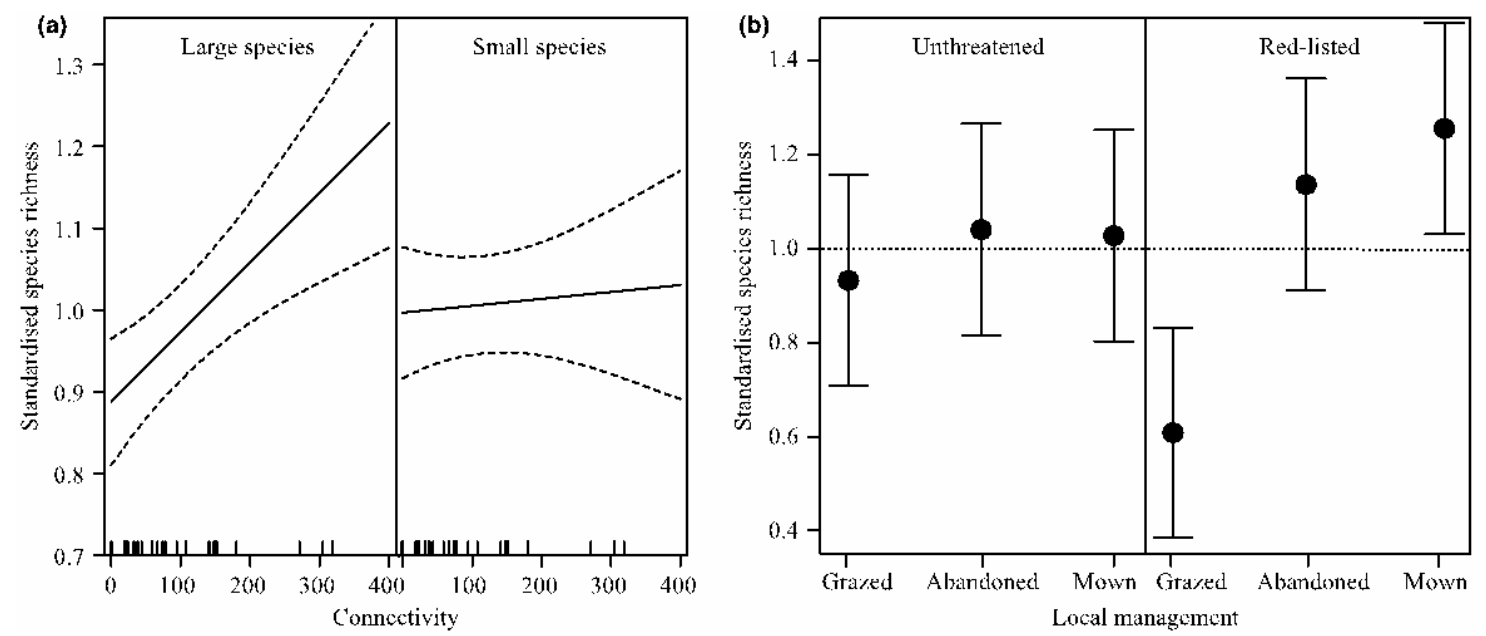

Fig. 4. Response of trait-specific species richness per taxon predicted by the best linear mixed model including all species. a) Response of large and small species to habitat 
connectivity, b) response of red-listed and unthreatened species to local management. Shown is the standardized species richness per taxon (y-axis). Standardized species richness is calculated as species richness divided by the mean species richness of that taxon for large or small species respectively in a), and divided by the mean species richness of that taxon for unthreatened and red-listed species respectively in b). For improved visualisation, average species richness per taxon $(=1)$ is indicated by a horizontal dashed line in $b)$.

\section{DisCUSSION}

Our sampling approach combined with our joint analysis allowed us to disentangle the effects of local management, habitat connectivity and landscape complexity on a broad array of taxa. As hypothesized, high proportions of arable land reduced species richness for all taxa combined, whereas habitat connectivity increased overall species richness. Similar patterns were found at the taxon level. Local management strongly influenced community composition in most taxa. Grazing generally reduced species richness and abundance more than mowing or abandonment and affected red-listed species in particular. As expected, the effect of habitat connectivity was modified by body size. Within each taxon, increasing habitat connectivity increased species richness more in large than in small-bodied species.

\section{Landscape complexity}

Landscape simplification had a surprisingly consistent, negative influence on species richness across taxa. Simple landscapes dominated by agriculture are often characterized by low matrix quality, offering less alternative habitat, since many species require resources outside fragment borders (Öckinger et al., 2012). In addition, dispersing individuals may experience a lack of resources (Rösch et al., 2013) and an inhospitable matrix (e.g. Nowicki et al., 2014, Baum et al., 2004). Similar to our study, Prugh et al. (2008) emphasized the central importance of matrix effects for patch occupancy in a broad variety of species.

Local communities are subsets of the landscape wide species pool (Tscharntke et al., 2012). Since agriculturally dominated landscapes often show depauperate species pools (Steffan-Dewenter et al., 2002; Tscharntke et al., 2005; Ekroos et al., 2010), habitat fragments embedded in such landscapes will only gain few additional species through disperal. In contrast, complex landscapes harbour a more diverse species pool and can therefore be assumed to subsidize local species richness to a greater extent. Small fragments as studied by us may also experience greater edge effects and higher spillover from adjacent arable land (Rand et al., 2006). 
Bee and butterfly abundance both decreased by approximately two thirds in highly simplified landscapes (Fig. S1). Effects of reduced pollinator availability in simple landscapes could include reduced pollination efficiency in insect-pollinated plants, threatening their persistence on grassland fragments (Meyer et al., 2007; Clough et al., 2014). In contrast to all other taxa, hoverfly abundance (but not species richness) increased in agriculturally dominated landscapes. This likely resulted from increased densities of the hyperabundant species Syrphus vitripennis (869 vs, 400 specimens on fragments in simple vs. complex landscapes), whose aphidophagous larvae feed on cereal aphids (Speight et al., 2008).

\section{Habitat connectivity}

Despite variation between taxa, increasing habitat connectivity generally boosted species richness, and this effect was most accentuated for butterflies, grasshoppers and rove beetles. This is in line with a previous meta-analysis (Öckinger et al., 2010), which showed a positive effect of connectivity on insect species richness across studies. As predicted by metapopulation theory, connected fragments can be reached by dispersing individuals more easily than isolated ones, recolonising them after extinction events (Hanski, 1998). Interestingly, we found that relative body size consistently modified the positive connectivity effect: The species richness of large species within each taxon increased with increasing connectivity, while species richness of small species did not. Large-bodied species tend to have stronger dispersal capacities and can thereby benefit from connectivity (Sekar, 2012), whereas smaller-bodied species appeared unable to bridge the given connectivity level in our landscapes. Apparently, the isolated small fragments of calcareous grassland were already too distant from each other for the majority of the small species, which can be assumed to be less dispersive. However, body size may not always be directly linked with dispersal ability: For example, several species of grasshoppers, leafhoppers and true bugs display a wing dimorphism or are short-winged, which impairs their flight ability and thereby their capability of bridging gaps between habitats (Biedermann \& Niedringhaus, 2004; Wachmann et al., 2004, 2006, 2007, 2008; Baur et al., 2006). Further, large spiders disperse better by walking, but some small spiders can disperse aerially by ballooning (Crawford et al., 1995). This dichotomy explains well why connected patches were more easily reached by larger spiders, while small spiders were unaffected by connectivity (Oberg et al., 2008), as these could equally well transverse the matrix by ballooning (Weyman, 1993). 


\section{Effects of management}

Our results suggest that local management strongly modifies species richness, abundance and community composition. While vertebrate herbivory is often selective and long-term, mowing is a rather sudden event that unselectively removes a large part of the food resources available (Humbert et al., 2009). For most taxa, we found high species richness and abundances in mown patches. This supports previous research that showed that calcareous grasslands require management for long-term persistence (Poschlod \& WallisDeVries, 2002). In contrast, the positive effect of short term abandonment was unexpected (but see Pöyry et al., 2006). Short-term abandonment (5-15 years) can be beneficial for species richness since it increases local habitat heterogeneity and leads to the development of different successional plant communities with associated arthropod communities (WallisDeVries et al., 2002). In contrast, long-term abandonment (>15 years) may lead to a gradual decrease in species richness due to increasing dominance of grass species (e.g. Brachypodium, Bromus), gradually replacing other plant species. The next stage is shrub encroachment by woody species like Prunus spinosa and Crataegus monogyna, ultimately leading to a loss of the characteristic open structure favouring thermophilic organisms (Butaye et al., 2005; Piqueray \& Mahy, 2010).

The traditional management paradigm of yearly grazing has been shown to efficiently keep calcareous grasslands open and support typical plant species, which in turn host specialist arthropod species (Pöyry et al., 2009; Westrich et al., 2011; Littlewood et al., 2012). Grazing also generates and maintains areas of open soil that are important e.g. as nesting sites for bees (Westrich, 1989) and for the establishment of plant seedlings (Kahmen et al., 2002). These areas of open soil help to increase the temperatures near the ground level, generating microclimatic conditions preferred by thermophilic species (e.g. Krämer et al., 2012). Furthermore, sheep-mediated propagule dispersal guarantees genetic connectivity of plant populations, important for long-term persistence of isolated populations (Wagner et al., 2013; Rico et al., 2014).

Surprisingly, our results starkly contrast with this paradigm: Grazing the way it is conducted at present seems to be the least appropriate management strategy for small fragments of calcareous grassland. Intensive and prolonged grazing by heavy livestock such as cattle or horses causes a drastic and continuous removal of food resources for herbivorous insects through consumption of plants and trampling. This either directly affects herbivores like leafhoppers or butterflies, or indirectly affects predatory arthropods 
like spiders, which suffer from decreases in prey abundance and a loss of structural heterogeneity of the vegetation (e.g. Szinetár \& Samu, 2012). Our results are particularly alarming, since we found that red-listed species, the focus of conservation management, were affected most strongly. These species can be assumed to be most vulnerable due to very specific habitat requirements (Davies et al., 2004). They are thus likely to be the first to be negatively affected by unsuitable management like grazing over a too long time period or with to high stocking rates. Some previous studies have reported negative effects of grazing intensity, in particular on herbivorous insects (e.g. Kruess \& Tscharntke, 2002; Pöyry et al., 2006; Körösi et al., 2012). In line with our results, these studies suggested that insect herbivores benefit from local breaks of one or a few years in grazing management, or from landscape-scale variation in grazing intensity (Öckinger et al., 2006; Pöyry et al., 2006; Konvicka et al., 2007).

The decreasing number of sheep flocks combined with the necessity of keeping calcareous grasslands open, leads to increasing reliance on unsuitable livestock. However, our study shows that this management alternative entails a high uncertainty concerning the persistence of endangered communities.

\section{CONCLUSIONS}

Taxa as different as the ones studied here strongly differ in their ecological requirements and life history traits. Given this striking plurality, it is remarkable that our joint analysis revealed generalisable responses across taxa. Cross-taxon biodiversity was strongly affected both by landscape simplification and by connectivity. Large-bodied and more dispersive species benefited from connectivity. Intensive grazing led reduced species richness, with a particularly severe reduction in red-listed species. Given these results, grazing in the way it is currently practised, seems to be the least favourable management option.

An intermediate management strategy, alternating between mowing or lenient grazing (preferably late-season) and short-term abandonment, combined with complex landscapes surrounding each fragment and low levels of habitat isolation, would benefit plant and arthropod species richness on small fragments of calcareous grassland most. We conclude that appropriate local management is essential, but must be complemented by a landscape perspective. 


\section{Acknowledgements}

We thank Filipe Nogueira Madeira, Nora German, Felix Weiß and Cecilia Cantor for help with field data collection, Zsolt Józan for bee identification, Sándor Tóth for hoverfly identification, László Ádám for rove beetles identification and Susanne Grube for true bug identification. We thank Laura Sutcliffe for language editing and comments. Ingolf Kühn and four anonymous referees provided valuable comments. Financial support to VR by the MWK graduate school "Biodiversität und Gesellschaft", to UK by the DFG Research Training Group 1644 (Scaling Problems in Statistics), to FS by OTKA (K81971) and to PB by the German Research Foundation (DFG BA4438/1-1) is acknowledged. 


\section{REFERENCES}

Baum, K.A., Haynes, K.J., Dillemuth, F.P. \& Cronin, J.T. (2004) The matrix enhances the effectiveness of corridors and stepping stones. Ecology, 85, 2671-2676.

Biedermann, R. \& Niedringhaus, R. (2004) Die Zikaden Deutschlands - Bestimmungstafeln für alle Arten. WABV Fründ, Scheeßel.

Binot-Hafke, M., Balzer, S., Becker, N., Gruttke, H., Haupt, H., Hofbauer, N., Ludwig, G., Matzke-Hajek, G. \& Strauch, M. (2011) Rote Liste gefährdeter Tiere, Pflanz̧en und Pilz̨e Deutschlands, Band 3: Wirbellose Tiere (Teil 1).

Bommarco, R., Biesmeijer, J.C., Meyer, B., Potts, S.G., Pöyry, J., Roberts, S.P.M., SteffanDewenter, I. \& Ockinger, E. (2010) Dispersal capacity and diet breadth modify the response of wild bees to habitat loss. Proceedings of the Royal Society B Biological Sciences, 277, 2075-2082.

Brückmann, S. V., Krauss, J. \& Steffan-Dewenter, I. (2010) Butterfly and plant specialists suffer from reduced connectivity in fragmented landscapes. Journal of Applied Ecology, 47, 799-809.

Butaye, J., Adriaens, D. \& Honnay, O. (2005) Conservation and restoration of calcareous grasslands: a concise review of the effects of fragmentation and management on plant species. Biotechnology, Agronomy, Society and Environment, 9, 111-118.

Crawford, R.L., Sugg, P.M. \& Edwards, J.S. (1995) Spider Arrival and Primary Establishment on Terrain Depopulated by Volcanic-Eruption at Mount St-Helens, Washington. American Midland Naturalist, 133, 60-75.

Davies, K.F., Margules, C.R. \& Lawrence, J.F. (2004) A synergistic effect puts rare, specialized species at greater risk of extinction. Ecology, 85, 265-271.

Ellenberg, H. \& Leuschner, C. (2010) Vegetation Mitteleuropas mit den Alpen in ökologischer, dynamischer und historischer Sicht. Ulmer, Stuttgart.

Ewers, R.M. \& Didham, R.K. (2006) Confounding factors in the detection of species responses to habitat fragmentation. Biological Reviews, 81, 117-142.

Eycott, A.E., Stewart, G.B., Buyung-Ali, L.M., Bowler, D.E., Watts, K. \& Pullin, A.S. (2012) A meta-analysis on the impact of different matrix structures on species movement rates. Landscape Ecology, 27, 1263-1278.

Fahrig, L. (2003) Effects of Habitat Fragmentation on Biodiversity. Annual Review of Ecology, Evolution and Systematics, 34, 487-515. 
Fischer, J. \& Lindenmayer, D.B. (2007) Landscape modification and habitat fragmentation: a synthesis. Global Ecology and Biogeography, 16, 265-280.

Gardiner, T. \& Hill, J. (2006) A comparison of three sampling techniques used to estimate the population density and assemblage diversity of Orthoptera. Journal of Orthoptera Research, 15, 45-51.

Gardiner, T., Hill, J. \& Chesmore, D. (2005) Review of the Methods Frequently Used to Estimate the Abundance of Orthoptera in Grassland Ecosystems. Journal of Insect Conservation, 9, 151-173.

Hanski, I. (1998) Metapopulation dynamics. Nature, 396, 41-49.

Hanski, I., Alho, J. \& Moilanen, A. (2000) Estimating the parameters of survival and migration of individuals in metapopulations. Ecology, 81, 239-251.

Holzschuh, A., Dormann, C.F., Tscharntke, T. \& Steffan-Dewenter, I. (2013) Massflowering crops enhance wild bee abundance. Oecologia, 172, 477-484.

Hothorn, T., Bretz, F. \& Westfall, P. (2008) Simultaneous inference in general parametric models. Biometrical Journal, 50, 346-363.

Humbert, J.-Y., Ghazoul, J. \& Walter, T. (2009) Meadow harvesting techniques and their impacts on field fauna. Agriculture, Ecosystems \& Environment, 130, 1-8.

Jenkins, D.G., Brescacin, C.R., Duxbury, C. V., Elliott, J.A., Evans, J.A., Grablow, K.R., Hillegass, M., Lyon, B.N., Metzger, G.A., Olandese, M.L., Pepe, D., Silvers, G.A., Suresch, H.N., Thompson, T.N., Trexler, C.M., Williams, G.E., Williams, N.C. \& Williams, S.E. (2007) Does size matter for dispersal distance? Global Ecology and Biogeography, 16, 415-425.

Kahmen, S., Poschlod, P. \& Schreiber, K.-F. (2002) Conservation management of calcareous grasslands. Changes in plant species composition and response of functional traits during 25 years. Biological Conservation, 104, 319-328.

Kőrösi, Á., Batáry, P., Orosz, A., Rédei, D. \& Báldi, A. (2012) Effects of grazing, vegetation structure and landscape complexity on grassland leafhoppers (Hemiptera: Auchenorrhyncha) and true bugs (Hemiptera: Heteroptera) in Hungary. Insect Conservation and Diversity, 5, 57-66.

Krämer, B., Kämpf, I., Enderle, J., Poniatowski, D. \& Fartmann, T. (2012) Microhabitat selection in a grassland butterfly: a trade-off between microclimate and food availability. Journal of Insect Conservation, 16, 857-865. 
Krauss, J., Steffan-Dewenter, I. \& Tscharntke, T. (2003) How does landscape context contribute to effects of habitat fragmentation on diversity and population density of butterflies? Journal of Biogeography, 30, 889-900.

Kruess, A. \& Tscharntke, T. (2002) Grazing Intensity and the Diversity of Grasshoppers, Butterflies, and Trap-Nesting Bees and Wasps. Conservation Biology, 16, 1570-1580.

Legendre, P. \& Gallagher, E. (2001) Ecologically meaningful transformations for ordination of species data. Oecologia, 129, 271-280.

Littlewood, N.A., Stewart, A.J.A. \& Woodcock, B.A. (2012) Science into practice - how can fundamental science contribute to better management of grasslands for invertebrates? Insect Conservation and Diversity, 5, 1-8.

Losos, J.B. \& Ricklefs, R.E. (2010) The Theory of Island Biogeography Revisited. Princeton University Press, Princeton, New Jersey.

MacArthur, R.H. \& Wilson, E.O. (1967) The Theory of Island Biogeography. Princeton University Press, Princeton, New Jersey.

Meyer, B., Gaebele, V. \& Steffan-Dewenter, I.D. (2007) Patch Size and Landscape Effects on Pollinators an Seed Set of the Horseshoe Vetch, Hippocrepis comosa, in an Agricultural Landscape of Central Europe. Entomologia Generalis, 30, 173-185.

Nowicki, P., Vrabec, V., Binzenhöfer, B., Feil, J., Zakšek, B., Hovestadt, T. \& Settele, J. (2014) Butterfly dispersal in inhospitable matrix: rare, risky, but long-distance. Landscape Ecology, 29, 401-412.

Oberg, S., Mayr, S. \& Dauber, J. (2008) Landscape effects on recolonisation patterns of spiders in arable fields. Agriculture, Ecosystems \& Environment, 123, 211-218.

Öckinger, E., Lindborg, R., Sjödin, N.E. \& Bommarco, R. (2012) Landscape matrix modifies richness of plants and insects in grassland fragments. Ecography, 35, 259267.

Öckinger, E., Schweiger, O., Crist, T.O., Debinski, D.M., Krauss, J., Kuussaari, M., Petersen, J.D., Pöyry, J., Settele, J., Summerville, K.S. \& Bommarco, R. (2010) Lifehistory traits predict species responses to habitat area and isolation: a crosscontinental synthesis. Ecology letters, 13, 969-979.

Oksanen, A.J., Blanchet, F.G., Kindt, R., Minchin, P.R., Hara, R.B.O., Simpson, G.L., Sólymos, P., Stevens, M.H.H. \& Wagner, H. (2013) vegan: Community Ecology Package. R package version 2.0-9, http:// cran.r-project.org/package= $=$ egan $\% 20$. . 
Pinheiro, J., Bates, D., DebRoy, S., Sarkar, D. \& R-Core-Team (2014) nlme: Linear and Nonlinear Mixed Effects Models. R package version 3.1-116, http://CRAN.Rproject.org $/$ package $=$ nlme. .

Piqueray, J. \& Mahy, G. (2010) Revue bibliographique sur la restauration des pelouses calcicoles en Europe: contraintes rencontrées et solutions proposées. Biotechnologie, Agronomie, Société et Environnement, 14, 471-484.

Poschlod, P. \& WallisDeVries, M.F. (2002) The historical and socioeconomic perspective of calcareous grasslands - lessons from the distant and recent past. Biological Conservation, 104, 361-376.

Pöyry, J., Paukkunen, J., Heliölä, J. \& Kuussaari, M. (2009) Relative contributions of local and regional factors to species richness and total density of butterflies and moths in semi-natural grasslands. Oecologia, 160, 577-87.

Prugh, L.R., Hodges, K.E., Sinclair, A.R.E. \& Brashares, J.S. (2008) Effect of habitat area and isolation on fragmented animal populations. Proceedings of the National Academy of Sciences of the United States of America, 105, 20770-20775.

Rico, Y., Holderegger, R., Boehmer, H.J. \& Wagner, H.H. (2014) Directed dispersal by rotational shepherding supports landscape genetic connectivity in a calcareous grassland plant. Molecular Ecology, 23, 832-842.

Rösch, V., Tscharntke, T., Scherber, C. \& Batáry, P. (2013) Landscape composition, connectivity and fragment size drive effects of grassland fragmentation on insect communities. Journal of Applied Ecology, 50, 387-394.

Sala, O.E., Chapin, F.S., Armesto, J.J., Berlow, E., Bloomfield, J., Dirzo, R., HuberSanwald, E., Huenneke, L.F., Jackson, R.B., Kinzig, A., Leemans, R., Lodge, D.M., Mooney, H.A., Oesterheld, M., Poff, N.L., Sykes, M.T., Walker, B.H., Walker, M. \& Wall, D.H. (2000) Global biodiversity scenarios for the year 2100. Science, 287, $1770-1774$.

Saura, S., Bodin, Ö. \& Fortin, M.-J. (2014) Stepping stones are crucial for species' longdistance dispersal and range expansion through habitat networks. Journal of Applied Ecology, 51, 171-182.

Sekar, S. (2012) A meta-analysis of the traits affecting dispersal ability in butterflies: can wingspan be used as a proxy? Journal of Animal Ecology, 81, 174-184.

Sjödin, N.E. (2006) Pollinator behavioural responses to grazing intensity. Biodiversity and Conservation, 16, 2103-2121. 
Sjödin, N.E., Bengtsson, J. \& Ekbom, B. (2007) The influence of grazing intensity and landscape composition on the diversity and abundance of flower-visiting insects. Journal of Applied Ecology, 45, 763-772.

Speight, M.C.D., Castella, E., Sarthou, J.-P. \& Monteil, C. (2008) Species accounts of European Syrphidae (Diptera). Syrph the Net publications, Dublin.

Standen, V. (2000) The adequacy of collecting techniques for estimating species richness of grassland invertebrates. Journal of Applied Ecology, 37, 884-893.

Steffan-Dewenter, I., Munzenberg, U., Burger, C., Thies, C. \& Tscharntke, T. (2002) ScaleDependent Effects of Landscape Context on Three Pollinator Guilds. Ecology, 83, 1421-1432.

Stephen, W.P. \& Rao, S. (2005) Unscented Color Traps for Non-Apis Bees (Hymenoptera: Apiformes). Journal of the Kansas Entomological Society, 78, 373-380.

Van Swaay, C.A.M. (2002) The importance of calcareous grasslands for butterflies in Europe. Biological Conservation, 104, 315-318.

Szinetár, C. \& Samu, F. (2012) Intensive grazing opens spider assemblage to invasion by disturbance-tolerant species. Journal of Arachnology, 40, 59-70.

Tscharntke, T., Klein, A.M., Kruess, A., Steffan-Dewenter, I. \& Thies, C. (2005) Landscape perspectives on agricultural intensification and biodiversity - ecosystem service management. Ecology Letters, 8, 857-874.

Tscharntke, T., Steffan-Dewenter, I.D., Kruess, A. \& Thies, C. (2002) Contribution of small habitat fragments to conservation of insect communities of grasslandcropland landscapes. Ecological Applications, 12, 354-363.

Tscharntke, T., Tylianakis, J.M., Rand, T.A., Didham, R.K., Fahrig, L., Batáry, P., Bengtsson, J., Clough, Y., Crist, T.O., Dormann, C.F., Ewers, R.M., Fründ, J., Holt, R.D., Holzschuh, A., Klein, A.M., Kleijn, D., Kremen, C., Landis, D.A., Laurance, W., Lindenmayer, D., Scherber, C., Sodhi, N., Steffan-Dewenter, I., Thies, C., van der Putten, W.H. \& Westphal, C. (2012) Landscape moderation of biodiversity patterns and processes - eight hypotheses. Biological Reviews, 87, 661-685.

Venables, W.N. \& Ripley, B.D. (2002) Modern Applied Statistics with S. Springer, New York.

Wagner, H.H., Rico, Y., Lehnert, H. \& Boehmer, H.J. (2013) Process-based long-term evaluation of an ecological network of calcareous grasslands connected by sheep herding. Ecography, 36, 374-382. 
WallisDeVries, M.F., Poschlod, P. \& Willems, J.H. (2002) Challenges for the conservation of calcareous grasslands in northwestern Europe: integrating the requirements of flora and fauna. Biological Conservation, 104, 265-273.

Westphal, C., Bommarco, R., Carré, G., Lamborn, E., Petanidou, T., Potts, S.G., Roberts, S.P.M., Szentgyörgyi, H., Tscheulin, T., Vaissière, B.E., Woyciechowski, M., Biesmeijer, J.C., Kunin, W.E., Settele, J., Steffan-dewenter, I., Monographs, E., Biesmeijer, C. \& Kunin, E. (2008) Measuring Bee Diversity in Different European Habitats and Biogeographical Regions. Ecological Monographs, 78, 653-671.

Westrich, P. (1989) Die Wildbienen Baden-Württembergs. Allgemeiner Teil: Lebensräume, Verhalten, Ökologie und Schutz. Ulmer, Stuttgart.

Westrich, P., Frommer, U., Mandery, K., Riemann, H., Ruhnke, H., Saure, C. \& Voith, J. (2011) Rote Liste und Gesamtartenliste der Bienen (Hymenoptera, Apidae) Deutschlands. 5. Fassung, Stand Februar 2011. Bundesamt für Naturschutz. Naturschutz und Biologische Vielfalt, 70, 373-416.

Weyman, G.S. (1993) A review of the possible causative factors and significance of ballooning in spiders. Ethology, Ecology \& Evolution, 5, 279-291.

Wilmanns, O. (1993) Ökologische Pflanzensoziologie, Eine Einführung in die Vegetation Mitteleuropas. Quelle und Meyer, Heidelberg \& Wiesbaden.

Zulka, K.P., Abensperg-Traun, M., Milasowszky, N., Bieringer, G., Gereben-Krenn, B.-A., Holzinger, W., Hölzler, G., Rabitsch, W., Reischütz, A., Querner, P., Sauberer, N., Schmitzberger, I., Willner, W., Wrbka, T. \& Zechmeister, H. (2013) Species richness in dry grassland patches of eastern Austria: A multi-taxon study on the role of local, landscape and habitat quality variables. Agriculture, Ecosystems \& Environment, 182, 25-36. 


\section{SUPPORTING INFORMATION}

Figure S1

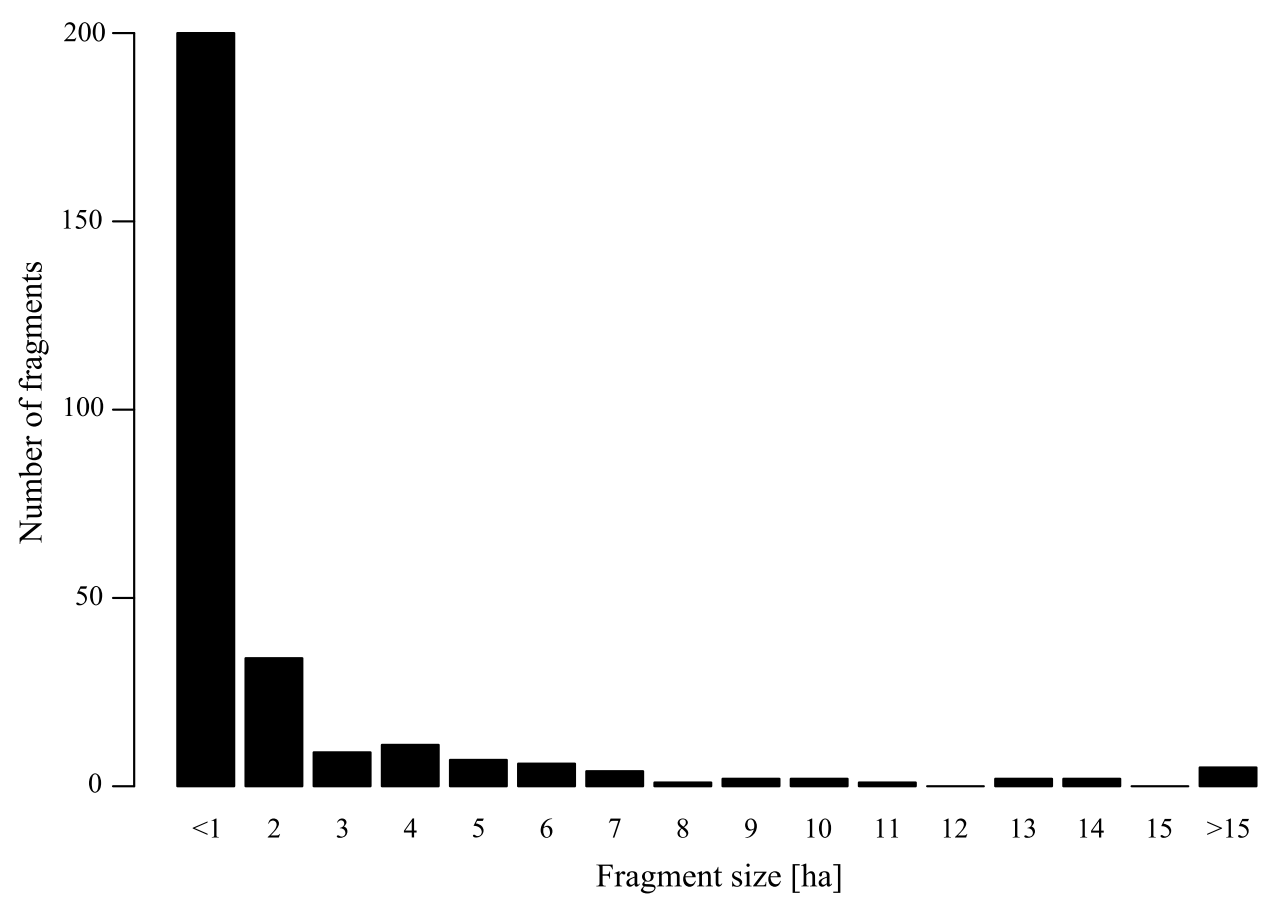

Fig. S1. Fragment size distribution in the study area.

\section{Figure S2:}
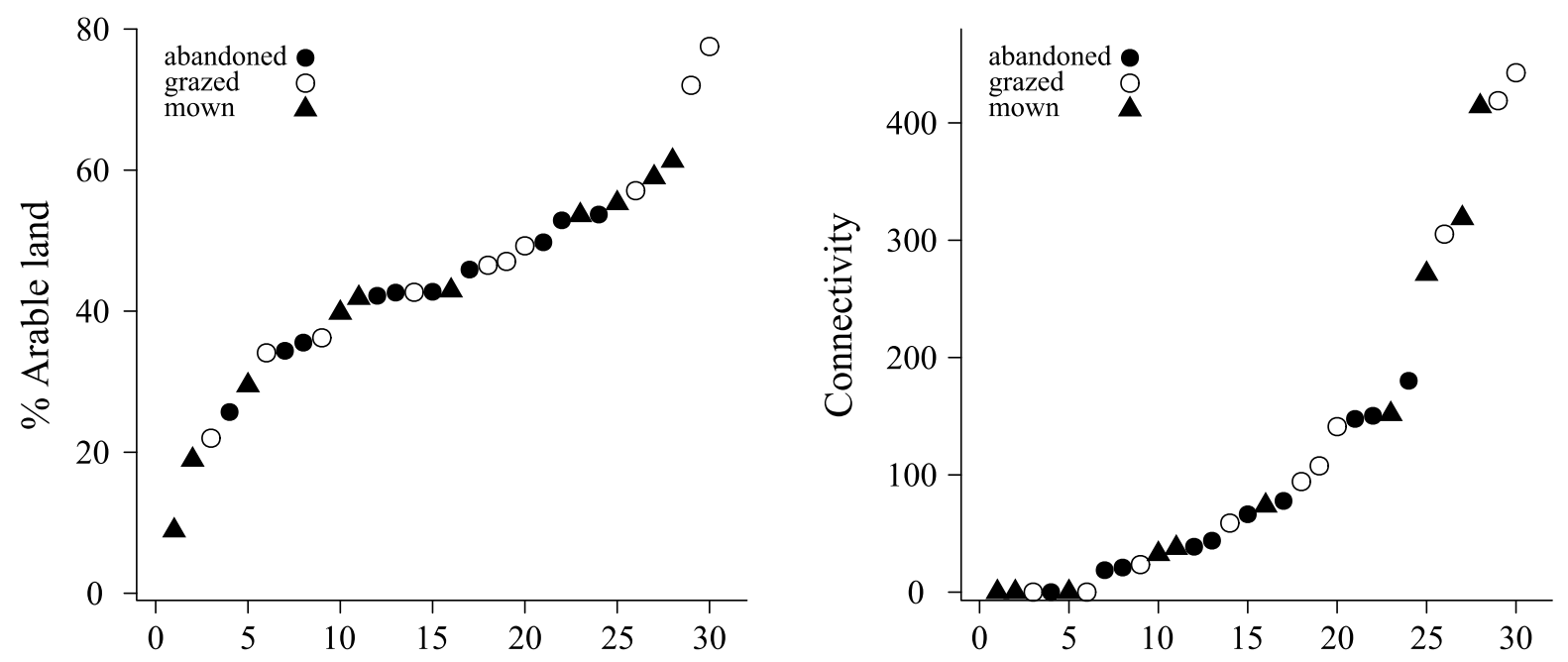

Fig. S2. Gradients of landscape complexity and connectivity of the 30 fragments of calcareous grassland. 
Map S1. Location of the 30 small fragments of calcareous grassland. Grazed grasslands are marked in red, mown grasslands in blue and abandoned ones in yellow.

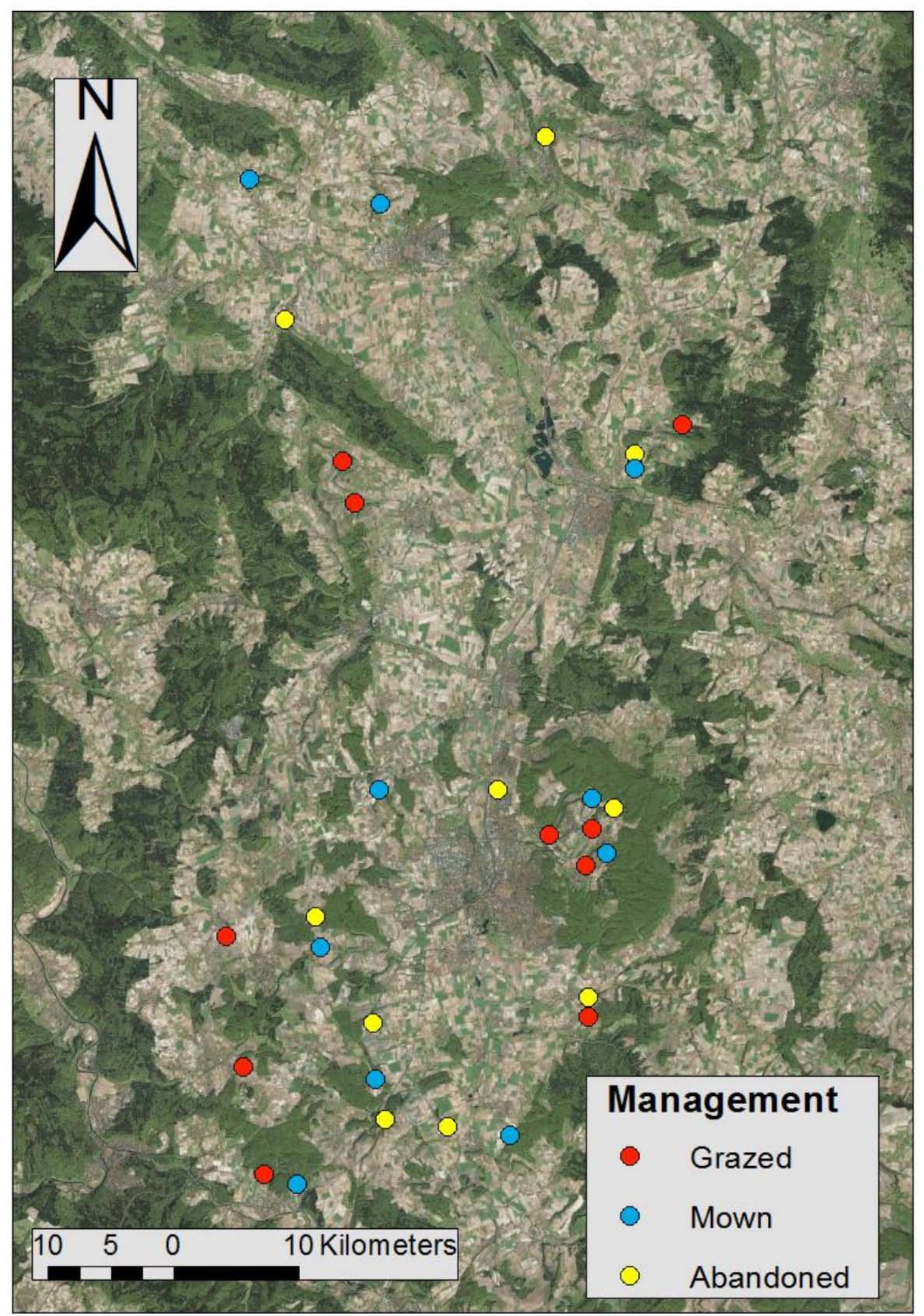


Table S1. Models used for the analysis of abundance and species richness (SpR) of the nine taxa.

\begin{tabular}{lcc}
\hline & Abundance & SpR \\
\hline All taxa & glm.nb & glm.nb \\
Specialists & glm.nb & glm.nb \\
Generalists & glm.nb & glm.nb \\
Plants & - & glm.nb \\
Bees & glm.nb & glm (poisson) \\
Butterflies & glm.nb & $\operatorname{lm}$ \\
Grasshoppers & glm.nb & $\operatorname{lm}$ \\
True bugs & glm.nb & glm (poisson) \\
Spiders & glm.nb & glm (poisson) \\
Hoverflies & glm.nb & $\operatorname{lm}$ \\
Rove beetles & glm.nb & glm (poisson) \\
Leafhoppers & glm.nb & glm.nb \\
\hline
\end{tabular}

Table S2. Overall species richness (SpR), overall abundances and mean \pm SEM of abundances and species richness of all nine taxa on the 30 fragments of calcareous grassland.

\begin{tabular}{ccrcccccc}
\hline & $\begin{array}{c}\text { Overall } \\
\text { SpR }\end{array}$ & \multicolumn{2}{c}{$\begin{array}{c}\text { SpR per } \\
\text { fragment }\end{array}$} & & $\begin{array}{c}\text { Overall } \\
\text { abundance }\end{array}$ & $\begin{array}{c}\text { Abundance } \\
\text { per fragment }\end{array}$ \\
\hline Plants & 148 & 41.9 & \pm & 2.1 & - & - & - & \\
Specialists & 61 & 22.5 & \pm & 1.2 & - & & - & \\
Generalists & 87 & 19.4 & \pm & 1.2 & - & & - & \\
Bees & 82 & 17.5 & \pm & 0.9 & 4318 & 143.9 & \pm & 27.2 \\
Specialists & 12 & 2.1 & \pm & 0.2 & 2342 & 78.1 & \pm & 25.4 \\
Generalists & 69 & 15.4 & \pm & 0.8 & 1975 & 65.8 & \pm & 4.8 \\
Butterflies & 47 & 14.2 & \pm & 1.0 & 2553 & 85.1 & \pm & 9.5 \\
Specialists & 16 & 3.4 & \pm & 0.5 & 960 & 32.0 & \pm & 6.7 \\
Generalists & 31 & 10.7 & \pm & 0.7 & 1593 & 53.1 & \pm & 5.3 \\
Grasshoppers & 10 & 3.8 & \pm & 0.2 & 891 & 29.7 & \pm & 4.5 \\
Specialists & 3 & 0.9 & \pm & 0.2 & 136 & 4.5 & \pm & 1.6 \\
Generalists & 7 & 2.9 & \pm & 0.2 & 755 & 25.2 & \pm & 3.8 \\
True bugs & 80 & 11.8 & \pm & 0.7 & 1167 & 38.9 & \pm & 4.4 \\
Specialists & 20 & 3.4 & \pm & 0.3 & 397 & 13.2 & \pm & 2.6 \\
Generalists & 60 & 8.4 & \pm & 0.5 & 770 & 25.7 & \pm & 3.2 \\
Spiders & 83 & 15.7 & \pm & 0.7 & 1030 & 34.3 & \pm & 2.2 \\
Specialists & 16 & 3.0 & \pm & 0.2 & 147 & 4.9 & \pm & 0.5 \\
Generalists & 67 & 12.7 & \pm & 0.6 & 883 & 29.4 & \pm & 2.1 \\
Hoverflies & 46 & 12.2 & \pm & 0.5 & 2528 & 84.3 & \pm & 9.9 \\
Rove beetles & 43 & 4.4 & \pm & 0.5 & 1008 & 33.6 & \pm & 7.8 \\
Leafhoppers & 65 & 16.4 & \pm & 0.8 & 6202 & 206.7 & \pm & 31.8 \\
Specialists & 26 & 7.8 & \pm & 0.5 & 4034 & 134.5 & \pm & 20.5 \\
Generalists & 39 & 8.6 & \pm & 0.7 & 2168 & 72.3 & \pm & 16.2 \\
\hline
\end{tabular}


Table S3. Code number,site name, management, percentage of arable land in a $1000 \mathrm{~m}$ radius around each site, fragment area [m2] and values of a connectivity index (Hanski et al., 2000) of the 30 fragments of calcareous grassland.

\begin{tabular}{|c|c|c|c|c|c|}
\hline Code & Site name & Management & $\%$ Arable land & Connectivity & Area $\left[\mathrm{m}^{2}\right]$ \\
\hline 7 & Volkerode & abandoned & 53.6 & 107.7 & 1306 \\
\hline 21 & Bratental8 & abandoned & 34.4 & 442.7 & 5143 \\
\hline 46 & Diemarden1 & abandoned & 57.1 & 150.3 & 1269 \\
\hline 88 & Weende & abandoned & 45.9 & 0.0 & 452 \\
\hline 90 & Dahlenrode1 & abandoned & 42.8 & 77.8 & 2548 \\
\hline 116 & Orxhausen & abandoned & 34.1 & 21.0 & 1000 \\
\hline 138 & Wellersen1 & abandoned & 55.3 & 23.5 & 2527 \\
\hline 151 & Langenholtensen 1 & abandoned & 46.5 & 66.4 & 5560 \\
\hline 170 & Elkershausen1 & abandoned & 72.0 & 0.0 & 2499 \\
\hline 177 & Ossenfeld ost & abandoned & 42.2 & 37.7 & 2707 \\
\hline 3 & Nikolausberg1 & grazed & 22.0 & 318.8 & 4444 \\
\hline 20 & Bratental4 & grazed & 41.9 & 418.9 & 2324 \\
\hline 58 & Dransfeld4 & grazed & 77.5 & 38.7 & 1325 \\
\hline 111 & Bratental1 & grazed & 39.8 & 271.2 & 1556 \\
\hline 139 & Denkershausen & grazed & 36.2 & 0.0 & 1645 \\
\hline 143 & Oldenrode1 & grazed & 49.3 & 32.5 & 6875 \\
\hline 146 & Nienhagen5 & grazed & 53.7 & 147.7 & 2236 \\
\hline 187 & Scheden2 & grazed & 42.7 & 414.2 & 6843 \\
\hline 202 & Herberhausen & grazed & 35.5 & 73.8 & 4790 \\
\hline 203 & Hedemünden10 & grazed & 29.5 & 58.9 & 5613 \\
\hline 1 & Tiefetal & mown & 25.7 & 43.9 & 3372 \\
\hline 2 & Emmenhausen1 & mown & 42.9 & 18.7 & 4017 \\
\hline 11 & Roringen1 & mown & 18.9 & 0.0 & 2114 \\
\hline 63 & Varmissen1 & mown & 61.3 & 0.0 & 4385 \\
\hline 71 & Friedland1 & mown & 47.1 & 305.2 & 835 \\
\hline 125 & Andershausen2 & mown & 52.9 & 0.0 & 1663 \\
\hline 172 & Hedemünden1 & mown & 8.9 & 151.8 & 2324 \\
\hline 178 & Reinhausen3 & mown & 49.8 & 141.1 & 3138 \\
\hline 192 & Langenholtensen2 & mown & 42.6 & 94.2 & 2476 \\
\hline 193 & Portenhagen1 & mown & 59.0 & 180.1 & 3016 \\
\hline
\end{tabular}



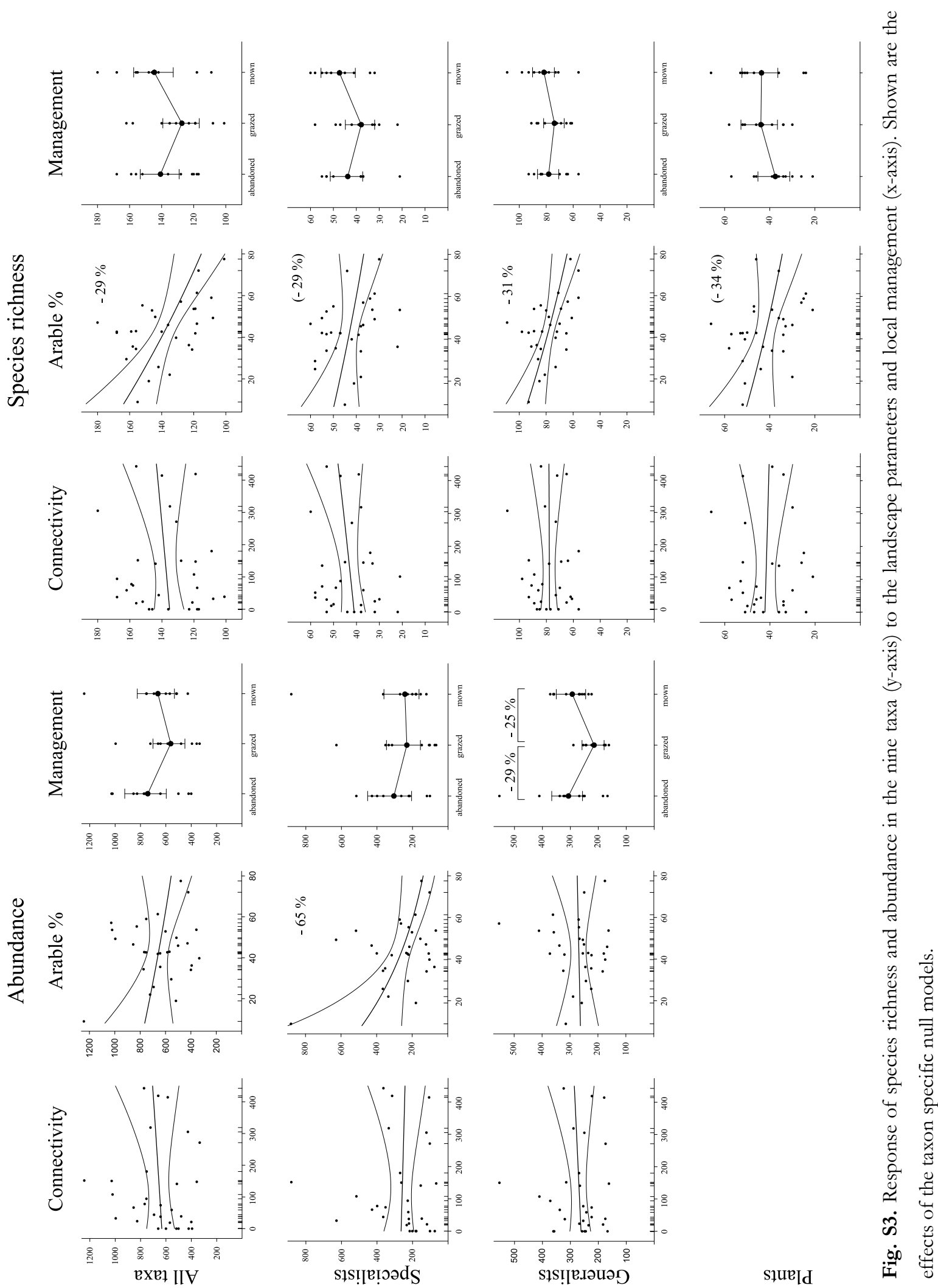

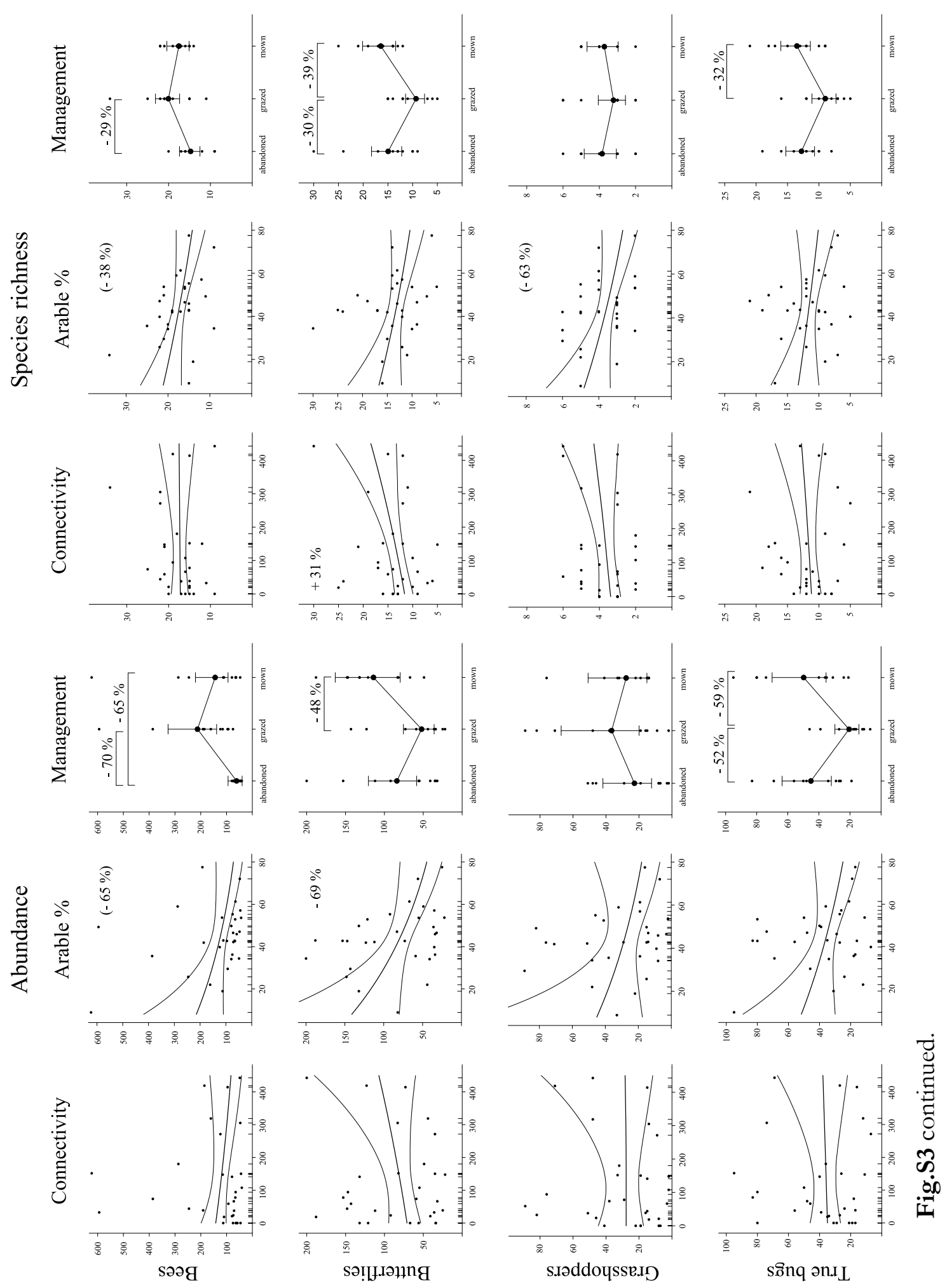

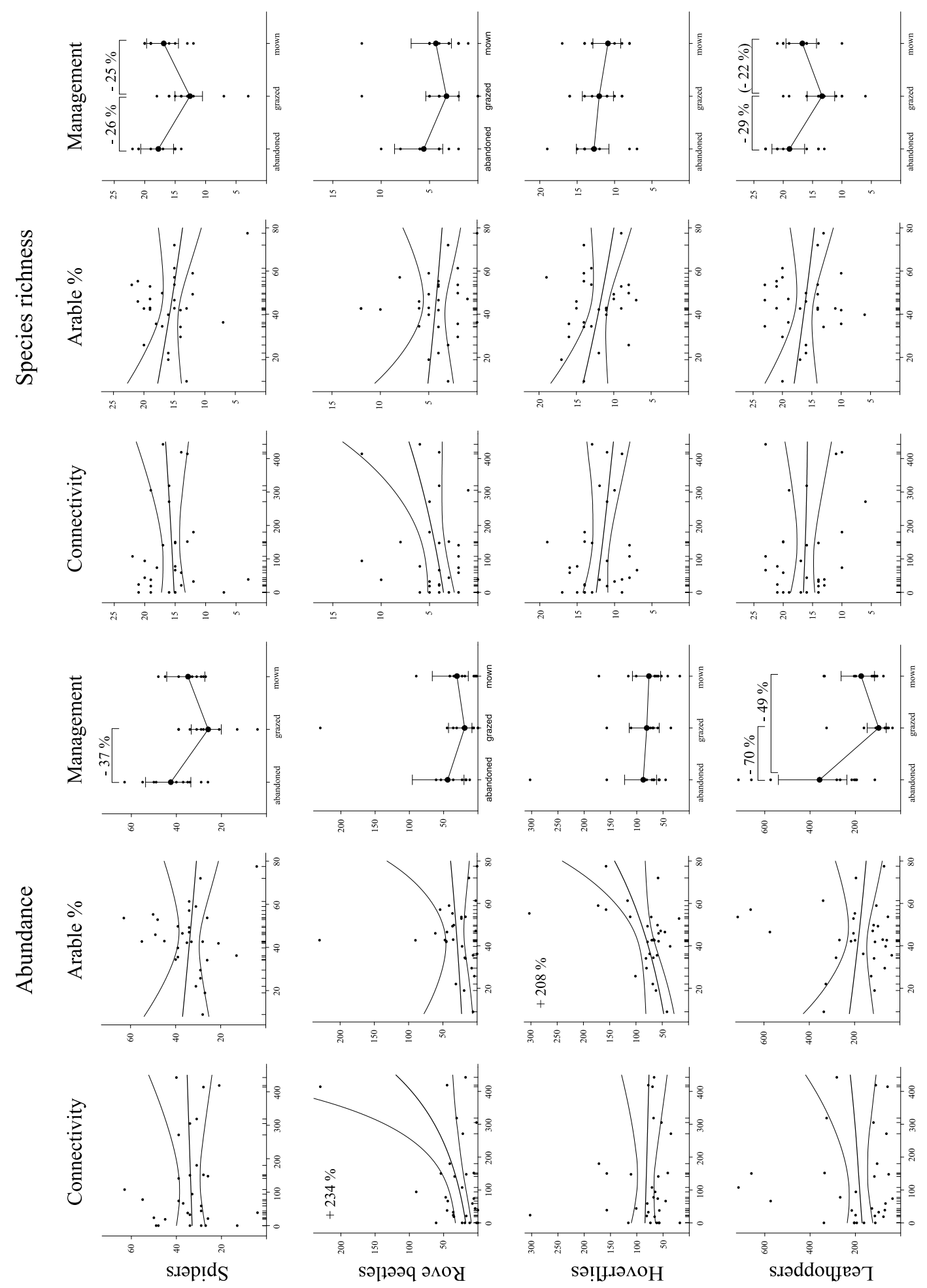
Table S4. Generalized linear models and linear models on the effects of landscape context (\% arable land), connectivity (a connectivity index described by Hanski et al. (2000)) and management on the abundance and species richness of all nine taxa. Only variables included in the final models are shown. $P$-values $<0.05$ are depicted in bold characters.

\begin{tabular}{|c|c|c|c|c|c|c|c|c|c|c|c|c|}
\hline \multirow[t]{3}{*}{ Abundance } & \multirow{2}{*}{\multicolumn{4}{|c|}{ Plants }} & \multirow{2}{*}{\multicolumn{4}{|c|}{ Bees }} & \multirow{2}{*}{\multicolumn{4}{|c|}{ Butterflies }} \\
\hline & & & & & & & & & & & & \\
\hline & Estimate & SEM & $z$ & $P$ & Estimate & SEM & $\mathrm{z}$ & $P$ & Estimate & SEM & $\mathrm{z}$ & $P$ \\
\hline Intercept & & & & & 4.74 & 0.41 & 11.49 & $<0.001$ & 5.23 & 0.35 & 14.81 & $<0.001$ \\
\hline$\%$ Arable land & & & & & -0.01 & 0.01 & -1.78 & 0.075 & -0.02 & 0.01 & -2.76 & 0.006 \\
\hline \multicolumn{13}{|l|}{ Connectivity } \\
\hline Management g-a & & & & & 1.18 & 0.27 & 4.42 & $<0.001$ & -0.42 & 0.23 & -1.83 & 0.159 \\
\hline Management m-a & & & & & 0.84 & 0.27 & 3.11 & 0.005 & 0.26 & 0.23 & 1.12 & 0.504 \\
\hline \multirow[t]{3}{*}{ Management m-g } & & & & & -0.34 & 0.26 & -1.29 & 0.399 & 0.68 & 0.23 & 3.00 & 0.008 \\
\hline & \multicolumn{4}{|c|}{ Grasshoppers } & \multicolumn{4}{|c|}{ True bugs } & \multicolumn{4}{|c|}{ Spiders } \\
\hline & Estimate & SEM & $\mathrm{z}$ & $P$ & Estimate & SEM & $\mathrm{z}$ & $P$ & Estimate & SEM & $z$ & $P$ \\
\hline Intercept & 3.39 & 0.1537 & 22.06 & $<0.001$ & 3.79 & 0.15 & 24.51 & $<0.001$ & 3.7329 & 0.09657 & 38.656 & $<0.001$ \\
\hline \multirow{2}{*}{\multicolumn{13}{|c|}{$\begin{array}{l}\% \text { Arable land } \\
\text { Connectivity }\end{array}$}} \\
\hline & & & & & & & & & & & & \\
\hline Management g-a & & & & & -0.74 & 0.22 & -3.31 & 0.003 & -0.46 & 0.14 & -3.25 & 0.003 \\
\hline Management m-a & & & & & 0.16 & 0.22 & 0.72 & 0.751 & -0.18 & 0.14 & -1.33 & 0.381 \\
\hline \multirow[t]{3}{*}{ Management $\mathrm{m}-\mathrm{g}$} & & & & & 0.90 & 0.22 & 4.03 & $<0.001$ & 0.28 & 0.14 & 1.93 & 0.131 \\
\hline & \multicolumn{4}{|c|}{ Rove beetles } & \multicolumn{4}{|c|}{ Hoverflies } & \multicolumn{4}{|c|}{ Leafhoppers } \\
\hline & Estimate & SEM & $z$ & $P$ & Estimate & SEM & $\mathrm{z}$ & $P$ & Estimate & SEM & $\mathrm{z}$ & $P$ \\
\hline Intercept & 3.10 & 0.25 & 12.27 & $<0.001$ & 3.68 & 0.27 & 13.42 & $<0.001$ & 5.84 & 0.18 & 32.75 & $<0.001$ \\
\hline$\%$ Arable land & & & & & 0.02 & 0.01 & 2.78 & 0.005 & & & & \\
\hline Connectivity & 0.003 & 0.001 & 1.96 & 0.050 & & & & & & & & \\
\hline Management g-a & & & & & & & & & -1.19 & 0.25 & -4.70 & $<0.001$ \\
\hline Management m-a & & & & & & & & & -0.68 & 0.25 & -2.70 & 0.019 \\
\hline Management m-g & & & & & & & & & 0.51 & 0.25 & 2.00 & 0.112 \\
\hline
\end{tabular}

Species richness

\begin{tabular}{|c|c|c|c|c|c|c|c|c|c|c|c|c|}
\hline & \multicolumn{4}{|c|}{ Plants } & \multicolumn{4}{|c|}{ Bees } & \multicolumn{4}{|c|}{ Butterflies } \\
\hline & Estimate & SEM & $z$ & $P$ & Estimate & SEM & $\mathrm{z}$ & $P$ & Estimate & SEM & $z$ & $P$ \\
\hline Intercept & 4.00 & 0.15 & 26.8 & $<0.001$ & 2.94 & 0.17 & 17.50 & $<0.001$ & 2.54 & 0.11 & 23.58 & $<0.001$ \\
\hline$\%$ Arable land & -0.01 & 0.003 & -1.871 & 0.061 & -0.01 & 0.003 & -1.84 & 0.066 & & & & \\
\hline Connectivity & & & & & & & & & 0.001 & $<0.001$ & 2.59 & 0.016 \\
\hline Management g-a & & & & & 0.31 & 0.11 & 2.81 & 0.014 & -0.45 & 0.15 & -3.08 & 0.013 \\
\hline Management $\mathrm{m}$-a & & & & & 0.17 & 0.11 & 1.51 & 0.287 & 0.14 & 0.14 & 1.02 & 0.570 \\
\hline \multirow[t]{3}{*}{ Management m-g } & & & & & -0.14 & 0.10 & -1.34 & 0.373 & 0.59 & 0.15 & 4.07 & 0.001 \\
\hline & \multicolumn{4}{|c|}{ Grasshoppers } & \multicolumn{4}{|c|}{ True bugs } & \multicolumn{4}{|c|}{ Spiders } \\
\hline & Estimate & SEM & $\mathrm{z}$ & $P$ & Estimate & SEM & $\mathrm{z}$ & $P$ & Estimate & SEM & $z$ & $P$ \\
\hline Intercept & 1.65 & 0.20 & 8.43 & $<0.001$ & 2.53 & 0.09 & 28.24 & $<0.001$ & 2.86 & 0.08 & 37.68 & $<0.001$ \\
\hline$\%$ Arable land & -0.01 & 0.004 & -2.02 & 0.053 & & & & & & & & \\
\hline \multicolumn{13}{|l|}{ Connectivity } \\
\hline Management g-a & & & & & -0.31 & 0.14 & -2.23 & 0.066 & -0.31 & 0.12 & -2.64 & 0.023 \\
\hline Management m-a & & & & & 0.08 & 0.12 & 0.68 & 0.774 & -0.02 & 0.11 & -0.22 & 0.975 \\
\hline \multirow[t]{3}{*}{ Management m-g } & & & & & 0.39 & 0.13 & 2.90 & 0.011 & 0.28 & 0.12 & 2.43 & 0.041 \\
\hline & \multicolumn{4}{|c|}{ Rove beetles } & \multicolumn{4}{|c|}{ Hoverflies } & \multicolumn{4}{|c|}{ Leafhoppers } \\
\hline & Estimate & SEM & $\mathrm{z}$ & $P$ & Estimate & SEM & $z$ & $P$ & Estimate & SEM & $\mathrm{z}$ & $P$ \\
\hline $\begin{array}{l}\text { Intercept } \\
\% \text { Arable land }\end{array}$ & 1.49 & 0.12 & 12.54 & $<0.001$ & 2.47 & 0.05 & 53.15 & $<0.001$ & 2.93 & 0.07 & 40.23 & $<0.001$ \\
\hline Connectivity & & & & & & & & & & & & \\
\hline Management g-a & & & & & & & & & -0.35 & 0.11 & -3.06 & 0.006 \\
\hline Management m-a & & & & & & & & & -0.10 & 0.11 & -0.95 & 0.608 \\
\hline Management $\mathrm{m}-\mathrm{g}$ & & & & & & & & & 0.25 & 0.12 & 2.12 & 0.086 \\
\hline
\end{tabular}




\section{References S1.}

Experts who provided information on habitat specialisation and literature used for classification of species into specialists and generalists.

H. Nickel (Göttingen), leafhoppers

M. Goßner (Fronreute), true bugs

R. Theunert (Hohenhameln), bees

Biedermann, R. \& Niedringhaus, R. (2004) Die Zikaden Deutschlands - Bestimmungstafeln für alle Arten. WABV Fründ, Scheeßel.

Hanski, I., Alho, J. \& Moilanen, A. (2000) Estimating the parameters of survival and migration of individuals in metapopulations. Ecology, 81, 239-251.

Krauss, J., Steffan-Dewenter, I. \& Tscharntke, T. (2003) How does landscape context contribute to effects of habitat fragmentation on diversity and population density of butterflies? Journal of Biogeography, 30, 889-900.

Meyer, B. (2007) Pollinator communities and plant-pollinator interactions in fragmented calcareous grasslands. Georg-August Universität, Göttingen,

Wachmann, E., Melber, A. \& Deckert, J. (2004) Wanzen 2 - Tierw. Deutschlds., 75: 1-294. Goecke \& Evers, Keltern.

Wachmann, E., Melber, A. \& Deckert, J. (2006) Wanzen 1 - Tierw. Deutschlds., 77: 1-263. Goecke \& Evers, Keltern.

Wachmann, E., Melber, A. \& Deckert, J. (2007) Wanzen 3 - Tierw. Deutschlds., 78: 1-272. Goecke \& Evers, Keltern.

Wachmann, E., Melber, A. \& Deckert, J. (2008) Wanzen 4 - Tierw. Deutschlds., 81: 1-230. Goecke \& Evers, Keltern. 


\section{CHAPTER 3}

\section{CORRIDORS RESTORE ANIMAL-MEDIATED POLLINATION IN FRAGMENTED TROPICAL FOREST LANDSCAPES}

Urs Kormann, Christoph Scherber, Teja Tscharntke, Nadja Klein, Manuel Larbig,Jonathon J. Valente, Adam S. Hadley, Matthew G. Betts

To be submitted to Proceedings of the Royal Society B 


\section{AbSTraCt}

Tropical biodiversity and associated ecosystem functions are heavily eroded through habitat loss. Animal-mediated pollination is required in $>94 \%$ of higher tropical plant species and $75 \%$ of the world's leading food crops, but it remains unclear if corridors avert deforestation-driven pollination breakdown in fragmented tropical landscapes. Here, we use manipulative resource experiments and field observations to show that corridors functionally connect neotropical forest fragments for forest-associated hummingbirds and increase pollen transfer. Further, corridors boosted forest-associated pollinator availability in fragments by 14.3 times compared to unconnected equivalents, increasing overall pollination success. Plants in patches without corridors showed pollination rates equal tobagged control flowers, indicating pollination failure in isolated fragments. This indicates, for the first time, that corridors benefit tropical forest ecosystems beyond boosting local species richness, by functionally connecting mutualistic network partners. We conclude that small-scale adjustments to landscape configuration safeguard native pollinators and associated pollination services in tropical forest landscapes.

Keywords: Animal-mediated pollination, Costa Rica, dispersal, ecosystem function, fragmentation, functional connectivity, pollen flow, pollinator limitation 


\section{INTRODUCTION}

In an era of rocketing human-driven habitat modification, maintaining biodiversity and ecosystem functions is increasingly at risk $(1,2)$. Animal-mediated pollination is such a crucial ecosystem function, required in $87 \%$ of higher terrestrial plant species and $75 \%$ of the world's leading food crops $(3,4)$. Critically, loss of pollinator function through increased habitat conversion is of global concern $(2,5,6)$, particularly in the tropics, where high rates of habitat loss and fragmentation coincide with an above-average proportion of angiosperms dependent on animal-mediated pollination (> 94\% species; $(3,7,8)$ ).

Breakdown of pollination mutualisms through habitat modification (i.e. habitat loss and fragmentation), can result from reduced availability of suitable pollen donors, degraded pollinator pools and restricted movement of pollinators, and subsequently reduced pollenflow between habitat fragments (the "pollinator-movement-hypothesis" sensu (9)). In turn, many animal-pollinated plants suffer from impaired sexual reproduction as a consequence of pollination limitation after habitat loss and fragmentation $(6,10)$, thus filtering plant communities towards non-animal-pollinated species $(6,11)$.

Corridors may benefit pollination services by facilitating pollinator movement among habitat fragments, improved pollinator demography and higher availability of pollinators and outcross pollen (10,12-15). To date, however, it remains unexplored whether corridors affect animal-mediated pollination in tropical, highly biodiverse systems, which are of global conservation importance $(7,16)$

Narrow wooded elements such as living fencerows and slender riparian buffers $(<$ 15m, see Fig. 1C) often constitute the only abundant wooded structures outside forest remnants in tropical agricultural landscapes worldwide(17). In Latin America, these structures are often retained by local landowners, mostly for agricultural purposes, and recent studies highlight their capacity to harbor a substantial proportion of tropical biodiversity $(17,18)$. To date, however, it remains unclear if such elements increase connectivity for species associated with remaining tropical forest and whether this ultimately translates into the provision of ecosystem processes such as pollination (19)

Here, we tested whether linear wooded corridors between tropical forest remnants enhance functional connectivity (20) for pollinators and subsequently, animal-mediated pollination. In our southern Costa Rican study area, only 30 percent of the original forest cover persists - mostly in scattered fragments surrounded by pasture and coffee plantations (21). However, narrow linear wooded corridor elements are quite common (18). Previous work in the study region has reported that forest loss and fragmentation erode insect and 
avian pollinator communities (22-24). We used hummingbird-mediated pollination as a model system, as birds may be powerful agents for connecting fragmented plant populations, given their large potential foraging distances (25). Between 18 to $34 \%$ of neotropical understory flowering plants show adaptations for hummingbird pollination $(26,27)$, however the species richness of hummingbird pollinated flowers may be reduced in highly disturbed landscapes (11). Further, forest gaps appear to limit hummingbird movement (28), resulting in pollen limitation of the understory herb Heliconia tortuosa, the most common, long-blooming floral resource in the regional hummingbird-plant pollination network $(24,29,30)$

We tested if narrow woody corridors affect animal-mediated pollination by using four complementary approaches: First, we experimentally assessed if living fencerows promote hummingbird foraging movement through deforested land, expecting that such an effect is more accentuated for forest specialists compared to habitat generalist species. For this, we traced foraging visits of whole hummingbird communities along experimentally manipulated resource gradients placed in paired corridor / non-corridor set-ups. Second, we tested if hummingbird-mediated pollen dispersal between neighboring forest fragments is stimulated by corridors compared to pastures, by quantifying the transfer of analogue pollen in replicated experimental setups. Third, we tested if corridors boost the occupancy of the two most abundant forest specialist and habitat generalist hummingbird species in pollinator-depleted forest fragments. Fourth, we evaluated whether corridors increase pollinationin $H$. tortuosa in small, pollination-depressed forest fragments.

\section{METHODS}

We conducted the study in Southern Costa Rica around the Las Cruces Biological Station $\left(8^{\circ} 47 \mathrm{~N}, 82^{\circ} 57 \mathrm{~W}\right)$. The region was originally characterized by contiguous Pacific premontane humid forest, but massive deforestation since the 1950s resulted in a patchwork of forest fragments $(900-1500 \mathrm{~m}$ asl), ranging from $<1$ to $>1000$ ha in size surrounded by pastures $(>90 \%)$, coffee plantations and human settlements. Details are given in (24).

\section{Pollinator movement}

We tested the corridor effect on hummingbird foraging movement by measuring foraging visits in two replicated, standardized food titration experiments between April and June 2012 (Fig. 1A). Food titration experiments are a method for measuring the motivation of organisms to move through a given habitat type under standardized conditions. 
Standardization is accomplished by experimentally supplementing resources (e.g., food) across a suite of land cover types differing in hypothesized functional connectivity (31). First, we measured rates of hummingbird visits to artificial flowers placed according to two experimental titration treatments replicated 16 times at spatially discrete sites (Fig. S1A). All sites were composed of a central forest fragment surrounded by pasture and an adjacent living fencerow. Fencerows consisted of rows of remnant or planted trees (length: $182 \mathrm{~m}$ \pm 35 ; width: $1.2 \mathrm{~m} \pm 0.2$; height: $7.5 \mathrm{~m} \pm 0.6$, mean $\pm \mathrm{SE}$, Fig. $1 \mathrm{C})$. Within each site, we applied two treatments (Fig. 1A): seven artificial flowers placed along the living fencerow (treatment: corridor) and seven directly in pasture (treatment: no corridor). In both treatments, the first two flowers were placed at the forest edge, followed by five consecutive flowers placed in a line $10 \mathrm{~m}$ apart, thus representing a crossed 'treatment*distance' design. Treatments within sites were $>150 \mathrm{~m}$ apart. To limit potential confounds, existing flowers along the treatments were removed or covered with mesh bags to render them unavailable during the experiments.

Artificial flowers consisted of $50 \mathrm{ml}$ Falcon tubes equipped with a red plastic flower and a straight tubular 'corolla', mimicking a highly attractive ornithophilous flower with constant nectar supply (Fig. 1D). Although of high resource quality, these flowers are assumed not to substantially alter hummingbird foraging behavior, that is hummingbirds maintain typical behaviour such as traplining despite feeder presence (pers. obs. UK, ASH, MGB).

Feeders were constantly available during five successive days per site, and daily refilled with 10\% saccharose nectar. After three days of habituation, two observers visited each site on day four and five of exposure to visually quantify hummingbird visits during peak hummingbird activity (between $0530-1000$ and $1430-1800$ ) for a total of 40 minutes per feeder. Treatments were randomly assigned to observers on day four and assignment changed on day five. We statistically analyzed the six most common species (> 30 observations), which resulted in sufficient data for four forest-associated hummingbird species and two habitat generalist species, which also occur in open habitats (Table 1). Habitat affiliation was determined based on previous work in the region $(30,32)$, field guides (33) and per. observations (UK, ASH, MGB, pers. obs.).

Further, we conducted a second experiment at seven additional sites using the same design as above, but with experimental, live plants of $H$. tortuosa in lieu of artificial flowers. H. tortuosa requires visits of long-distance traplining hummingbird species with specialized bills for successful sexual reproduction $(24,34)$, butpollen tubes can be initiated both by 
self- and outcross pollen (partial self-compatibility;(34)). Individual H. tortuosa plants bloom for several month, but individualflowers are only open and pollen receptive for a single day before abscising, after which an indicative colour change occurs. Although $H$. tortuosa is mostly found in forest, it can thrive in open areas such as pastures and readily set seed given sufficient pollination (e.g.(34), pers. obs. UK). For each site, we selected 14 plants with 4 - 6 flowers in the central forest patch, and transplanted them into the adjacent pasture. Importantly, nectar volume and sucrose concentration of bagged control flowers did not differ between transplanted corridor and pasture flowers (volumetwo-way ANOVA, $F_{1,26}=0.052, P=0.822$; sucrose two-way ANOVA $\left.: F_{1,26}=0.462, P=0.503\right)$.

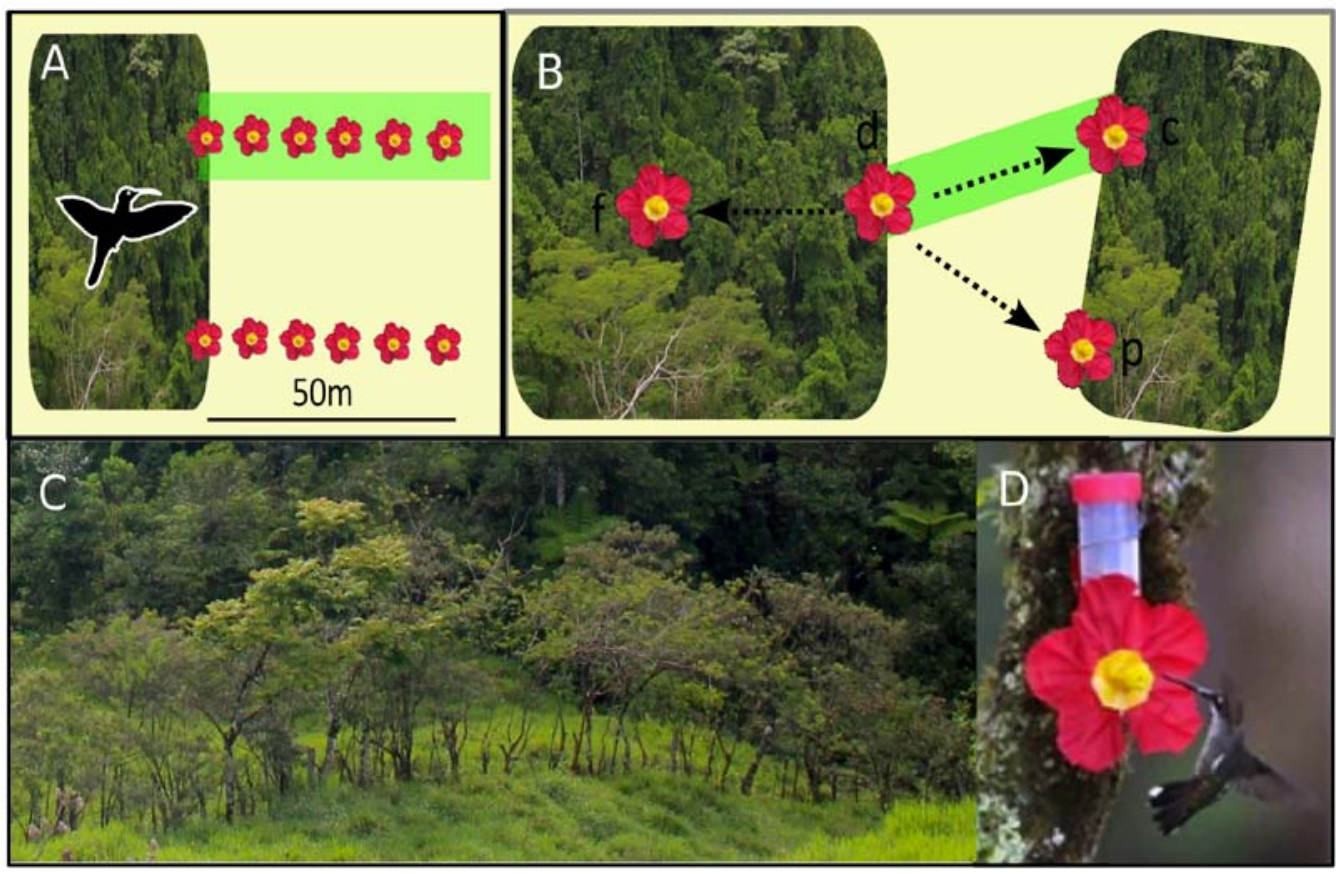

Fig.1:A) Experimental design to test the effects of narrow wooded corridors on hummingbird movement through pasture. Sites consisted of forest patches sourrounded by pasture and a living fencerow ('corridor', light green). Experimental food resources (artificial flowers or live H. tortuosa plants) were placed at 0 to 50 $\mathrm{m}$ distance from the forest edge, at $10 \mathrm{~m}$ intervals, along pasture or along the corridor. B.) Experimental design used to assess hummingbird-mediated pollen transfer between forest fragments. Sites had two forest patches surrounded pasture, connected by a living fencerow ('corridor', light green). A central artificial flower treated with pollen analogue ('pollen donor', d) was encircled by three 'pollen receiver' flowers placed at equal distances (arrows). 'Pollen receivers' differed in the type of intervening land cover to the 'pollen donor': forest (f), corridor (c) or pasture (p). C) Slender woody corridor (living fencerow) used in this study. D) Hummingbird (Heliomaster longirostris) visiting an artificial flower.

To quantify pollinator visits, we visited treatments on day four and five after plant transplantation between 0530 - 0930am, for a total of 40 minutes of observation per plant $(2 * 20 \mathrm{~min})$. In addition, we collected 280 day-old styles from the exposed plants (mean = 
3.42 styles per plant collected during at least two days) identified by indicative colour change according to (34) and (24). We determined pollen tube growth with epifluorescent microscopy (sensu (34), SI 2 for details ).

We provide a statistical overview with methodological details in Table S1. We analyzed hummingbird visits at artificial and planted flowers, and number of pollen tubes observed per style with mixed Bayesian, Generalized Additive Models for Location, Scale and Shape (BGAMLSS (35)) implemented in BayesX (36) This method allowed us to (i) take into account the hierarchical data structure, (ii) incorporate the spatial dependency of neighboring flowers (serial autocorrelation) by a smoother, (iii) model the nonlinear effect of distance to forest via a nonparametric function for distance and (iv) to model the detected zero-inflation and/or overdispersion in the dependent variable (see SI 1 for details). We first selected the adequate response distribution by choosing among Poisson, zero-inflated Poisson (ZIP), negative binomial (NegBin), and zero-inflated negative binomial (ZINB) based on quantile residual-plots of the full model. Full models included corridor (linear), distance to forest (nonparametric) and their interactions as fixed factors, as well as Treatment nested within Site as random factor (further details on predictor specifications in S1). Second, we followed (35) to identify the relevant predictors by comparing models with all possible variable combinations, using the deviance information criterion (DIC, a Bayesian analogue of AIC) and significance values of parameters to determine the top candidate models $(\Delta \mathrm{DIC}<5)$. More details on model specifications and selection are given in S1 and Table S1.

\section{Pollen movement}

To test if corridors facilitate hummingbird mediated pollen flow between neighboring forest fragments, we tracked pollen transfer among artificial flowers using fluorescent dye as a pollen substitute (37) Fluorescent dyes have been shown to accurately mirror pollen movement by hummingbirds (38) and plant gene flow (37). In April and May 2013, we established a pollen tracking experiment in 14 replicated landscapes, each with two neighboring forest fragments surrounded by pasture (Fig. 1B and Fig. S1B). Both fragments were connected by a living fencerow (corridor), ranging in length from 40 to $120 \mathrm{~m}$. A central artificial flower was placed in the first fragment at the beginning of the corridor, the 'pollen donor'. Three 'pollen receiver' flowers encircled the donor at equal distances (i.e. the length of the corridor): the 'corridor flower' at the corridor end in the second fragment, the 'pasture flower' also at the edge of the second fragment, but isolated from the donor by pasture, and the 'forest flower' at equidistant position inside the first 
forest fragment. Pastures were virtually free of floral ressources. All feeders remained operative for $\sim 96$ hours, and were equipped on day three with filaments and the donor additionally with yellow fluorescent dye (RadgloR, Radiant Color, Belgium). After 24 h of exposure, filaments were collected, replaced by clean filaments for 24 hours, and dye reapplied. We then photographed the collected filaments under UV-light and used automated image analysis to count the number of pollen particles on filaments (function "AnalyzeParticle“ in ImageJ, (39), following (40)). We used generalized linear mixed models (41) with a negative-binomial distribution in R (3.0.3 beta) and stepwise backwards model selection based on AICc to identify the best fitting model (Table S1). The full model contained the number of deposited pollen particles as a function of distance to the dye source, intervening cover type (treatment) and their interaction. Flower position was nested within 'site' as a random factor. Multiple comparisions among treatments types were done using Tukey's pairwise comparisons (glht function(42)).

\section{Pollinator presence in forest fragments}

To test if corridors increase pollinator availability in pollinator-depauperate forest fragments, we assessed the presence of the two most common hummingbird species, the highly mobile, but forest restricted $P$. guy (forest specialist) and the habitat generalist $A$. tracatl. For this, we selected 26 small forest patches (2.23ha \pm 1.29 SE, Fig. S1C), as previous studies in the region indicated strongly reduced hummingbird communities and abundances in small forest fragments (24). Patches represented a gradient in the number of corridor connections to other forest patches ([0-3], CORRIDOR). Corridors were 1-2 trees wide, and either living fencerows or slender riparian buffers. Fragments were not connected to other forest fragments by any additional riparian strips, that is, all connecting corridors per patch were included in the design. Patches were selected based on aerial images and corridor integrity later verified in the field. For each patch, we measured patch size (SIZE), proportion of forest within a $250 \mathrm{~m}$ radius of the patch centroid (PROPFOR) and altitude (ALT) based on existing digital forest cover maps (24).

In 2012, we visited each forest fragment and assessed presence/absence of both hummingbird species visually and acousticallyat three haphazardly placed point count locations inside the forest (radius $25 \mathrm{~m}$, count duration 12 minutes). We detected $P$. guy and A. tracatl during $35 \%$ and $60 \%$ of all point counts respectively $(\mathrm{n}=78)$, corresponding to $15(58 \%)$ and $21(80 \%)$ of all patches, respectively. We then used an occupancy modeling 
approach (43) to evaluate the effect of the explanatory variables (CORRIDOR, SIZE, PROPFOREST, and ALTITUDE) on patch use by each species while simultaneously accounting for detection probability. Points within patches were treated as spatial subsamples of the patch, and this sampling approach should yield unbiased occupancy parameter estimates for highly mobile species such as hummingbirds (44). All covariates were standardized by subtracting the mean and dividing by the standard deviation before inclusion in the models. We selected the single best combination of explanatory variables for each species by starting with a full model and using backwards variable selection based on AICc (Table S1). Because previous work indicates that individuals that utilize multiple forest patches may spend more time in the larger ones, we also included patch size as a covariate for detection probability in all models.

\section{Pollination success}

To test if enhanced hummingbird movement afforded by corridors subsequently boosted pollination, we assessed pollination rates in naturally occurring $H$. tortuosa in fragments differing in their connectivity. For this, we selected 13 small forest fragments (AREA: $1.03 \mathrm{ha} \pm 0.43$, Fig. S1D, Tab. S8) surrounded by pasture and connected to neighbouring forest fragments by zero, one or two corridor elements (CORRIDOR). Again, linear corridor elements were either living fencerows or slender riparian buffers, ranging from one to two trees in width. In May 2013, we sampled $\sim 20$ one day old flowers per fragment (mean per fragment $\pm \mathrm{SD}=18.58 \pm 2.39$, following $(24)$ ) and systematically recorded $H$. tortuosa density per patch (FLOWER). We then determined the distance to the next forest $>5$ ha (DISTANCE) and proportion of forest as described above (PROPFOREST). Pollination was then assessed for every flower by the presence of pollen tubes (see Supporting Methods S2). Of 238 collected H. tortuosa styles, 59 were pollinated (mean per fragment $\pm \mathrm{SD}=26.46 \% \pm 16.32$ ). As a pollinator exclusion control, we further bagged 5-6 inflorescenses in four sites with mesh bags and subsequently collected two one-day old flowers from each inflorescence ( 42 flowers in total). We then analyzed the proportion of styles with pollen tubes per patch using logistic regression with a binomial error structure in $\mathrm{R}$ (glm, (45)), including CORRIDOR, AREA, FLOWER, DISTANCE and PROPFOREST as explanatory variables. Here, we used stepwise model selection based on AICc to identify the best fitting model (Table S1). 


\section{RESULTS}

\section{Pollinator Movement}

We quantified hummingbird visits at artificial flowers over a total of 1280 minutes. We analyzed the six most common species ( $\mathrm{n}>30$ observations/ species) that accounted for $98.5 \%$ of all observations. During observation bouts all forest specialist individuals performed sequential foraging movement (traplining) along feeder transects; birds typically originated from the forest fragment, visited feeders sequentially, and returned to the fragment. In two cases we observed Green Hermits moving along the entire corridor, but starting from opposite direction. While the best-fitting additive model indicated that all four forest specialists visited more flowers along corridors (Fig. 2, effect significant in three of four species, $P \leq 0.005$, Table 1, Table S1, Table S2), we detected no corridor effect for the two habitat generalists (Fig. 2, Table 1, Table S1, Table S2). Further, visitation rates for all species showed significant and strong decays with increasing distance to forest (Fig. 2, Table S1, Table S2). An exception was the species most strongly affiliated with open land ((30), (32)), Heliomaster longirostris, which showed a unimodal activity pattern peaking at intermediate distances to forest.

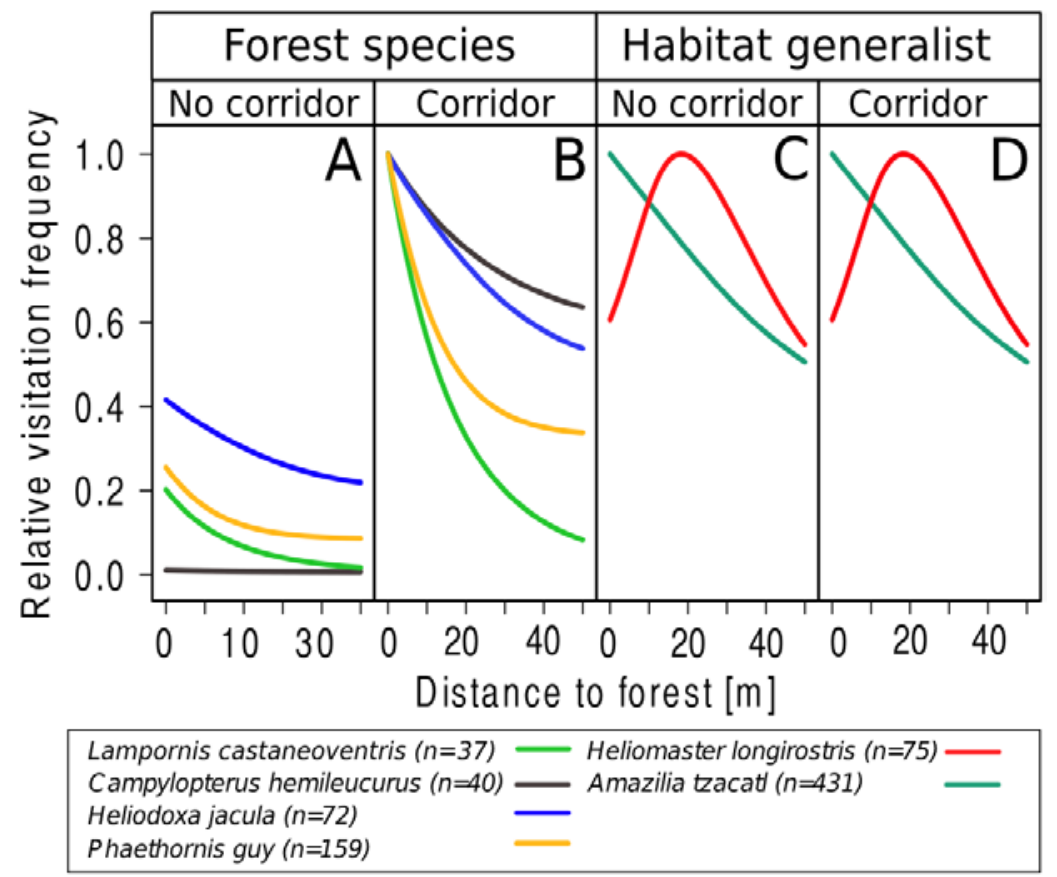

Fig. 2: Effect of corridors and habitat preferences on hummingbird foraging movement through deforested habitat, to visit artificial resources placed at increasing distances to the forest edge. Shown are predicted visitation rates for four forest species without corridors (A) and along corridors (B), and for two habitat generalists along corridors $(\mathrm{C})$ and without corridor (D). Visitation rates are scaled to [0,1] per species and based on the best fitting models. Numbers in the legend show the number of observed visits per species. 
Next, in addition to counting visits to feeders, we examined hummingbird visits to experimental plants over 560 minutes (28 observation periods), resulting in a total of 37 visits by the primary pollinator P. guy and only 4 by $C$. hemileucurus. Therefore, we analyzed only $P$. guy visits. Frequency of visits to artificial flowers were significantly greater along corridors $(P=0.008)$ and significantly decreased with increasing distance to forest (Table S2, Fig. S2). Also, the number of pollen tubes per style decayed significantly with increasing distance to forest, and tended to be higher along corridors $(P=0.12, n=280$ styles, Table S2, Fig. S1).

Table 1: Linear effects (intercept and corridor) on predictors for visits of six hummingbird species at artificial flowers, based on the best fitting Bayesian model. Shown are posterior means (mean), lower 2.5\% credible interval (p2.5) and upper 97.5\% credible interval (p97.5). Significance (Sign.) indicates if the 95\% credible interval includes 0 or not.

\begin{tabular}{lllll}
\hline & mean & $\mathrm{p} 2.5$ & $\mathrm{p} 97.5$ & Sign. \\
\hline $\boldsymbol{P}$. guy & & & & \\
Intercept & -2.040 & -2.989 & -1.255 & 0 \\
Corridor & 1.380 & 0.448 & 2.384 & 0.005 \\
\hline C. hemileucurus & & & & \\
Intercept & -10.945 & -20.791 & -5.324 & 0 \\
Corridor & 7.851 & 2.185 & 17.736 & 0.002 \\
\hline $\begin{array}{l}H . \text { jacula } \\
\text { Intercept }\end{array}$ & -3.528 & -4.990 & -2.284 & 0 \\
Corridor & 1.002 & -0.588 & 2.629 & 0.208 \\
\hline $\begin{array}{l}\text { L. castaneoventris } \\
\text { Intercept }\end{array}$ & -4.240 & -6.177 & -2.698 & 0 \\
Corridor & 1.650 & 0.699 & 2.674 & 0.005 \\
\hline $\begin{array}{l}\text { A. tzacatl } \\
\text { Intercept }\end{array}$ & 0.036 & -0.487 & 0.467 & 0.240 \\
\hline $\begin{array}{l}\text { H. longirostris } \\
\text { Intercept }\end{array}$ & -2.168 & -3.509 & -1.004 & 0.005 \\
\hline
\end{tabular}

\section{Pollen movement}

The best model contained additive effects of "treatment" and "distance" only. Even though pollen was transferred up to $120 \mathrm{~m}$ between feeders in some cases (Fig. 3), we found that the number of dye particles transferred decreased by a factor $9.92(95 \% \mathrm{CI}=$ [1.69 - 57.98]) along the $40-120 \mathrm{~m}$ distance gradient (Fig. 3.; GLMM: $z=-2.03, P=0.042$ ).

While corridors and forest did not significantly differ in their permeability for pollen $(P=0.13$; Table S3), pasture strongly impeded pollen transfer relative to corridor and forest treatments (Fig. 3; $P=0.00$ each; Table S3). However, this compensation effect of corridors decreased with increasing distance between fragments (Fig. 3; Table S3). 


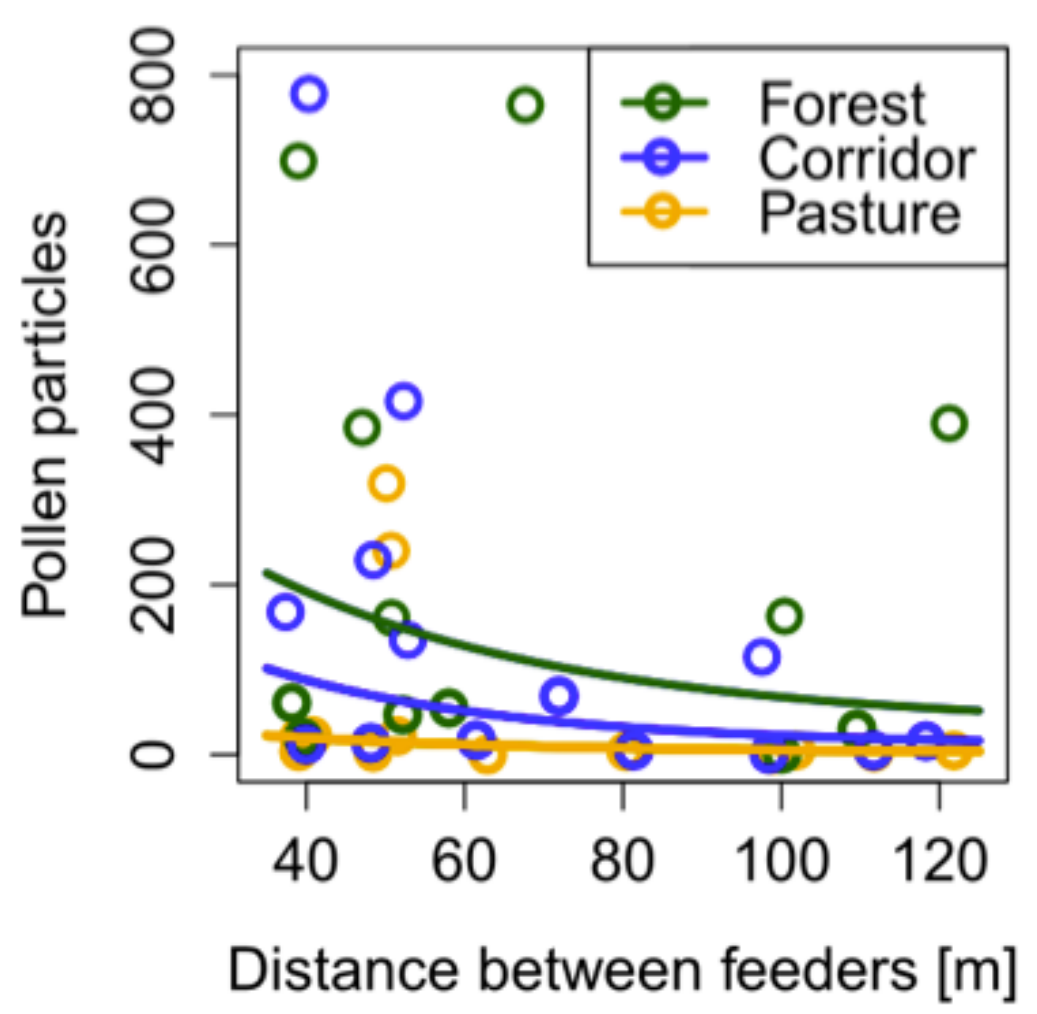

Fig. 3: Pollen transfer between artificial flowers with interjacent forest, corridor or pasture. Shown is the mean number of artificial pollen particles as a function of the distance to the pollen source and intervening cover type. Pollen transport decreased with increasing distance between feeders $(P=0.04)$ and was higher between feeders with interjacent forest $(P<0.0001)$ or corridors $(P=0.0003)$ compared to pasture. Circles represent data points.

\section{Pollinator presence in forest fragments}

The number of corridor connections to other forest patches was the only explanatory variable remaining in the best occupancy model for P. guy (Table S5, Fig. 4b). In contrast, the intercept-only occupancy model was chosen for the habitat generalist A. tzacatl (Table S5). Corridors substantially boosted P. guy occupancy rates in forest fragments (Figure 4), as the probability of use significantly increased by a factor 14 from nearly 0 in isolated patches $(=0.14,95 \% \mathrm{CI}=[0.02-0.60])$ to nearly 1 in patches with 3 corridors $(=0.98,95 \% \mathrm{CI}=[0.50-1.00])$. Indeed, we did not observe any P. guy during point counts in isolated patches $(n=4)$. These results not only suggest that corridors increase the patch use of the forest specialist pollinator, but that perhaps there may be a threshold in connectivity below which this species does not visit fragments. 


\section{Pollination success}

Paralleling the effect on the main pollinator, $P . g u y$, connectivity to forests by corridors was the only variable that determined the proportion of pollinated flowers (Table S6). Pollen tube growth, the first critical step in successful fertilization, was significantly enhanced by corridors (Fig. 4B, GLM: $z=3,358, P=0.000$ ); the fraction of styles with pollen tubes was 5.66 times higher $(95 \% \mathrm{CI}=[4.32$ - 7.01]) in patches with two corridors compared to isolated patches. Importantly, pollen tube growth rate in isolated patches was not different from bagged control flowers, suggesting a breakdown of the pollination mutualism in isolated patches (proportion of styles with tubes for isolated vs. bagged: 0.091 vs. 0.077 , GLM: $₹=-0.220, P=0.826)$. This indicates that connectivity via the presence of corridors therefore not only strongly enhanced pollination rates, but also rescued plants in small patches from pollination failure.
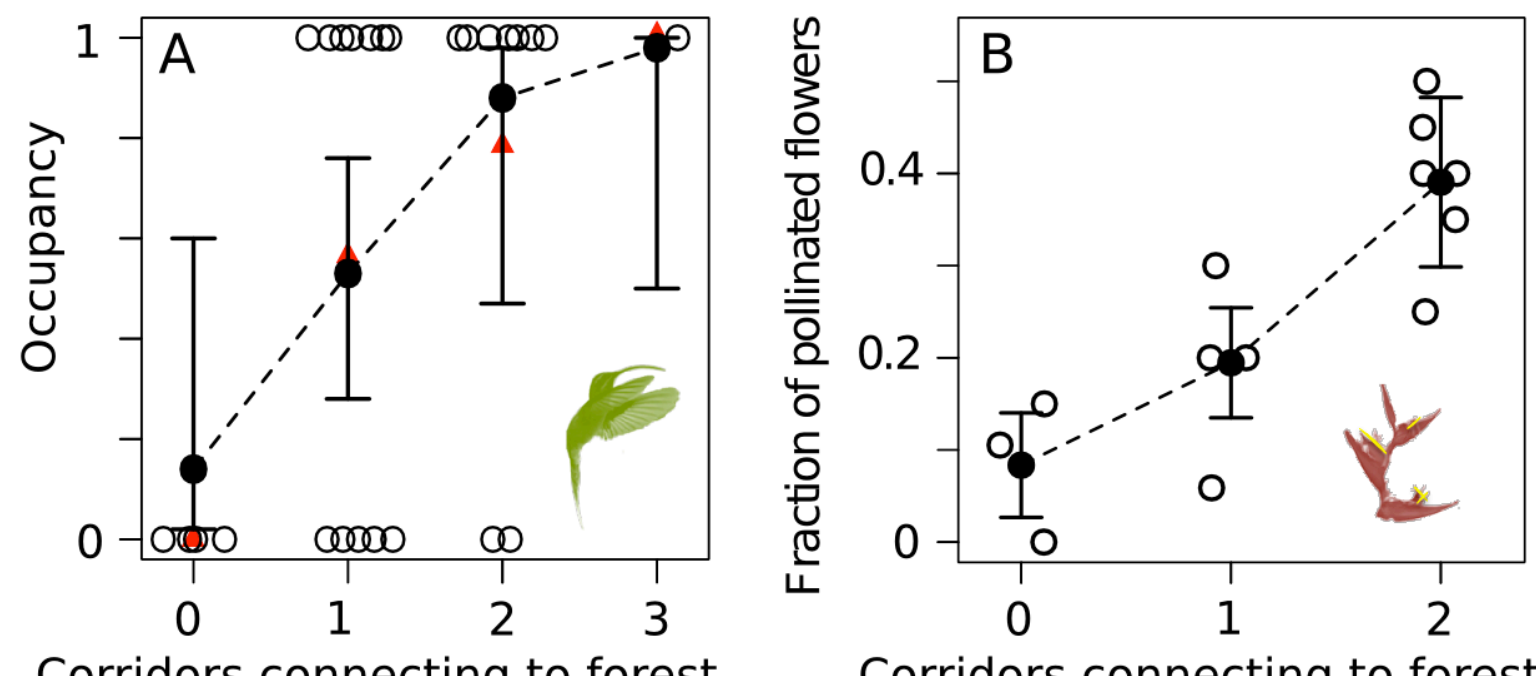

Corridors connecting to forest

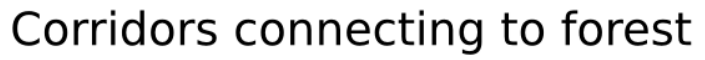

Fig. 4: Corridors and their effect on pollinator patch use (A) and subsequent pollination success (B) in small Costa Rican forest fragments. A.) Occupancy for the most common bird pollinator - P. guy strongly increased with increasing number of corridors connecting the fragment to a large forest ( $\mathrm{n}=26$ fragments, $\mathrm{P}$ $<0.05$ ). Shown are predicted occupancy values (black dots) and associated confidence intervals (bars). Red triangles represent naïve occupancy estimates (detection probability $=1$ ), jittered circles show data points. $(B)$ Pollen tube growth, measured as the proportion of flowers per forest fragment with pollen tubes, also significantly increased with the number of corridors $(n=13, P<0.000$, mean number of pollen tubes collected per fragment $\pm \mathrm{SD}=18.58 \pm 2.39)$. Error bars show the $95 \%$ prediction intervals, jittered circles represent data points. 


\section{DisCUSSION}

Our study provides four complementary lines of evidence for consistent and positive corridor effects on animal-mediated pollination in tropical landscapes: Corridors strongly enhanced (i) movement of habitat specialist hummingbirds and (ii) pollen transfer through highly modified farmland, and subsequently boosted (iii) pollinator patch occupancy and (iv) pollination rates. Overall, our experiments consistently suggest that simple wooded corridors canavert the breakdown of pollination mutualisms in tropical habitat fragments by restoring functional connectivity for mobile mutualism partners.

\section{Pollinator movement}

In accordance with our prediction, corridor effects on pollinator movement depended on habitat specialization: Structurally contrasting vegetation (pasture) strongly impeded foraging movement in all forest specialists but not for any habitat generalist hummingbirds. Similarly, we found that corridors enhanced movement of habitat specialists but not generalists. In particular, the pattern seen at the experimental heliconias mirrored exactly those seen at experimental flowers.

These results corrobate previous studies which showed that forest specialists, in contrast to habitat generalists, (i) generally show a poor capacity to move between forest fragments (46), and are (ii) more dependant on corridors to move through highly fragmented habitats (47). However, this study provides, to our knowledge for the first time, experimental evidence that corridors facilitate movement of forest dependent pollinators across tropical landscapes.

\section{Pollen movement}

We found evidence that pastures strongly impede pollen transfer for hummingbird pollinated flowers, but that corridors can substantially bolster this detrimental effect. However, positive corridor effects on pollen transfer appear to dampen with increasing distance. That is, at high inter-patch distances (e.g., $>120 \mathrm{~m}$ ), corridors are unlikely to maintain sufficient pollen flow to guarantee high connectivity among plant populations. The observed pollen flow pattern is consistent with the pollinator movement hypothesis(9), i.e. the idea that non-suitable habitat (matrix) significantly hamper pollen transfer by habitat-restricted pollinators, but that even narrow corridors can significantly facilitate foraging movements and therefore functional connectivity through these areas. Alternatively, differences in pollen transfer may also result from different hummingbird species visiting corridor and pasture feeders. Nevertheless, the realized net pollen transfer 
clearly differed between corridors and pasture. Thus, our results support the idea that plant gene flow through habitat-restricted pollen vectors can be drastically limited in highly modified landscapes $(14,28)$.

\section{Pollinator presence in forest fragments}

Consistent with the strong effect of corridors on specialist movement, corridors were important drivers of within-patch specialist but not generalist presence in forest fragments. Indeed, P. guy appeared to be virtually absent from unconnected patches. This species is thought to be a key pollinator in the local hummingbird-plant pollination network, pollinating up to $35 \%$ of all hummingbird pollinated plant species in the region and elsewhere (30), so its absence may have potential negative consequences for the structure of the entire pollination network. Although recent findings suggest pollinators may shift their realized niche in absence of competing species and thus partly compensate for pollinator extinctions (48), this was not the case in our study system; apparent local extinction of $P$. guy in isolated patches was paralleled by nearly a complete breakdown of pollination in $H$. tortuosa, which was not ameliorated by the availability of the habitat generalist pollinator. Fortunately, our results show that potential perturbations to the network may be moderated by the maintenance of narrow wooded corridors.

\section{Pollination success}

A striking result of this study is that small-scale configurational landscape adjustments (wooded corridors) can benefit biodiversity in highly disturbed tropical landscapes beyond simply boosting local species richness $(18,49)$ and movement $(47)$, but have benefits to ecosystem functioning (19). Previous empirical studies have found that various animal taxa responsible for ecosystem functions increased along narrow corridors in fragmented systems $(12,15,49)$. In contrast, our study is to our knowledge the first showing that simple wooded corridors may not only benefit biodiversity by providing additional habitat and movement conduits, but that these elements have the potential to functionally connect otherwise spatially isolated partners in a mutualistic network.

Pollinators with strong edge avoidance behavior are unlikely to use narrow corridors (47). Therefore, in instances where such edge-avoidance behavior exist in native pollinators, conserving interactions will ultimately require the conservation of large pristine habitat patches (16). Overall, these results highlight the need to maintain movement of mobile, "linking" species sensu (1) to ensure the persistence of pollination mutualisms in spatially structured, human modified landscapes. 


\section{CONCLUSIONS}

The broad consistency of outcomes among our approaches suggests that simple wooded corridors can reduce deforestation-driven breakdown of pollination services by boosting landscape connectivity for pollinators and subsequently pollen flow for animalpollinated plants. However, we note that our findings may also apply to other organism groups that disperse along corridor elements, potentially providing other ecosystem services. Our results thereforemay have broad implications for the conservation of ecosystem services in tropical landscapes in general. So far, wooded corridor elements have remained abundant in many tropical farmland landscapes $(50,51)$ and appear to be widely accepted by farmers(17).

However, as tropical forests are the globally most important source of new agricultural land (Gibbs et al. 2010), quick action will be required to avert the disappearance of corridor elements between fragments. If this suggestion is not followed, then there will be substantial losses of connectivity between forest fragments, leading to accelerated biodiversity loss.

Complementary to large-scale conservation strategies (i.e.,formally protected areas), small-scale improvements in landscape connectivity (via simple corridors) constitute lowcost - big-gain tools to conserve biodiversity and ecosystem processes in tropical landscapes.

\section{ACKNOWLEDGEMENTS}

We would like to thank Felix Klaus, Jeisson Figuero, Hanna Eberlein, Evan Jackson, Dajan Ramirez, Noelia Volpe, M. Paniagua, and E. Sandiand the Schwann-Schleiden center for support during field work and lab analysis, and all landowners for access to their properties. This research was funded by the DFG Research Training Group 1644 Scaling Problems in Statistics (UGK \& NF), NSF-DEB-1050954 (MGB), NSERC-PDF (ASH) and NSF-DEB1457837 (MGB and ASH) 


\section{REFERENCES}

1. Kremen C, Williams NM, Aizen MA, Gemmill-Herren B, LeBuhn G, Minckley R, et al. Pollination and other ecosystem services produced by mobile organisms: a conceptual framework for the effects of land-use change. Ecol Lett. 2007;10(4):299_ 314.

2. Winfree R, Bartomeus I, Cariveau DP. Native Pollinators in Anthropogenic Habitats. Annu Rev Ecol Evol Syst. 2011;42(1):1-22.

3. Ollerton J, Winfree R, Tarrant S. How many flowering plants are pollinated by animals? Oikos. 2011;120(3):321-6.

4. Klein A-M, Vaissière BE, Cane JH, Steffan-Dewenter I, Cunningham S a, Kremen $\mathrm{C}$, et al. Importance of pollinators in changing landscapes for world crops. Proc Biol Sci. 2007;274(1608):303-13.

5. Biesmeijer JC, Roberts SPM, Reemer M, Ohlemüller R, Edwards M, Peeters T, et al. Parallel declines in pollinators and insect-pollinated plants in Britain and the Netherlands. Science. 2006;313(5785):351-4.

6. Clough Y, Ekroos J, Báldi A, Batáry P, Bommarco R, Gross N, et al. Density of insect-pollinated grassland plants decreases with increasing surrounding land-use intensity. Ecol Lett. 2014;17(9):1168-77.

7. Hansen MC, Potapov P V, Moore R, Hancher M, Turubanova S a, Tyukavina A, et al. High-resolution global maps of 21 st-century forest cover change. Science. 2013;342(6160):850-3.

8. Alexandratos N, Bruinsma J. World Agriculture towards 2030 / 2050 The 2012 Revision. ESA Work Pap. 2012;(12).

9. Hadley AS, Betts MG. The effects of landscape fragmentation on pollination dynamics: Absence of evidence not evidence of absence. Biol Rev. 2012;87(3):52644.

10. Aguilar R, Ashworth L, Galetto L, Aizen M a. Plant reproductive susceptibility to habitat fragmentation: Review and synthesis through a meta-analysis. Ecol Lett. 2006;9(8):968-80.

11. Mayfield MM, Ackerly D, Daily GC. The diversity and conservation of plant reproductive and dispersal functional traits in human-dominated tropical landscapes. J Ecol. 2006;94(3):522-36.

12. Tewksbury JJ, Levey DJ, Haddad NM, Sargent S, Orrock JL, Weldon A, et al. Corridors affect plants, animals, and their interactions in fragmented landscapes. Proc Natl Acad Sci U S A. 2002;99(20):12923-6. 
13. Townsend P a., Levey DJ. An experimental test of whether habitat corridors affect pollen transfer. Ecology. 2005;86(2):466-75.

14. Van Geert A, Van Rossum F, Triest L. Do linear landscape elements in farmland act as biological corridors for pollen dispersal? J Ecol. 2010;98(1):178-87.

15. Cranmer L, McCollin D, Ollerton J. Landscape structure influences pollinator movements and directly affects plant reproductive success. Oikos. 2012;121(4):5628.

16. Gibson L, Lee TM, Koh LP, Brook BW, Gardner T a., Barlow J, et al. Primary forests are irreplaceable for sustaining tropical biodiversity. Nature. 2011;478(7369):378-81.

17. Harvey C a., Villanueva C, Villacís J, Chacón M, Muñoz D, López M, et al. Contribution of live fences to the ecological integrity of agricultural landscapes. Agric Ecosyst Environ. 2005;111(1-4):200-30.

18. Mendenhall CD, Sekercioglu CH, Brenes FO, Ehrlich PR, Daily GC. Predictive model for sustaining biodiversity in tropical countryside. Proc Natl Acad Sci. 2011;108(39):16313-6.

19. Cardinale BJ, Duffy JE, Gonzalez A, Hooper DU, Perrings C, Venail P, et al. Corrigendum: Biodiversity loss and its impact on humanity. Nature. 2012;489(7415):326-326.

20. Taylor PD, Fahrig L, Henein K, Merriam G. Connectivity is a vital element of landscape structure. Oikos. 1993;571-3.

21. Daily GC, Ehrlich PR, Sánchez-Azofeifa GA. Countryside biogeography: Use of human-dominated habitats by the avifauna of southern Costa Rica. Ecol Appl. 2001;11(1):1-13.

22. Brosi BJ, Daily GC, Shih TM, Oviedo F, Durán G. The effects of forest fragmentation on bee communities in tropical countryside. J Appl Ecol. 2008;45(3):773-83.

23. Brosi BJ. The effects of forest fragmentation on euglossine bee communities (Hymenoptera: Apidae: Euglossini). Biol Conserv. 2009;142(2):414-23.

24. Hadley AS, Frey SJK, Douglas Robinson W, John Kress W, Betts MG. Tropical forest fragmentation limits pollination of a keystone understory herb. Ecology. 2014;95(8):2202-12.

25. Sekercioglu $\mathrm{CH}$. Increasing awareness of avian ecological function. Trends Ecol Evol. 2006;21(8):464-71.

26. Bawa KS. Plant-Pollinator Interactions in Tropical Rain Forests. Annu Rev Ecol Syst. 1990;21(1):399-422. 
27. Stratton DA. Longevity of individual flowers in a Costa Rican cloud forest: ecological correlates and phylogenetic constraints. 1989;308-18.

28. Volpe NL, Hadley AS, Robinson WD, Betts MG. Functional connectivity experiments reflect routine movement behavior of a tropical hummingbird species. Ecol Appl. 2014;24:2122-31.

29. Stiles FG. Ecology, flowering phenology, and hummingbird pollination of some Costa Rican Heliconia species. Ecology. JSTOR; 1975;285-301.

30. Borgella RJ, Snow AA, Gavin TA. Species Richness and Pollen Loads of Hummingbirds Using Forest Fragments in Species Richness and Pollen Loads of Hummingbirds Using Forest Fragments in Southern Costa Rical. Biotropica. 2001;33(1):90-109.

31. Bélisle M. Measuring landscape connectivity: The challenge of behavioral landscape ecology. Ecology. 2005;86(8):1988-95.

32. Hughes JB, Hughes JB, Daily GC, Daily GC, Ehrlich PR, Ehrlich PR. Conservation of tropical forest birds in countryside habitats. Ecol Lett. 2002;5(1):121-9.

33. Stiles FG, Skutch AF, others. Guide to the birds of Costa Rica. Comistock; 1989.

34. Kress WJ. Crossability barriers in neotropical Heliconia. Ann Bot. 1983;52:131-47.

35. Klein N, Kneib T, Lang S. Bayesian Generalized Additive Models for Location, Scale, and Shape for Zero-Inflated and Overdispersed Count Data. J Am Stat Assoc. Taylor \& Francis; 2015;110(509):405-19.

36. Belitz C, Brezger A, Klein N, Kneib T, Lang S, Umlauf N. BayesX-Software for Bayesian inference in structured additive regression models. Version 3.0 [Internet]. 2015. Available from: http://www.stat.uni-muenchen.de/ bayesx"

37. Van Rossum F, Stiers I, van Geert A, Triest L, Hardy OJ. Fluorescent dye particles as pollen analogues for measuring pollen dispersal in an insect-pollinated forest herb. Oecologia. 2011;165(3):663-74.

38. Fenster CB, Hassler CL, Dudash MR. Fluorescent dye particles are good pollen analogs for hummingbird-pollinated Silene virginica (Caryophyllaceae). Can J Bot. 1996;74:189-93.

39. Abràmoff MD, Magalhães PJ, Ram SJ. Image processing with ImageJ. Biophotonics Int. Laurin Publishing; 2004;11(7):36-42.

40. Klaus F, Bass J, Marholt L, Müller B, Klatt B, Kormann U. Hedgerows Have a Barrier Effect and Channel Pollinator Movement in the Agricultural Landscape. J Landsc Ecol. 2015;8(1):22-31.

41. Bates D, Maechler M, Bolker B, Walker S. lme4: Linear mixed-effects models using Eigen and S4. R package version 1.1-7. http://CRAN. R-project. org/package= lme4. 2014. 
42. Hothorn T, Bretz F, Westfall P, Heiberger R. Multcomp: simultaneous inference for general linear hypotheses. R Package Version 1.0-3. 2008.

43. MacKenzie DI, Nichols JD, Lachman GB, Droege S, Royle A a., Langtimm C a. Estimating site occupancy rates when detection probabilities are less than one. Ecology. 2002;83(8):2248-55.

44. Kendall WL, White GC. A cautionary note on substituting spatial subunits for repeated temporal sampling in studies of site occupancy. J Appl Ecol. 2009;46(6):1182-8.

45. Crawley M, The R. The R book. Imperial College London at Silwood Park. London, UK: John Wiley \& Sons, Ltd; 2007.

46. Lees AC, Peres $\mathrm{C}$ a. Rapid avifaunal collapse along the Amazonian deforestation frontier. Biol Conserv. 2006;133(2):198-211.

47. Gillies CS, St Clair CC. Riparian corridors enhance movement of a forest specialist bird in fragmented tropical forest. Proc Natl Acad Sci U S A. 2008;105(50):19774-9.

48. Frund J, Dormann CF, Holzschuh A, Tscharntke T. Bee diversity effects on pollination depend on functional complementarity and niche shifts. Ecology. 2013;94(9):2042-54.

49. Harvey C, Medina A, Sánchez DM, Vílchez S, Hernández B, Saenz JC, et al. Patterns of animal diversity in different forms of tree cover in agricultural landscapes. Ecol Appl. 2006;16(5):1986-99.

50. León MC, Harvey C. Live fences and landscape connectivity in a neotropical agricultural landscape. Agrofor Syst. 2006;68(1):15-26.

51. Sieving KE, Willson MF, De Santo TL. Defining corridor functions for endemic birds in fragmented south-temperate rainforest. Conserv Biol. 2000;14(4):1120-32. 


\section{SUPPORTING INFORMATION}

\section{SI Methods}

\section{SI 1: Statistical analysis of pollinator visits and pollen tube growth in the titration experiments}

The following text provides an intuitive description why and how we applied BAMMLSS to analyse the titration experiments. For further reading (particularly for people interested in the methodological background), we provide referencesat the end of SI1.

We start by giving four reasons why we opted for choosing BAMMLSS (Bayesian Additive Mixed Model for Location, Shape and Scale) instead of a GLMM:

First, BAMMLSS allows the predictor to be either linear (like in a GLMM) or nonlinear. In our particular situation, this means that we can estimate the effect of „distance“ as either a linear or a semiparametric function based on a linear combination of flexible Basis functions. Compared to a linear estimation of a certain effect (as in GLMMs), using a nonparametric estimation has the advantage that it allows the effect of a predictor "to change along its range in a smooth way". Note that the predictoris NOT to be confounded with the predicted values.
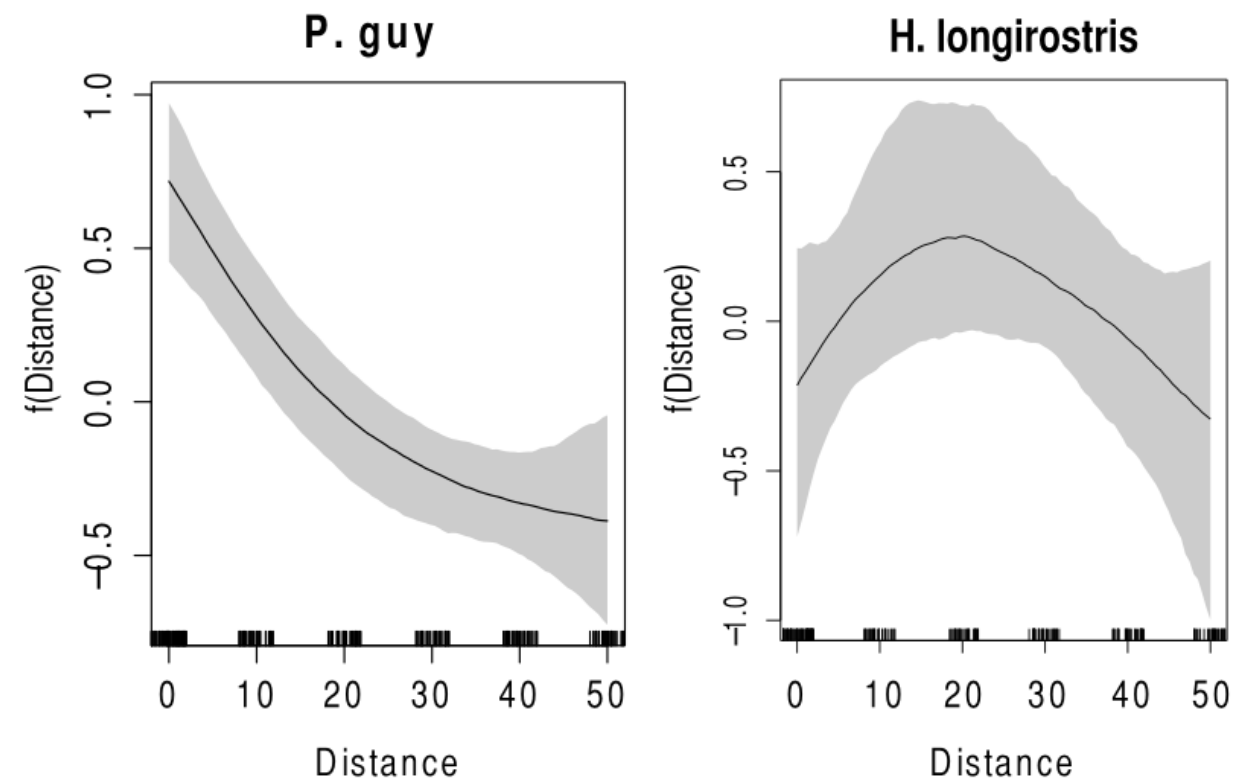

Fig SI 1-1: The clearly non-linear effect of distance on the predictor (solid line), that is, $\mathrm{f}$ (distance) for P. guy and $H$. longirostris. The solid lines indicates the effect of distance on the predictor, the grey areas indicate the corresponding $95 \%$ credible intervals. A straight line would suggest that a linear predictor would be sufficient. 
In our case, the clear non-linear trend of distance on the predictor was found in several species (P. guy,H. longirostris, Fig. SI 1-1), thus making a linear model NOT sufficiently flexible to model the data.

Second, we expected thatexperimental flowers placed at neighbouring distances show similar number of pollinator visits, and not to see an abrupt change in pollinator visits (i.e. serial correlation of pollinator visits). Smoothness of the effect of distance is achieved by the prior on the regression coefficients with second order difference matrix as precision. Additional variances (estimated with additional hyperprior) control the penalisation between neighbouring coefficients and the fit to the data. This replaces the implementation of a serial correlation structure (which would be required in most GLMM applications).

Third, adding the "LSS" gives the possibility to explicitly account for zero-inflation and overdispersion in the response variable. This substantially improved model fits for $L$. castaneoventris, $H$. longirostris, P.guy visits to $H$. tortuosa and H.tortuosa pollen tube growth. Thus, we clearly required a method capable of performing Poisson, Negative binomial, Zero-inflated Poisson and Zero-inflated Negative binomial models.

Forth, our experimental setup is clearly hierarchical, given that treatments are nested within sites. Thus, we required a method which can incorporate a hierarchical random effects structure.

We are not aware of any frequentist (maximum likelihood-based approach) that would allow to include all the four requirements simultaneously. Therefore, we have chosen Bayesian inference ("B"), namely the BAMMLSS framework.

The analysis process and the model selection for the Bayesian, Generalized Additive Models for Location, Scale and Shape (Bayesian GAMLSS) followed the procedure described in (1) This approach aims to identify sparse and parsimonious models and includes two successive steps. First, we selected the adequate response distribution for each species separately (also for the pollen tubes), choosing among Poisson (Pois), zeroinflated Poisson (ZIP), negative binomial (NegBin) and zero-inflated negative binomial (ZINB). This was done via visual comparison of quantile residuals of the full models. Predictor variables for the full models were: corridor, distance to forest and their interaction as fixed factors, corridoras linear effect with effect $(-1 / 1)$ coding, and distance to forest and the corridor distance to forest interactions as non-parametric effects. Nonparametric effects were estimated based on Bayesian P-splines (2) of degree three and with 20 inner knots (3). Further, Treatment nested within Site was treated as random factor using the multilevel 
framework recently developed in (4)ZIP and ZINB models additionally included Site as random factor in the zero-inflation part of the model. Second, we identified the relevant predictors for hummingbird visits and tubes, respectively. We then challenged models with all possible variable combinations including a null model, using the deviance information criterion (DIC)(5). The DIC is a commonly used criterion in hierarchical Bayesian model selection, and corresponds to the AIC but for Bayesian models. The lower the DIC; the better the predictive performance of the corresponding Bayesian model. In our case, the best modelswere those with the lowest DIC and a $\triangle \mathrm{DIC}>5$ to all alternative models. When multiple models shared the top 5 DIC range, we excluded models with nonsignificant effects (i.e., those where parametric or nonlinear effects included zero in their $95 \%$ credible interval or simultaneous $95 \%$ credible band, respectively (6)). For the generalist species $H$. longirostris, however, we retained an only marginally significant distance effect in the best model, as the null model showed $\Delta$ DIC $>5$. Models were run with 20000 burn in, 100000 full iterations, a thinning parameter of 100 and proved stable across different seeds.

We further tested the sensitivity to prior settings and alternative model formulations; as usual in additive regression models, nonparametric terms are regularized by an additional penalty term, thus imposing a certain degree of smoothness (7). Since we used a Bayesian approach, the corresponding penalty term was replaced by appropriate prior choices for the regression coefficients of nonparametric terms (8). Specifically, we used inverse gamma priors for smoothing variances with parameters $\mathrm{a}=5$ and $\mathrm{b}=0.001$. To check for prior sensitivity, we also we also applied less informative inverse gamma priors with parameters $\mathrm{a}=\mathrm{b}=0.001$ for the smoothing variance, but this yielded qualitatively similar results. For the NegBin and the ZINB models, we additionally ran models where the dispersion parameter was a function of corridor or distance to forest, but this did not yield qualitatively different results and did not improve model fit.

\section{Literature:}

1. Klein N, Kneib T, Lang S. Bayesian Generalized Additive Models for Location, Scale, and Shape for Zero-Inflated and Overdispersed Count Data. J Am Stat Assoc. Taylor \& Francis; 2015;110(509):405-19.

2. Brezger A, Lang S. Brezger, Lang: Generalized structured additive regression based on Bayesian P-splines Projektpartner Generalized structured additive regression based on Bayesian. Comput Stat Data Anal. 2003;321. 
3. Eilers PHC, Marx BD. Flexible smoothing with B -splines and penalties. Stat Sci. 1996;11(2):89-121.

4. Lang S, Umlauf N, Wechselberger P, Harttgen K, Kneib T. Multilevel structured additive regression. Stat Comput. Springer; 2014;24(2):223-38.

5. Spiegelhalter DJ, Best NG, Carlin BP, van der Linde A. Bayesian Measures of Model Complexity anf Fit. J R Stat Soc Ser B (Statistical Methodol. 2002;64(4):583-639.

6. Krivobokova T, Kneib T, Claeskens G. Simultaneous confidence bands for penalized spline estimators. J Am Stat Assoc. 2010;105(490).

7. Wood S. Generalized additive models: an introduction with R. CRC press; 2006.

8. Fahrmeir L, Kneib T, Lang S, Marx B. Regression: models, methods and applications. Springer Science \& Business Media; 2013. 


\section{SI 2: Pollen tube laboratory methods, adapted from (9)}

Pollen tubes are the first critical step in sexual plant reproduction and have been used widely to determine pollination success (10). We collected styles of abscised $H$. tortuosa flowers one day after blooming and fixed them in Formalin Aceto-Alcohol Solution (FAA) for $>24$ hours. For further lab analyses, we stored the styles in 40\% Ethanol. Only one observer (Felix Klaus), naïve to treatment, then continued to examine the styles. Styles were stained with aniline blue dye following the methods of (2). Styles were then rinsed in distilled water for 24 hours, followed by soaking in an $8 \mathrm{M}$ solution of sodium hydroxide $(\mathrm{NAOH})$ for 24 hours. Then, styles were rinsed in two subsequent baths of distilled water for 48 hours. We then soaked the styles in a $0.05 \%$ solution of aniline blue for at least 6 hours. We mounted the styles on slides using a drop of aniline blue dye and flattened them under a coverslip. Styles were then examined, again only one observer (Felix Klaus) naïve to treatment, by using an epifluorescence microscope for the presence of pollen tubes.

\section{Literature:}

1. Hadley AS, Frey SJK, Douglas Robinson W, John Kress W, Betts MG. Tropical forest fragmentation limits pollination of a keystone understory herb. Ecology. 2014;95(8):2202-12.

2. Kearns CA, Inouye DW. Techniques for pollination biologists. University Press of Colorado; 1993. 
SI Figures : Maps of experiments and observational sites.

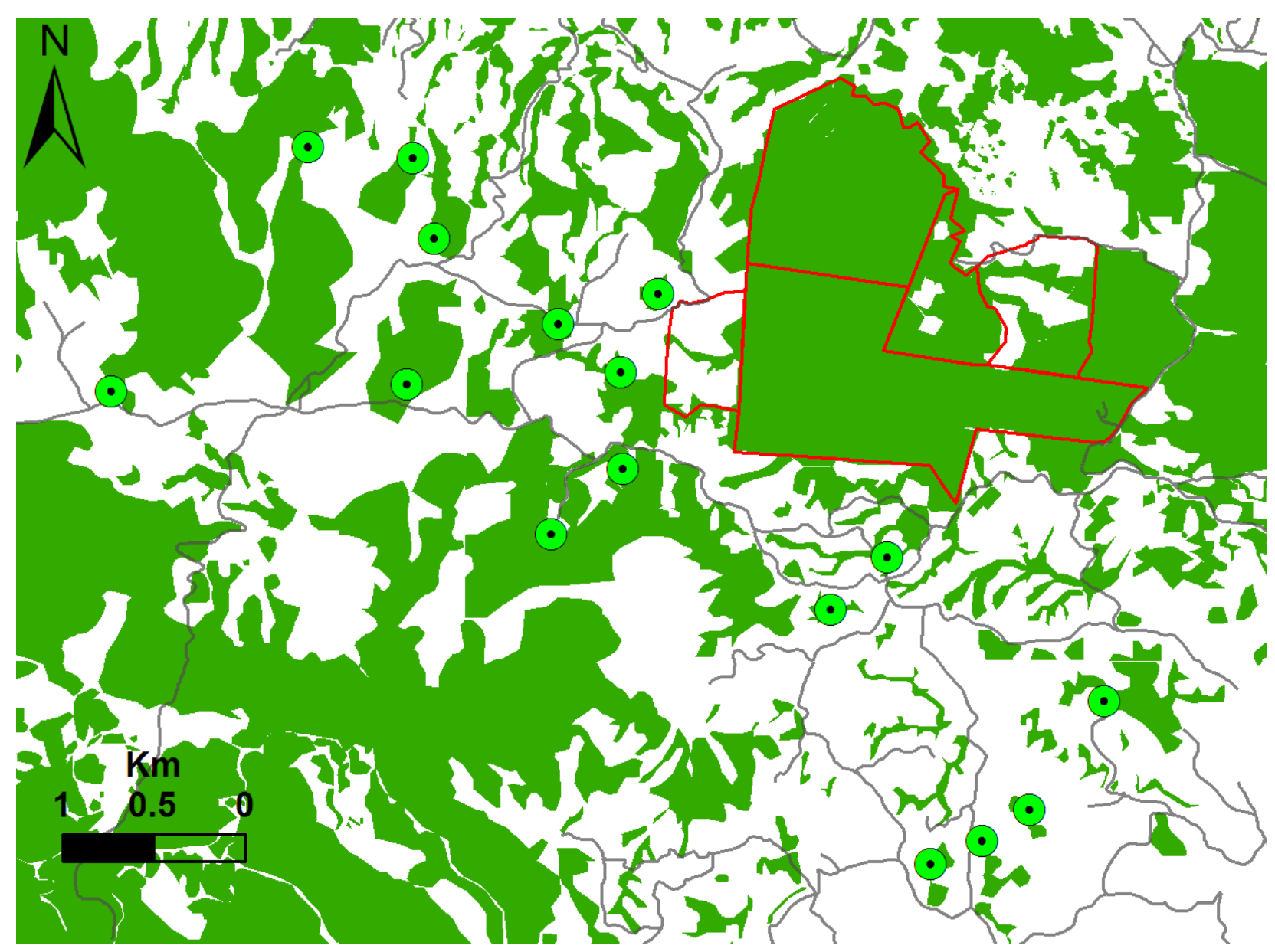

Fig. SI A. Map showing the sites where hummingbird movement experiments were performed ( $\mathrm{n}=16$, indicated by a green circle with central dot). Each site included a paired corridor and pasture. The red polygon depicts the perimeter of Las Cruces. 


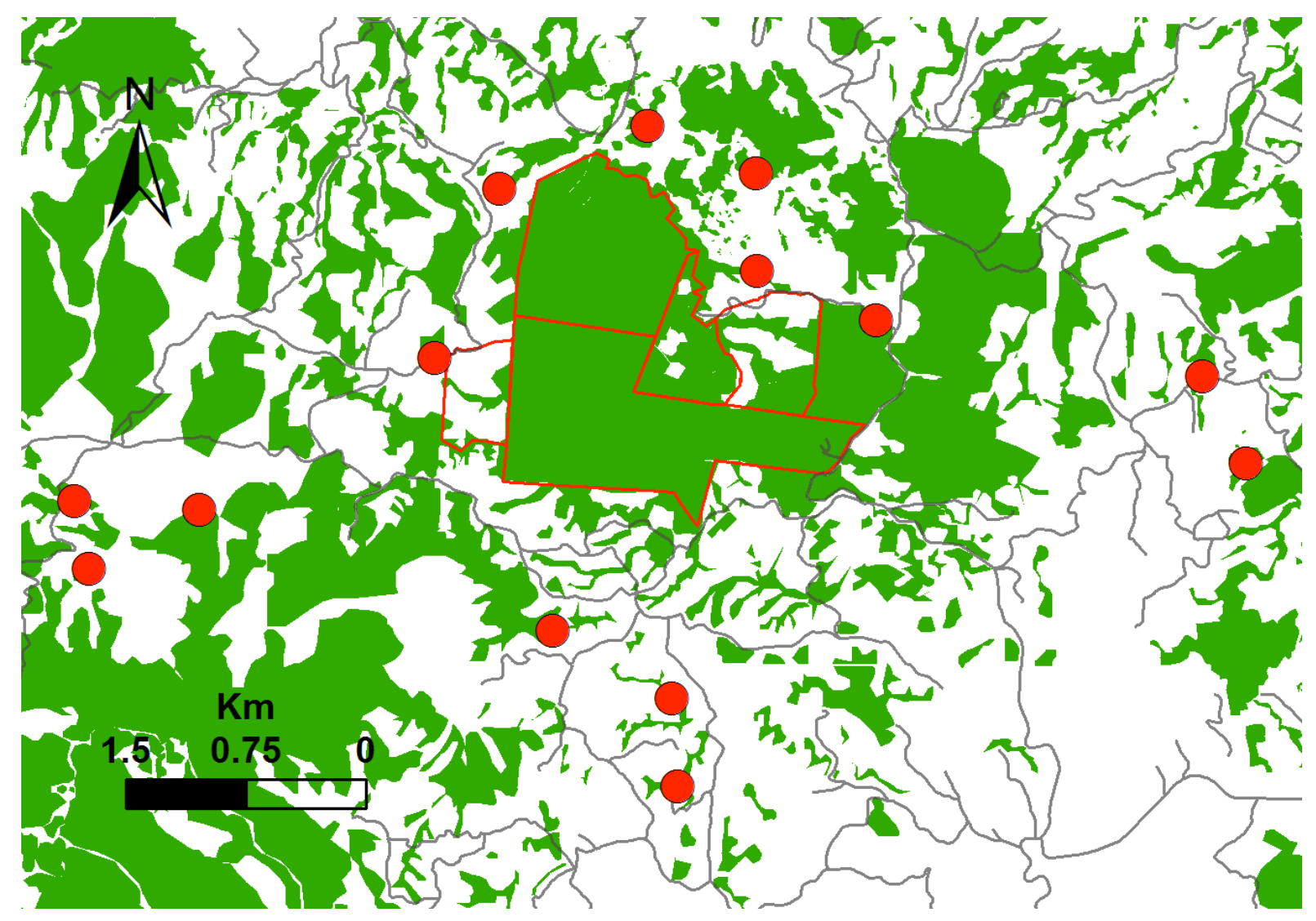

Fig. SI B. Map showing the sites where pollen transfer experiments were conducted (red dots, n=14). Each site had all three treatments (corridor, forest and pasture). The red polygon depicts the perimeter of Las Cruces. 


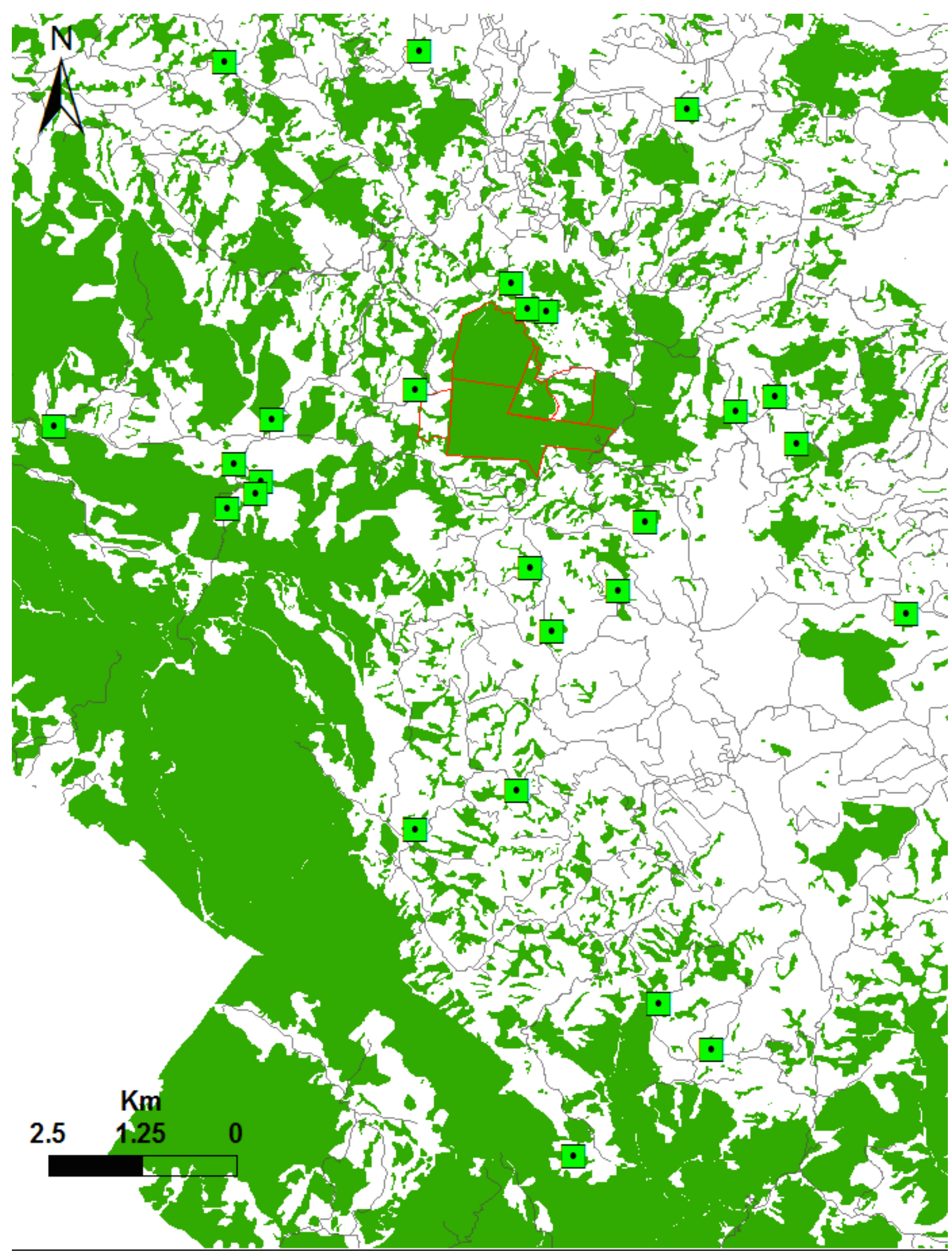

Fig. SI C. Map showing the forest fragments where pollinator availability surveys were conducted (green squares with central dot, $n=26$ ). The red polygon depicts the perimeter of Las Cruces. 


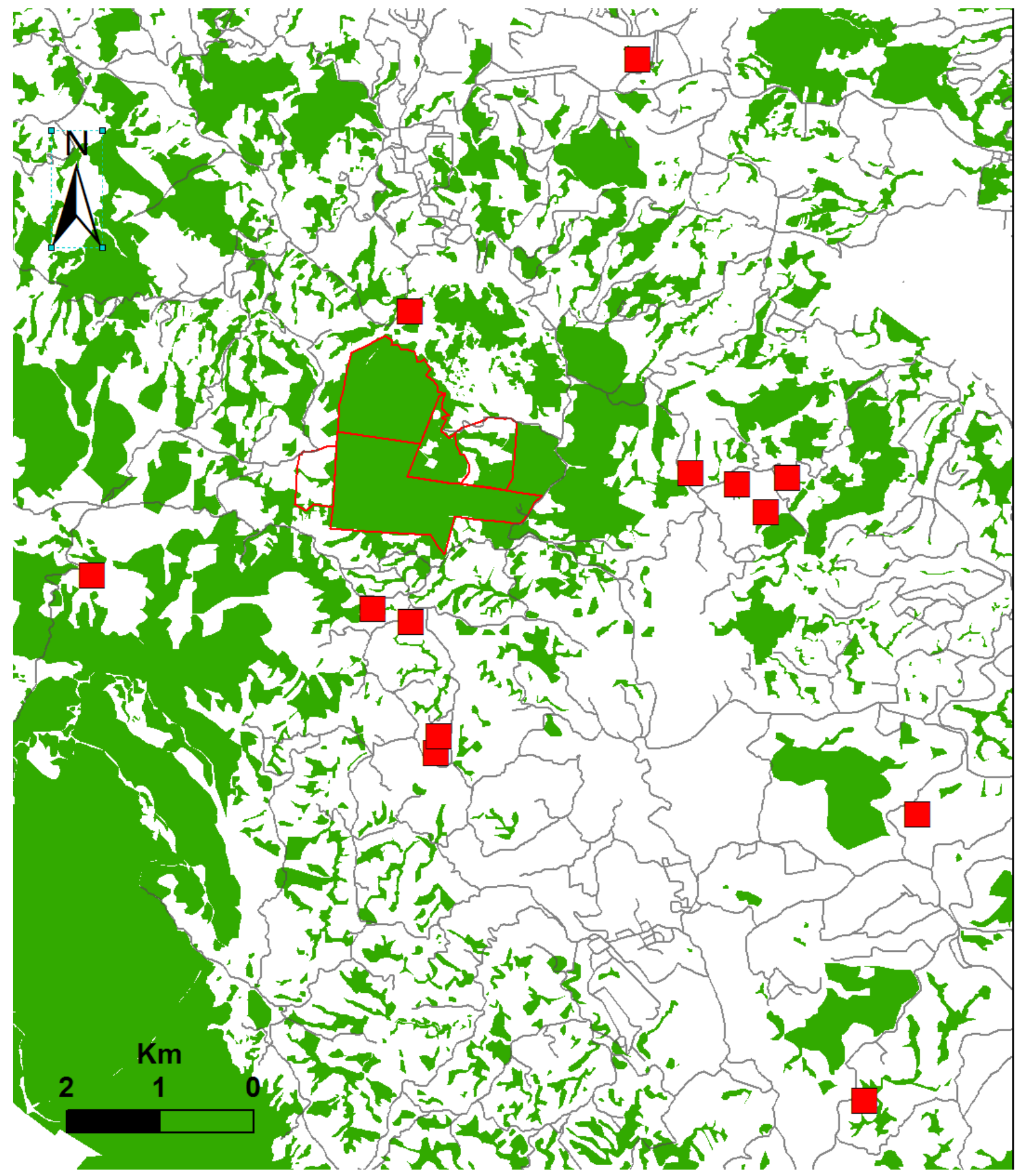

Fig. SI D.Map showing the forest fragments where pollination success of Heliconia tortuosa was measured (red squares, $n=13)$. The red polygon depicts the perimeter of Las Cruces. 
Figure S2:
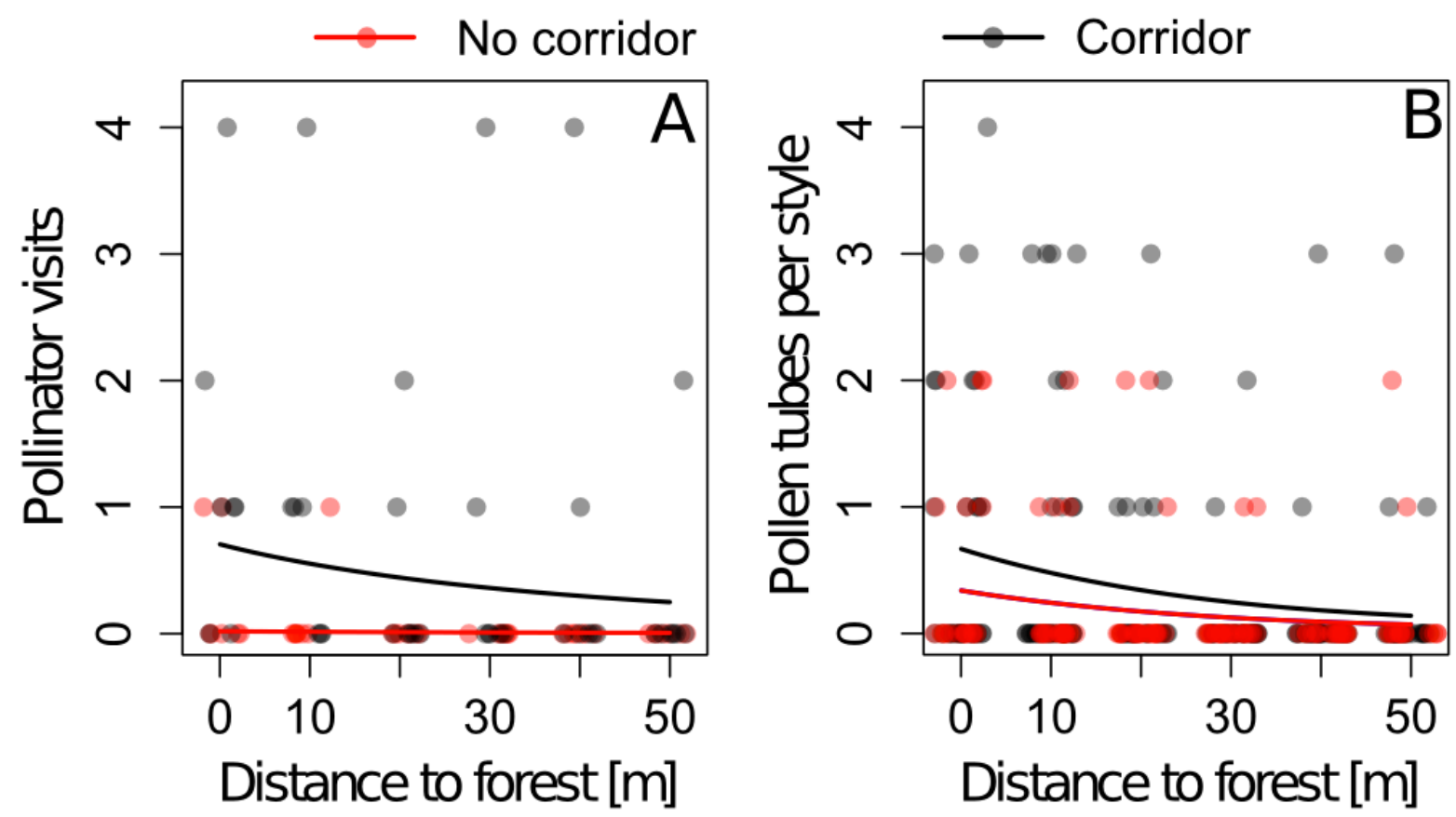

Fig. SI2: Effect of corridors on (A) on movement of the forest hummingbird P. guy through deforested habitat to visit planted $H$. tortuosa flowers placed at increasing distances to forest edges and (B) on pollen tubes per style found within these flowers. Visitation rates (A) were significantly higher along corridors and decrease with distance to forest $(\mathrm{P}=0.012)$. The number of pollen tubes per style $(\mathrm{B})$ tended to be higher along corridors also $(\mathrm{p}=0.12)$. Lines are are predicted visitation rates during 40 minutes of observation in $(\mathrm{A})$ and the number of pollen tubes predicted per style in (B). Dots represent jittered datapoints. Both graphs are based on the best fitting Bayesian additive ZINB mixed model. 
Table S1:Overview of the statistical methodology, the model selection procedure and implemented random factors used in this paper,

\begin{tabular}{|c|c|c|c|c|}
\hline Analysis & Statistical model & Model selection & Radom factor & Remarks \\
\hline Pollinator & Bayesian, & Manual selection of & Site & A separate model was \\
\hline movement: & Generalized Additive & informative predictors & & every \\
\hline Visits at & Models for Location, & based on deviance & & hummingbird species. \\
\hline experimenta & Scale and Shape & information & & \\
\hline lly placed & (BGAMLSS & (DIC, a Bayesian analogue & & \\
\hline feeders and & implemented & of AIC) and significance & & \\
\hline flowers & Software BayesX) & values of parameters & & \\
\hline & & (details given in S1) & & \\
\hline Pollen & Generalized & Stepwise model selection & Site & * \\
\hline movement & mixed models (function & based on second order & & \\
\hline & glmer, package lme4 & Akaikes information & & \\
\hline & for $\mathrm{R}$ ) & criterion (AICc). & & \\
\hline \multirow{4}{*}{$\begin{array}{l}\text { Pollinator } \\
\text { availability }\end{array}$} & \multirow{4}{*}{$\begin{array}{l}\text { Occupancy models in } \\
\mathrm{R}\end{array}$} & Manuel stepwise variable & Treatment & * \\
\hline & & selection & within Site & \\
\hline & & bootstrapped & & \\
\hline & & confidence intervals & & \\
\hline \multirow{5}{*}{$\begin{array}{l}\text { Pollination } \\
\text { success }\end{array}$} & \multirow{5}{*}{$\begin{array}{l}\text { logistic regression with } \\
\text { a binomial error } \\
\text { structure (function glm } \\
\text { in } \mathrm{R} \text {, Crawley 2007) }\end{array}$} & AICc based, automated & Not necessary for & * \\
\hline & & stepwise model selection & glms due to a lack of & \\
\hline & & (function stepAICc, URL: & hierarchical structure & \\
\hline & & http://wwwuser.gwdg.de/ & & \\
\hline & & $\sim$ cscherb1/stepAICc.txt) & & \\
\hline
\end{tabular}

* In addition to stepwise model selection, we used model averaging as an alternative way to identify important predictor variables. Both methods consistently identified the same predictor variables to be important. 
Table S2A: Summary for selection of models predicting visits at artificial flowers. Statistical significance is shown for models in a $\triangle \mathrm{DIC}$ range of 5 and based on $95 \%$ credible intervals for the corridor effect, and simultaneous $95 \%$ credible bands for distance and distance*corridor. Significance levels: $*=95 \%$; ns $=$ not significant. The best models, used for predicting visitation rates in illustration 1 , are indicated in grey.

P. guy (forest species) based on Poisson distribution $(\mathrm{n}=159)$

\begin{tabular}{llllrr}
\hline Model structure & Distance & Corridor & Distance*Corridor & DIC & \multicolumn{1}{c}{$\Delta$ DIC } \\
\hline Distance + Corridor +Distance * Corridor & $*$ & $*$ & ns & 370.25 & 2.51 \\
Distance + Corridor & $*$ & $*$ & & $\mathbf{3 6 8 . 8 3}$ & $\mathbf{1 . 1}$ \\
Corridor & & & & 403.85 & 36.12 \\
Distance & $*$ & & 367.73 & 0 \\
Null Model & & & 402.84 & 35.11
\end{tabular}

H. jacula(forest species) based on Poisson distribution $(\mathrm{n}=72)$

\begin{tabular}{llllrr}
\hline Model structure & Distance & Corridor & Distance*Corridor & DIC & \multicolumn{1}{c}{$\Delta$ DIC } \\
\hline Distance + Corridor +Distance * Corridor & ns & $*$ & $*$ & 233.72 & $\mathbf{0}$ \\
Distance + Corridor & & & & 242.85 & 9.13 \\
Corridor & & & & 268.83 & 35.12 \\
Distance & & & & 243.16 & 9.44 \\
Null Model & & & & 268.48 & 34.76
\end{tabular}

C. hemileucurus(forest species) based on Poisson distribution $(\mathrm{n}=40)$

\begin{tabular}{lllrrr}
\hline Model structure & Distance & Corridor & Distance*Corridor & DIC & \multicolumn{1}{c}{$\Delta$ DIC } \\
\hline Distance + Corridor +Distance * Corridor & $*$ & $*$ & $*$ & 128.35 & $\mathbf{0}$ \\
Distance + Corridor & & & & 139.46 & 11.11 \\
Corridor & & & 143.2 & 14.85 \\
Distance & & & 138.83 & 10.48 \\
Null Model & & & 142.6 & 14.25
\end{tabular}

L. castaneoventris(forest species)based on zero-inflated Poisson distribution $(\mathrm{n}=37)$

\begin{tabular}{llllrr}
\hline Model structure & Distance & Corridor & Distance*Corridor & DIC & \multicolumn{1}{c}{$\Delta$ DIC } \\
\hline Distance + Corridor +Distance * Corridor & $*$ & $*$ & ns & 124.14 & 0 \\
Distance + Corridor & $*$ & $*$ & & $\mathbf{1 2 4 . 6 5}$ & $\mathbf{0 . 5 1}$ \\
Corridor & & & & 145.11 & 20.97 \\
Distance & & & & 131.44 & 7.3 \\
Null Model & & & 152.75 & 28.61
\end{tabular}

A. tracatl (habitat generalist) based on Poisson distribution $(\mathrm{n}=431)$

\begin{tabular}{|c|c|c|c|c|c|}
\hline Model structure & Distance & Corridor & Distance*Corridor & DIC & $\Delta \mathrm{DIC}$ \\
\hline Distance + Corridor +Distance * Corridor & * & $\mathrm{ns}$ & $\mathrm{ns}$ & 645.7 & 0 \\
\hline Distance + Corridor & * & ns & & 649.17 & 3.47 \\
\hline Corridor & & & & 670.94 & 25.24 \\
\hline Distance & * & & & 648.84 & 3.14 \\
\hline Null Model & & & & 670.85 & 25.14 \\
\hline
\end{tabular}

H. longirostris(habitat generalist) based on negative binomial distribution $(\mathrm{n}=75)$

\begin{tabular}{llllrr}
\hline Model structure & Distance & Corridor & Distance*Corridor & DIC & \multicolumn{1}{c}{$\Delta$ DIC } \\
\hline Distance + Corridor +Distance * Corridor & ns & ns & ns & 251.38 & 0.35 \\
Distance + Corridor & ns & ns & & 251.03 & 0 \\
Corridor & & & & 256.43 & 5.4 \\
Distance & ns & & & 251.14 & $\mathbf{0 . 1 1}$ \\
Null Model & & & 257.66 & 6.62
\end{tabular}


Table S2B: Summary for selection of models predicting visits at transplanted $H$. tortuosa flowers by the main pollinator $P$. guy, and thenumber of pollen tubes per style in transplanted $H$. tortuosa plants, respectively. Statistical significance is shown for models within a $\triangle \mathrm{DIC}$ range of 5 and based on $95 \%$ credible intervals for linear effects (corridor), and simultaneous 95\% credible bands for nonlinear effects (distance and

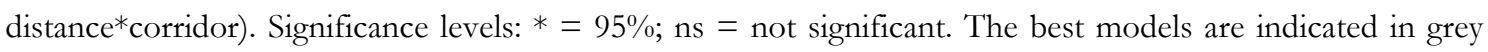
and were those predicting visitation rates in illustration 1.

Model structure for predicting $P$. guy visits to $H$. tortuosa based on a zero-inflated Negative Binomial distribution

\begin{tabular}{llllll}
\hline Model structure & Distance & Corridor & Distance*Corridor & DIC & $\Delta$ DIC \\
\hline Distance + Corridor +Distance * Corridor & $*$ & $*$ & ns & 85.98 & 0.00 \\
Distance + Corridor & $*$ & $*$ & & $\mathbf{8 8 . 0 5}$ & $\mathbf{2 . 0 7}$ \\
Corridor & & & & 95.51 & 9.53 \\
Distance & $*$ & & & 87.76 & 1.78 \\
Null Model & & & & 92.97 & 6.99
\end{tabular}

Model structure for predicting pollen tube growth in H. tortuosa based on a zero-inflated Negative Binomial distribution

\begin{tabular}{llllll}
\hline Model structure & Distance & Corridor & Distance*Corridor & DIC & $\Delta$ DIC \\
\hline Distance + Corridor +Distance * Corridor & ns & ns & ns & 368.38 & 2.34 \\
Distance + Corridor & $*$ & ns & & 366.04 & 0.00 \\
Corridor & & ns & & 379.69 & 13.65 \\
Distance & $*$ & & & 367.24 & 1.20 \\
Null Model & & & & 380.60 & 14.57
\end{tabular}


Table S3A: Nonlinear effects (distance to forest and distance*corridor) on predictors for visits of six hummingbird species at artificial flowers, based on the best-fitting Bayesian model. Shown are posterior means (mean), lower simultaneous 2.5\% credible interval (p2.5) and upper simultaneous 97.5\% credible interval (p97.5) estimated at the six feeder distances. Significance (Sign.) indicates if the simultaneous 95\% credible interval includes 0 (ns) or not $\left(^{*}\right)$. The corridor - distance interaction only remained in the best model for $C$. hemileucurus and $H$. jacula.

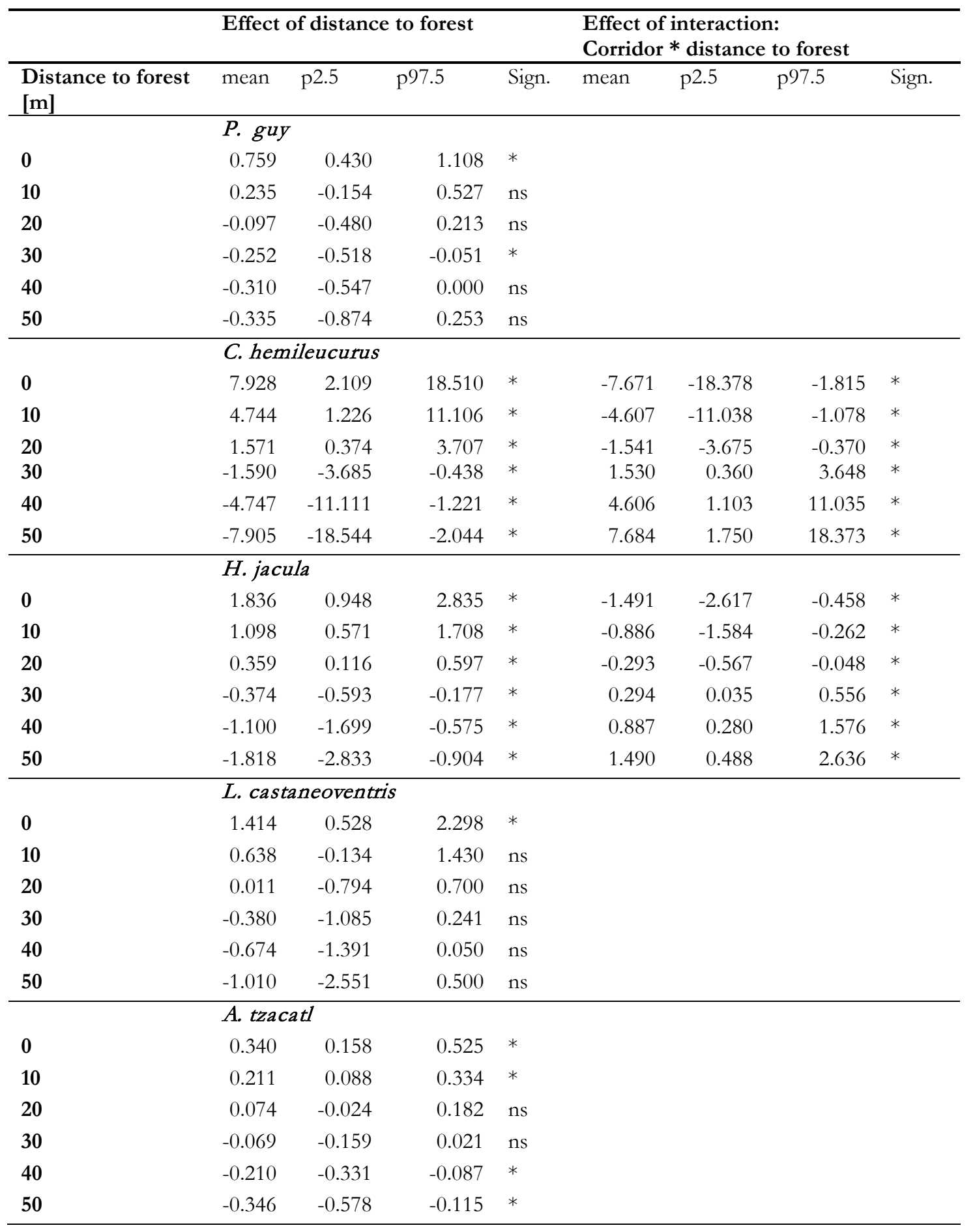


Table S3A (continued)

\begin{tabular}{|c|c|c|c|c|c|c|c|}
\hline \multirow[b]{2}{*}{$\begin{array}{l}\text { Distance to forest } \\
{[\mathrm{m}]}\end{array}$} & \multicolumn{4}{|c|}{ Effect of distance to forest } & \multicolumn{3}{|c|}{$\begin{array}{l}\text { Effect of interaction: } \\
\text { Corridor } * \text { distance to forest }\end{array}$} \\
\hline & mean & $\mathrm{p} 2.5$ & p97.5 & Sign. & $\begin{array}{ll}\text { mean } & \mathrm{p} 2.5\end{array}$ & $\mathrm{p} 97.5$ & Sign. \\
\hline & \multicolumn{4}{|c|}{ H. longirostris } & & & \\
\hline 0 & -0.535 & -1.378 & 0.270 & ns & & & \\
\hline 10 & -0.125 & -0.744 & 0.595 & ns & & & \\
\hline 20 & 0.108 & -0.321 & 0.740 & ns & & & \\
\hline 30 & 0.195 & -0.155 & 0.694 & ns & & & \\
\hline 40 & 0.200 & -0.399 & 0.805 & ns & & & \\
\hline 50 & 0.157 & -1.057 & 1.246 & ns & & & \\
\hline
\end{tabular}

Table S3 B: Effects of corridor and distance to forest on predictors for a) visits of P. guy at experimentally placedH. tortuosa plants and a) number of pollen tubes per style in these plants. Shown are posterior means (mean), lower 2.5\% credible interval (p2.5) and upper 97.5\% credible interval (p97.5), based on the best fitting. Bayesian ZINB models. Simultaneous credible intervals are shown for distance to forest(p.sim.2.5 and p.sim.97.5). Significance (Sign.) indicates if the $95 \%$ credible interval includes 0 (ns) or not $(*)$.

\begin{tabular}{lllll}
\hline a) P. guy & mean & p2.5 & p97.5 & Sign. \\
\hline Corridor & -3.768 & -5.883 & -1.887 & $*$ \\
Intercept & 2.447 & 0.384 & 5.035 & $*$ \\
\hline \hline Distance to forest & pmean & p.sim.2.5 & p.sim.97.5 & Sign. \\
$\mathbf{0}$ & 0.690 & 0.012 & 1.326 & $*$ \\
$\mathbf{1 0}$ & 0.405 & -0.006 & 0.799 & $\mathrm{~ns}$ \\
$\mathbf{2 0}$ & 0.127 & -0.062 & 0.333 & $\mathrm{~ns}$ \\
$\mathbf{3 0}$ & -0.143 & -0.337 & 0.039 & $\mathrm{~ns}$ \\
$\mathbf{4 0}$ & -0.408 & -0.794 & -0.006 & $*$ \\
$\mathbf{5 0}$ & -0.672 & -1.347 & 0.013 & $\mathrm{~ns}$ \\
\hline
\end{tabular}

\begin{tabular}{lllll}
\hline b) Pollen tubes & pmean & p.2.5 & p.97.5 & Sign. \\
\hline Intercept & -1.203 & -2.001 & -0.452 & $*$ \\
Corridor & 0.695 & -0.033 & 1.420 & ns \\
\hline \hline Distance to forest & pmean & p.sim.2.5 & p.sim.97.5 & Sign. \\
$\mathbf{0}$ & 0.812 & 0.261 & 1.353 & $*$ \\
$\mathbf{1 0}$ & 0.487 & 0.151 & 0.814 & $*$ \\
$\mathbf{2 0}$ & 0.154 & -0.041 & 0.326 & $\mathrm{~ns}$ \\
$\mathbf{3 0}$ & -0.178 & -0.385 & -0.010 & $*$ \\
$\mathbf{4 0}$ & -0.492 & -0.808 & -0.148 & $*$ \\
$\mathbf{5 0}$ & -0.783 & -1.357 & -0.191 & $*$ \\
\hline
\end{tabular}


Table S4:Summary statistics of the top model for pollen transfer between forest fragments, based on generalized linear mixed models (negative-binomial distribution). Shown are parametes estimates and standard errors for the effect of distance between forest fragments and intervening land cover type (Corridor, forest or pasture) on the number of transferred pollen particles. Comparisions among treatment types are Tukey's pairwise comparisons (glht function of the R package multcomp, Hothorn et al., 2008).

\begin{tabular}{lllll}
\hline Variable & Estimate & $\mathbf{S E}$ & $\mathbf{z}$ & $\boldsymbol{p}$-value \\
\hline Intercept & 6.48 & 1.09 & 5.94 & 0.00 \\
Distance & -0.03 & 0.01 & -2.03 & 0.04 \\
Corridor - forest $==\mathbf{0}$ & -0.82 & 0.43 & -1.93 & 0.13 \\
Pasture - forest $=\mathbf{0}$ & -23.00 & 0.44 & -5.28 & 0.00 \\
Pasture - corridor $==\mathbf{0}$ & -14.80 & 0.41 & -3.61 & 0.00 \\
\hline
\end{tabular}


Table S5: Details of the top occupancy models selected for P. guy (forest specialist) and A. tracatl (habitat generalist) sampled with point counts in small Costa Rican forest fragments. Note that all explanatory variables were standardized prior to inclusion in these models.

\begin{tabular}{lccccc}
\hline Species & Parameter & Estimate & SE & Z & p-value \\
\hline P. guy & & & & & \\
& Occupancy & & & & \\
& Intercept & 0.619 & 0.591 & 1.05 & 0.295 \\
& Fence & 1.492 & 0.758 & 1.97 & 0.049 \\
& Detection & & & & \\
& Intercept & 0.405 & 0.401 & 1.01 & 0.312 \\
& Size & -0.456 & 0.349 & -1.31 & 0.192 \\
\hline \multirow{2}{*}{ A. tzacatl } & & & & & \\
& Occupancy & & & & \\
& Intercept & 1.61 & 0.591 & 2.72 & 0.007 \\
& Detection & & & & \\
& Intercept & 0.884 & 0.309 & 2.865 & 0.004 \\
& Size & -0.214 & 0.353 & -0.607 & 0.544 \\
\hline
\end{tabular}


Table S6: Summary statistics of the best model for predicting the proportion of heliconia flowers with pollen tubes in small forest patches, based on logistic regression with a binomial error structure (glm).

\begin{tabular}{lllll}
\hline Variable & Estimate & SE & $\mathbf{z}$ & $p$-value \\
\hline Intercept & -23.752 & 0.358 & -6.636 & 0.000 \\
Corridor & 0.957 & 0.222 & 4.258 & 0.000 \\
\hline
\end{tabular}


Table S7A: Characteristics of forest fragments used to investigate the effect of corridors on pollinator patch occupancy.

\begin{tabular}{|c|c|c|c|c|}
\hline Site & Corridor & Size[ha] & $\begin{array}{r}\text { Altitude } \\
\text { m.a.s.l. }\end{array}$ & $\begin{array}{r}\text { Proportion } \\
\text { of forest }\end{array}$ \\
\hline 1 & 0 & 1.1 & 1160 & 0.26 \\
\hline 2 & 0 & 1.7 & 1111 & 0.24 \\
\hline 3 & 0 & 1.8 & 850 & 0.29 \\
\hline 4 & 0 & 1.3 & 850 & 0.26 \\
\hline 5 & 1 & 3.2 & 1229 & 0.08 \\
\hline 6 & 1 & 1.7 & 1221 & 0.55 \\
\hline 7 & 1 & 0.8 & 1016 & 0.45 \\
\hline 8 & 1 & 3.5 & 1271 & 0.45 \\
\hline 9 & 1 & 4.9 & 986 & 0.18 \\
\hline 10 & 1 & 4.0 & 1226 & 0.13 \\
\hline 11 & 1 & 3.2 & 1141 & 0.19 \\
\hline 12 & 1 & 3.4 & 1304 & 0.52 \\
\hline 13 & 1 & 0.7 & 912 & 0.70 \\
\hline 14 & 1 & 3.3 & 1166 & 0.30 \\
\hline 15 & 1 & 1.1 & 1127 & 0.26 \\
\hline 16 & 1 & 1.1 & 1400 & 0.25 \\
\hline 17 & 2 & 1.4 & 1443 & 0.66 \\
\hline 18 & 2 & 4.2 & 1054 & 0.49 \\
\hline 19 & 2 & 4.6 & 1052 & 0.54 \\
\hline 20 & 2 & 1.7 & 1345 & 0.48 \\
\hline 21 & 2 & 2.8 & 1342 & 0.47 \\
\hline 22 & 2 & 1.0 & 1258 & 0.49 \\
\hline 23 & 2 & 1.1 & 1130 & 0.11 \\
\hline 24 & 2 & 1.3 & 1300 & 0.19 \\
\hline 25 & 2 & 2.5 & 950 & 0.42 \\
\hline 26 & 3 & 0.8 & 1141 & 0.23 \\
\hline
\end{tabular}

Table S7B: Pearson correlation coefficients of explanatory variables used to investigate the effect of corridors on pollinator patch occupancy (S7A).

\begin{tabular}{lllll}
\hline & Corridor & Size & Altitude & PropFor \\
\hline Corridor & 1.00 & 0.03 & 0.35 & 0.24 \\
Size & 0.03 & 1.00 & -0.02 & -0.06 \\
Altitude & 0.35 & -0.02 & 1.00 & 0.08 \\
PropFor & 0.24 & -0.06 & 0.08 & 1.00 \\
\hline
\end{tabular}


Table S7C: Forest fragments used to investigate the effect of corridors on pollination success of Heliconia tortuosa. Shown are the number of corridor elements per fragment, the number of styles sampled per fragment, the number of styles with pollen tubes. and the number of styles without pollen tubes.

\begin{tabular}{lllll}
\hline FragmentID & Corridor & Styles & Pollinated & NotPollinated \\
\hline $\mathbf{1}$ & 0 & 21 & 0 & 0 \\
$\mathbf{2}$ & 0 & 20 & 3 & 0 \\
$\mathbf{3}$ & 0 & 19 & 2 & 0 \\
$\mathbf{4}$ & 1 & 20 & 4 & 1 \\
$\mathbf{5}$ & 1 & 20 & 4 & 1 \\
$\mathbf{6}$ & 1 & 20 & 6 & 1 \\
$\mathbf{7}$ & 1 & 17 & 1 & 1 \\
$\mathbf{8}$ & 2 & 20 & 7 & 2 \\
$\mathbf{9}$ & 2 & 16 & 4 & 2 \\
$\mathbf{1 0}$ & 2 & 20 & 8 & 2 \\
$\mathbf{1 1}$ & 2 & 14 & 7 & 2 \\
$\mathbf{1 2}$ & 2 & 20 & 9 & 2 \\
$\mathbf{1 3}$ & 2 & 15 & 6 & 2 \\
\hline
\end{tabular}




\section{Chapter 4}

\section{OLD GROWTH FOREST MITIGATES THE EROSION OF TROPICAL BIRD}

COMMUNITIES IN HUMAN MODIFIED

LANDSCAPES

Urs Kormann, Teja Tscharntke, Matthew G. Betts, Adam S. Hadley, W. Douglas Robinson, Christoph Scherber 


\section{Abstract}

Tropical conservation strategies traditionally focus on large tracts of pristine tropical forests, but human-modified landscapes with small forest remnants may also sustain biodiversity. Here, we disentangled the effects of landscape composition (amount of forest) and configuration (fragment size) on bird communities, separating the distribution of old growth forest from secondary forest in a human-dominated landscape of southern Costa Rica. Utilizing point counts and stopping-rule based surveys, yielding 6906 individual detections, we characterized the bird community in 49 forest fragments representing independent gradients in patch size and amount of forest in the surrounding landscape (forest cover within $1000 \mathrm{~m}$ radius). While the entire bird community showed no change in species richness and total abundance among fragments, richness and abundance of forest birds decreased in secondary forest and near fragment edges. Forest species, in particular insectivores, strongly declined in small fragments - but only when the amount of old growth forest within the landscape dropped below a critical threshold of $22.6 \%$. Further, bird communities had significantly reduced levels of $\beta$-diversity in small vs. large patches - but only in landscapes with little old growth forest. Landscape-scale amount of old growth forest, but not overall forest cover or local patch size, was the most important driver of bird community shifts in small and large fragments. In conclusion, our results show that not the local area of forest remnants, but the landscape-level percentage of oldgrowth forest drives biodiversity conservation success. Secondary forests on their own are unlikely to sustain tropical avian biodiversity and at most play a subordinate role in shaping forest bird communities. Hence, retaining oldgrowth forest within human modified landscapes above a critical threshold level $(\sim 25 \%)$ is decisive for sustaining biodiversity friendly landscapes.

Keywords: fragmentation, habitat configuration, habitat composition, threshold, $\beta$-diversity, community dispersion, community similarity, Costa Rica, secondary forest 


\section{INTRODUCTION}

Across the globe, native habitats are converted into human-modified landscapes, largely because of rising demands for agricultural and industrial products (Foley et al. 2005, Dirzo et al. 2014). This process erodes biodiversity at alarmingly high rates (Dirzo et al. 2014), particularly in tropical forest regions, which are among the global biodiversity strongholds (Gibson et al. 2011, Laurance 2013). Worldwide, more than 50\% of the tropical or subtropical forest has been altered by humans (Laurance et al. 2014), up to 36\% of these forests existing in 2000 may have disappeared by 2050 (Wright 2010, MEA 2005), and approximately $25 \%$ of the existing tropical rainforest already persists in fragments (Wade et al. 2003).

While traditional approaches to conserving tropical biodiversity have primarily focused on large forest tracts only, recent strategies increasingly recognize the importance of biodiversity management in human-modified landscapes (Perfecto \& Vandermeer 2008, Perfecto \& Vandermeer 2010,Laurance et al. 2014). Human modified landscapes may still contain millions of hectares of small tropical forest remnants (Turner \& Corlett 1996), and the hope is that biodiversity can be maintained by creating landscapes where productive land coexists with natural forests (Fischer et al. 2011, Tilman et al.2011). This idea is enticing, but the potential for such landscapes to maintain biodiversity has remained unclear and controversial (Phalanet al. 2011, Meloet al. 2013, Fischer et al.2014). Further, this potential may be exaggerated given the critical shortage of knowledge about how different aspects of human modified landscapes affect their conservation capacity (Melo et al.2013, Burivalova et al.2014). In particular, the relative importance of retaining mature forest, the contribution of landscape configuration or the risk of deforestation/fragmentation thresholds, remain largely unclear (Melo et al. 2013, Villard \& Metzger 2014).

Changes in landscape composition (the relative amount of different habitat types), represent the primary processes affecting biodiversity in human modified landscapes (Fahrig 2003). Understanding the importance of forest composition and amount remaining within human modified landscapes is vital (Fahrig 2003). Expansion of secondary forests in abandoned agricultural landscapes may mitigate the effects of past and current deforestation trends (Chazdon et al.2009, Meloet al.2013, Laurance 2013). Some studies have found that a large proportion of the original biota is maintained (Gardeneret al. 2010, Steffan-Dewenteret al. 2007), while others suggest that these represent an impoverished 
subsample with limited conservation potential (Gibson et al.2011). In addition, it has been hypothesized that the capacity of regenerating tropical forest to sustain native biodiversity may rely on sufficiently high amounts of old forest within the landscape, providing a rich species pool for colonization (Clough et al.2009, Melo et al.2013).

Landscape configuration (the spatial arrangement of habitat) can also affect biodiversity and thus determine the effectiveness of human modified landscapes as biodiversity safeguards (Fahrig 2003). In human modified landscapes, a large proportion of habitat is often in close proximity to edges, potentially limiting their capacity to sustain edge-avoiding species (Taberelli et al.2010). In addition, much remnant forest is often restricted to small fragments (Turner \& Corlett 1996). Many tropical studies have documented negative effects of small fragment size on local species richness ( $\boldsymbol{\alpha}$-diversity, i.e. Stouffer \& Bierregard1995, Lees\& Peres 2006, Lens et al.2002). Nevertheless, some studies reported that small patches can provide habitat for numerous species (Turner \& Corlett 1996, Fischer\& Lindenmayer 2002, Arroyo-Rodriguez et al. 2008). In particular, it has been hypothesized that high proportions of forest in the landscape may counterbalance the detrimental effects of small fragment size, but that but below certain levels of forest cover, biodiversity in small fragments will collapse (Andren 1994, Villard \& Metzger 2014). Despite its high importance for biodiversity management, this hypothesis has rarely been tested in tropical system.

While it will be crucial to understand the capacity of human modified landscapes to maintain biodiversity at a local scale ( $\alpha$-diversity), restricting the focus to $\alpha$-diversity will fail to assess the full potential for conserving tropical biodiversity (see Tylianakiset al. 2005). Importantly, the conservation value for a given set of landscape elements (e.g., small forest fragments), will also depend on the degree of species variation among sites of that set, that is, $\beta$ - diversity (community dispersion sensu Andersonet al. 2006 and Anderson et al.2010). A key task is to assess if only the same species consistently occur across all elements (biotic homogenization). Despite the high relevance, this question has received surprisingly little attention in human modified landscapes across the tropics (e.g. Tylianakis et al.2005, Karp et al.2012)

We studied human modified landscapes in the Coto Brus region in southern Costa Rica. While part of the Mesoamerican biodiversity hotspot (Myers et al.2000), this region has lost approximately $70 \%$ of its original forest cover (Zahavi, Duran\& Kormann submitted). The remaining forest is now scattered into approximately 2100 forest fragments, providing an ample spectrum of differently sized fragments varying in their 
respective landscape context. Using the Coto Brus forest fragments as a human-modifiedlandscape model system, we examined independent effects of landscape composition and configuration on tropical bird communities.

Tropical birds not only maintain important ecosystem processes such as pollination and seed dispersal (Sekercioglou et al.2004, Sekercioglou 2006, Bregman et al.2014), but provide ecosystem services such as pest control to some of the economically most important crops (Maaset al. 2013, Karp et al. 2013). Further, they significantly contribute to tropical economies through ornithology-related tourism, for example $\sim 41 \%$ of the one billion US\$ that tourists spent 1999 in Costa Rica (Sekercioglu 2003). Recent studies show that disturbance of native forest patches through agricultural intensification (Frishkoff et al.2014, Karp et al. 2012) or intense selective logging (Burivalova et al.2014) drastically reduce avian sfunctional and phylogenetic diversity. Importantly, certain functional groups such as insectivorous forest species appear to suffer particularly under the conversion of native forest into patchily distributed fragments (Sekercioglouet al.2004).

In this study, we focused on the effects of different deforestation parameters (i.e., fragment size, forest loss, degradation and edge effects) on a suite of bird diversity components: Local species richness and total abundance at the patch scale, undirected $\beta$ diversity measured as community dispersion at the fragment scale, and directed avian community shift of fragments relative to intact forests.

In particular, we tested the following hypotheses: (i) If high landscape-wide forest amount has the capacity to mitigate negative effects of small patch size, we expect reduced species richness, abundance and $\beta$-diversity in small fragments to occur only in landscapes with little remaining forest. Similarly, if (ii) fragment size and forest amount interactively drive bird community shifts in fragments after deforestation, we expect small isolated fragments to have the greatest dissimilarity to intact forest areas. (iii) If secondary forest is effective at maintaining avian communities then we expect that amount of old forest within the landscape will be no more important than total amount of remaining forest.

\section{MATERIAL AND METHODS}

\section{Study area}

The study was performed in the Coto Brus region, Southern Costa Rica, around the Las Cruces Biological Station $\left(8^{\circ} 47 \mathrm{~N}, 82^{\circ} 57 \mathrm{~W}\right)$. The original landscape cover consisted of Pacific pre-montane humid forest, but massive deforestation between ca. 1950 and 1980 
reduced the original forest cover to app. $30 \%$ of its former extent (Zahavi, Duran \&Kormann submitted). This degree of habitat destruction is representative for the situation in many areas of Costa Rica (FAO \& JRC 2012), and many Latin American regions with moderately intense land-use. The remaining forest fragments range from $<1$ ha to $>1000$ ha in size and span across an altitudinal gradient from ca. 850 - $1500 \mathrm{~m}$ a.s.l. Today's forest patchwork is largely surrounded by an agricultural matrix consisting of pastures $(>90 \%)$, coffee plantations $(\sim 5 \%)$ and to a lesser extent by human settlements. A detailed description of the landscape can be found in Hadley et al. (2014).

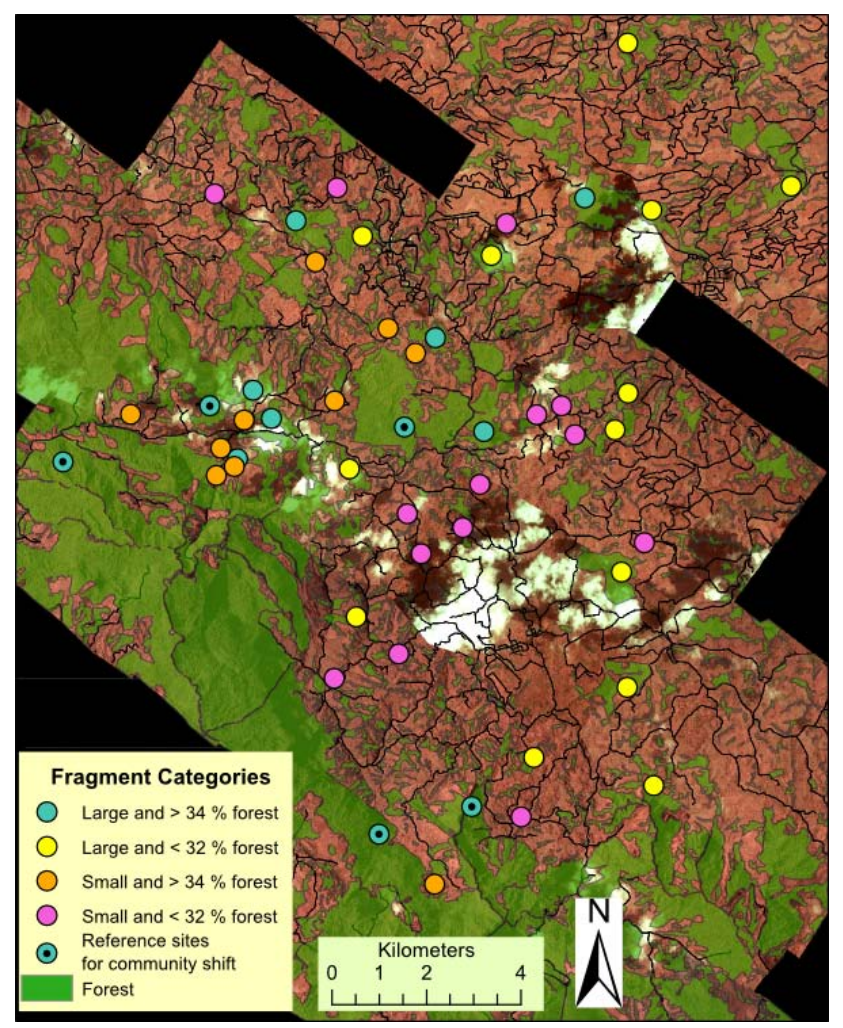

Fig. 1: Map of the studied human modified landscape of the Coto Brus region, Southern Costa Rica, showing the distribution of the four different forest fragment types. Circles with a dot indicate the five reference forests used to calculate the community shift index.

\section{Study design}

Our experimental design consisted of forest patches selected to represent two uncorrelated gradients in patch size and forest amount (forest cover within $1000 \mathrm{~m}$ radius), stratified across altitude (Fig. 1, for details see Hadleyet al. 2014). Using forest cover maps and a geographical information system (see below), we randomly selected 40 forest fragments in 2011, representing four categories: Half of the selected patches were small (< 5 ha patch area) and the other half was large $(<35 \mathrm{ha})$. In both size classes, forests 
represented a gradient along the available forest amount within a $1000 \mathrm{~m}$ radius $(5 \%$ to $80 \%$ ), and were either isolated $(<32 \%$ forest with $1000 \mathrm{~m}$ radius) or connected $(>34 \%$ forest with $1000 \mathrm{~m}$ radius)(Fig. 2). Thus, fragments were small and isolated, small and connected, large and isolated or large and connected. We opted for a $1000 \mathrm{~m}$ radius, as this distance represents the expected maximum daily movement distance for a forest specialist bird in the region $(P . g u y)$. Forest maps were constructed using ARCGIS 10.0 (ESRI Geoinformatik GmbH, Hanover, Germany) and orthophotos with a resolution of $2 \mathrm{~m}$. Two forest fragments were considered to be separate if they were at least $30 \mathrm{~m}$ apart. This distance already poses a severe barrier for the movement of many forest birds in the study region (see chapter 3: Kormann et al. in prep., Hadley \& Betts 2009) and elsewhere (Lees \& Perez 2009).

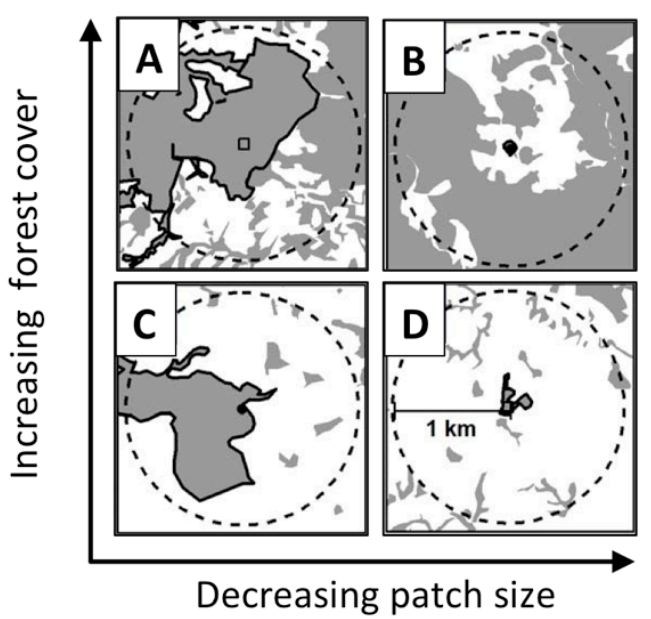

Fig. 2: Four forest fragment, representing the four fragment categories of our study design to disentangle the effect of fragment size and forest amount (forest cover within a $1000 \mathrm{~m}$ radius). A: large with high forest amount ( $>35$ ha and $>34 \%$ forest cover). B: small with high forest amount ( $<5$ ha and $>34 \%$ forest cover). C: large with low forest amount $(>25$ ha and $<34 \%$ forest cover). D: small with low forest amount $(<5$ ha and $<34 \%$ forest cover). Circles represent the $1000 \mathrm{~m}$ radius within forest amount was calculated. (Adapted after Hadley et al. (2014))

Further, fragments were stratified in altitude in each category, equally representing two altitudinal bands (880 - 1100 a.s.l. and > 1100 - 1500 a.s.l.) to avoid confounding effects of altitude. In 2012, we selected nine additional fragments to spread the different categories more homogeneously across the whole landscape. This selection guaranteed that patch size, forest amount and altitude were not strongly correlated (all Pearson's $\mathrm{r}<0.5$, see Table S1). 


\section{Bird surveys and quantification of local variables in the field}

Our bird surveys served two goals: first, to assess bird abundance and local species richness per unit area. Second, to perform a rapid species inventory per fragment to characterize the bird community. For the first goal, we performed fixed radius point counts $(\mathrm{r}=25 \mathrm{~m})$. However, neotropical bird communities often contain certain many rare and secretive species, which might stay undetected during point counts (Robinson 1999; Robinson et al. 2000). To address the second goal, we therefore combined the point counts with stopping rule-based walkabout surveys. The rationale behind walkabouts is to accumulate observations until levels of accumulated species richness stabilize. This can be achieved by surveying birds while walking across the fragment until no new species has been recorded for a previously fixed time span (Herzog et al.2002). Walkabout surveys have been successfully used for rapid assessments of neotropical bird communities and allow to maximize the number of sites sampled, while providing improved estimates of species richness compared to point counts (Robinson \&Terborgh1995, Herzog et al.2002, Watson 2010).

Bird surveys were performed between May and June 2011 and in early June 2012, when most resident species reproduce (Slud 1976; Stiles \& Skutch 1989). Only one fragment was surveyed per day. We randomized the visitation order: in 2011, we first randomly grouped all 40 fragments into 10 groups of four fragments, each containing one site of every category (small isolated, small connected etc.). The order of these groups was then randomized again, and all sites per group visited during a maximum of six subsequent days. As only nine sites were visited in 2012, we randomized visitation sequence completely in that year.

Surveys consisted of the following protocol: upon entering the fragment, we started with the walkabout survey and recorded all birds visually and acoustically detectable inside the fragment. The observer kept slowly walking into the fragment (keeping track of new birds), until distance of $25 \mathrm{~m}$ from fragment edge was reached. Here, the walkabout survey was stopped and a first $12 \mathrm{~min}$ point count performed. Then, the walkabout continued, followed after app. 20minby the next point count and so on. In small fragments, we performed three, in large fragments six point counts. Point count plots did not overlap. After the last point count, walkabouts were continued until no new species was detected for half an hour. Birds crossing the forest by flight were not considered, except if they perched in the forest fragment. All surveys were performed during peak song activity, starting about half an hour before dawn and ending four hours after dawn at the latest. 
Point counts with heavy rain or noise of cicadas were excluded from the analysis and visits were continued the next day. Birds not identified to species level (3 Contopus ssp., 1 Euphonia sp., 6 hummingbirds, 1 pigeon, 3 woodcreepers) were excluded from richness analyses unless they represented an extra genus for the sample. They were excluded from abundance analysis in case of unclear diet or habitat affiliation, and always excluded in analyses of $\beta$-diversity and community shift. Walkabouts lasted $80 \pm 20$ min (means $\pm \mathrm{SE}$ are given throughout) in small patches, and $155 \pm 33 \mathrm{~min}$ in large patches.

Bird species were classified as forest insectivores, if their main diet consisted of insects and if their habitat was largely restricted to forest. Diet was based on Stiles \& Skutch (1989). Habitat affiliation was based on three sources: Hughes et al.(2002), Stiles \& Skutch (1989) and the assessment of WDR, an experienced ornithologist in the Neotropics. We considered a species to be forest-restricted, if at least two out of the three sources indicated so.

\section{Forest parameters}

For every point count (hereafter "plot"), we measured the distance to the nearest fragment edge, using the "distance on ground" function in Google Earth. Elevation was derived with a digital elevation model (NASA Shuttle Radar Topography Mission) based on the coordinates. In addition, the observer (JSF) directly assigned one of three alternative forest classes to each plot in the field: Primary forest, selectively logged forest ("bosque intervenido") and secondary forest. Primary forests were characterized by no visible largescale disturbance such as logging inside the plot and a high abundance of large trees (DBH $>50 \mathrm{~cm})$. Selectively logged forests showed obvious, recent signs of selective logging and firewood removal (in all cases), and recent disturbance such as hunting (6 cases) or grazing (8 cases). Finally, secondary forests were characterized by apparent regrowth after heavy logging. For primary forest fragments, we additionally verified with historical aerial images if patches had existed 60 years ago, but we found no mismatch with field classification. Similarly, secondary forest plots were not older than 24 years, based on aerial imagery. With GIS, we additionally determined the amount of old-growth forest per plot within a buffer of $\mathrm{r}=1000 \mathrm{~m}$. Areas were considered to be old growth, if they had been continuously forested during the last 60 years. Details on forest classification are given in Zahavi, Duran \& Kormann (submitted). 


\section{Statistical analyses}

\section{Species richness and abundance at the plot level}

To identify patterns of species richness and abundance at the plot level, we used linear mixed-effects models (function lme, package nlme, version 3.1-113, Pinheiro et al. 2014) in R (R Core Team 2014). Species richness and abundance of all bird species and of forest insectivore bird species per plot were used as response variables. Variance functions were used to account for heteroscedasticity in the responses if necessary. Nonlinearity in explanatory variables was assessed using machine learning approaches with smooth components including a spatial component (function gamboost with bspatia(X,Y,knots=6), package mboost, version 2.3-0, Hothorn et al. 2014) and generalized additive mixed models with a spatial component (function gamm with 's $(\mathrm{X}, \mathrm{Y}, \mathrm{k}=6)$ ', package $m g c v$, version 1.8-3, Wood 2006). Both approaches suggested that the percentage of old forest, fragment area and edge distance had nonlinear effects.

In the linear mixed effect models, we started with the following explanatory variables: local forest type (FORTYP), fragment area (AREA), proportion of old growth forest (OLDFOR), proportion of total forest amount (ALLFOR), edge distance (DIST), altitude (ALT), daytime (TIME) and interactions between AREA and OLDFOR, AREA and ALLFOR, and FORTYP and OLDFOR. Based on the explanatory analysis, we $\log _{10}-$ transformed AREA and DIST and included a quadratic term for OLDFOR. All models included fragment ID as random intercept and a spatial correlation structure ('correlation $=\operatorname{corLin}\left(\right.$ form $\left.=\sim \mathrm{X}+\mathrm{Y}^{`}\right)$.

We used model averaging based on second-order Akaike's information criterion (AICc) to identify the important predictor variables (function dredge, packageMuMIn, version 1.10.5, Barton 2014). Variables were considered important, if they had a relative variable importance of $>0.7$. The model including these variables was considered as the best model, was used for post-hoc comparisons between forest types (function glht, package multcomp, version 1.3-6, Hothorn et al.2008) and to graphically represent the results. We also performed all analyses at the plot scale with ALLFOR and OLDFOR measured at smaller radii $(\mathrm{r}=100 \mathrm{~m}$ and $\mathrm{r}=500 \mathrm{~m})$, but model performance for these models was consistently worse $(\triangle \mathrm{AICc}>3.5)$.

Since ALLFOR and OLDFOR were strongly correlated (Pearson's $r=0.69$ ), we additionally performed model selection with the full suite of variables but without ALLFOR or without OLDFOR. However, this showed that model selection was robust against the simultaneous inclusion of both factors. 
A loess smoother (effects package, version 3.0-1, Fox 2014) indicated that species richness of forest insectivore birds in small fragments not only declined with decreasing old forest amount, but steeply dropped at low levels (red line in Fig. 3). To identify thresholds, we applied nonlinear mixed-effects models using saturating Michaelis-Menten models. Due to convergence problems in models containing random effects, we employed nonlinear least-squares fits without random effects (function nls(SSmicmen), R stats base package, version 3.0.3 beta). These models were also more parsimonious and had lower AICc values.

\section{及-diversity}

Since the amount of old growth forest appeared to drive patterns of local diversity and community shift (see results), we additionally assessed if the amount of old growth forest and fragment size affect patterns of $\beta$-diversity. For this, we first re-categorized forest fragments based on their proportion of old-growth forest. We used the median proportion of old forest as a cut-off between connected and isolated patches $(25.6 \%)$. Then, we tested if the four fragment categories (large connected, large isolated, small connected and small isolated) differed in their degree of community dispersion.

We used a test of multivariate homogeneity of group dispersions to infer differences in $\beta$-diversity (function betadisper, package vegan, version 2.3-0, Oksanen et al.2013). This method uses a multivariate analogue of Levene's test for homogeneity of variances, and compares the mean distances of sites to their group centroids in multivariate species space (Anderson et al. 2006). A large mean distance to the group centroid can be interpreted as a high degree of $\beta$-diversity (high community dispersion) and vice versa.

Per fragment, we pooled the first three point counts to achieve equal sampling intensity across all fragments. Calculations were based on Raup-Crick similarities. This measure is based on null models and corrects for difference in $\alpha$-diversity between sites (Anderson et al. 2011).

This resulted in slightly changed numbers of fragments in the four categories (11small isolated, 12 small connected, 11 large isolated, 15 large connected). To account for unequal group size (Stier et al.2013), we adjusted the group-wise mean distance to the centroidwith a $\operatorname{sgrt}(n /(n-1))$ correction ( $\mathrm{n}=$ number of sites per group). However, calculations based on balanced fragment numbers through random exclusion of surplus patches did not change the results. Significance for pairwise comparisons between groups was calculated with permutations tests (9999 permutations). Additional analysis based on the Walkabout dataset yielded similar results (data not shown). 


\section{Community shift}

To assess the effects of decreasing patch size and forest amount on bird community shifts, we tested their effect on a community shift index. This index is similar to the one used by Mendenhall et al.(2014), and describes the community shift of a fragment compared to large intact forest. The index ranges from 0 to 1 . Small values indicate an intact bird community similar to large intact forests (reference forests), whereas large values indicate a strongly altered community. Given the better representation of rare species, this analysis was based on the walkabout dataset. Our community shift index (CSI) was defined as

$$
C S I_{i}=\frac{1}{k}+\sum_{i=1}^{k} D_{i j}
$$

$\mathrm{CSI}_{i}$ is the community shift index for fragment $i$ out of $n$ fragments, $\mathrm{k}$ is the number of reference forests, $D i j$ a dissimilarity index between fragment $i$ and reference forest j.Following Mendenhall (2014), we used Chao's similarity index, a Jaccard type index which takes unseen pairs of species into account.

Following the above equation,we first calculated the mean Chao-dissimilarity of every forest fragment to the five largest and undisturbed forests in our dataset (indicated by dotted blue circles in Fig. 2). These forests are spatially well spread and are assumed to harbour a largely undisturbed bird community. Finally, we standardized mean dissimilarity per fragment by dividing through its maximum value.

To assess the importance of patch area and forest amount, we then fitted generalized linear models using family "Gaussian" (function glm, package MASS, 7.3-29, Venables \& Ripley 2002), with the CSI as response variable. Explanatory variables were patch area, proportion of old-growth forest, proportion of all forest and altitude, including two way interactions. Explanatory values were averaged across the corresponding point counts. As Chao-dissimilarity and thus the CSI are influenced by abundance, we also included the total abundance of birds per fragment as an explanatory variable. Model residuals did not show any spatial autocorrelation $\left(p_{\text {Moran's I }}=0.16\right.$, package 'ape', 3.0-11, Paradis et al.2004) and were not overdispersed. Model selection was accomplished by model averaging as for plot based analyses, but by mandatorily retaining abundance in all models. 


\section{RESULTS}

During 209 point counts (cumulative time $=2508 \mathrm{~min}$ ), we detected 2520 bird individuals from 174 species with 31 singletons. Of these, 977 individuals from 68 species were forest-restricted species (14 singletons), in particular 47 forest insectivore bird species (645 individuals, 8 singletons). The 49 walkabout surveys yielded 4386 individuals of 214 species (26 singletons). As expected for highly diverse systems (Robinson et al. 2000, Watson 2010), species pools for both methods did not completely overlap: 16 species were exclusively found during point counts and 56 were restricted to walkabouts.

\section{Species richness and abundance at the plot level}

We found strong patterns for forest birds at the plot scale but not for the total bird community (Table 1, Table 2, Table S3, Table S4). Richness and abundance only moderately decreased with daytime. In contrast, forest type, edge distance, patch area and the proportion of old forest were important predictors for forest species, in particular for forest insectivore abundance and species richness (Akaike's weight $>0.7$ ). Importantly, we found four substantial effects for the conservation relevant forest insectivore birds: (1) small isolated fragments supported significantly fewer species and lower abundances of forest insectivores than small connected or large patches (interaction in best model: species richness $p=0.001$; abundance $p=0.002$ ). Small connected fragments, however, showed comparable species richness and abundances as large fragments (Fig.3, Table 1, Table 2,). (2) Michaelis-Menten models showed that the loss of species richness tended to accelerate below a critical threshold of $22.6 \pm 15 \%$ of old forest cover (Table S2). However, this tipping point was only marginally significant $(t=1.482, p=0.143)$. (3) Primary forest harboured $24 \%$ more species and 31\% more individuals at the plot level than secondary forests (richness: $2.96 \pm 0.16$ vs. $2.21 \pm 0.20, p=0.016$; abundance: $3.74 \pm 0.22$ vs. $2.67 \pm$ 0.26, $p=0.009$, Fig. 3, Table S4). (4) Forest insectivore bird abundance and species richness strongly increased with increasing edge distance $(p<0.001$ in both cases, Fig. 3, Table 1, Table 2). For example, $1.92 \pm 0.16$ species and $2.8 \pm 0.21$ individuals were found on average at $25 \mathrm{~m}$ edge distance, while this increased to $3.00 \pm 0.27$ species and $4.41 \pm$ 0.35 individuals at $200 \mathrm{~m}$ edge distance. 
Table 1: Model averaging results for linear mixed-effects model (fit by Maximum Likelihood) predicting total abundance and species richness per plot, for all birds, forest birds and insectivorous forest birds, respectively. Shown are the relative variable importance (rel.var.imp) and the number of models containing the variable in the range of $\mathrm{AICc}<\Delta 2$ (n. models). Explanatory variables with a relative variable importance $>0.7$ are indicated in bold and were those used for predictions.

\begin{tabular}{|c|c|c|c|c|c|c|c|c|c|c|c|}
\hline $\begin{array}{l}\text { Response } \\
\text { variable }\end{array}$ & 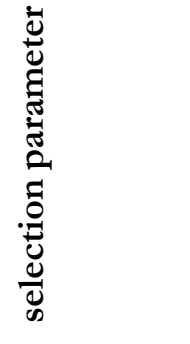 & $\sum_{\substack{0 \\
0 \\
0 \\
0 \\
0}}^{0}$ & $\underset{\mathscr{J}}{\mathscr{J}}$ & 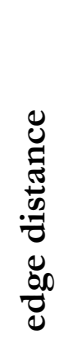 & $\begin{array}{l}00 \\
+\infty \\
0 \\
0 \\
0 \\
0 \\
0\end{array}$ & $\begin{array}{l}0^{0} \\
\vdots \\
0 \\
0 \\
0 \\
0 \\
0 \\
\Xi \\
0 \\
0\end{array}$ & 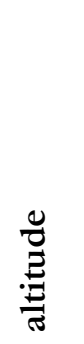 & 承 & 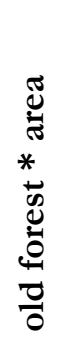 & 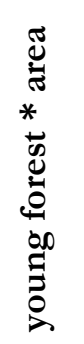 & 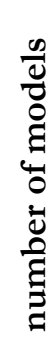 \\
\hline \multirow{2}{*}{$\begin{array}{l}\text { all birds: } \\
\text { species } \\
\text { richness }\end{array}$} & rel.var.imp & 0.28 & 0.22 & - & 0.46 & 0.08 & 0.37 & 1.00 & - & - & \\
\hline & n. models & 3 & 3 & - & 5 & 1 & 4 & 11 & - & - & 11 \\
\hline \multirow{2}{*}{$\begin{array}{l}\text { all birds: } \\
\text { abundance }\end{array}$} & rel.var.imp & 0.47 & 0.1 & 0.05 & 0.47 & 0.12 & 0.14 & 1.00 & - & - & \\
\hline & n. models & 6 & 2 & 1 & 6 & 2 & 2 & 11 & - & - & 13 \\
\hline \multirow{2}{*}{$\begin{array}{l}\text { forest birds: } \\
\text { species } \\
\text { richness }\end{array}$} & rel.var.imp. & 1.00 & 0.70 & 1.00 & 0.70 & 0.22 & - & 1.00 & 0.70 & 0.22 & \\
\hline & n. models & 3 & 2 & 3 & 2 & 1 & - & 3 & 2 & 1 & 3 \\
\hline \multirow{2}{*}{$\begin{array}{l}\text { forest birds: } \\
\text { abundance }\end{array}$} & rel.var.imp & 1.00 & 0.27 & 1.00 & 0.39 & 0.27 & 0.21 & 1.00 & 0.27 & 0.14 & \\
\hline & n. models & 6 & 2 & 6 & 3 & 2 & 1 & 6 & 2 & 1 & 6 \\
\hline \multirow{2}{*}{$\begin{array}{l}\text { forest } \\
\text { insectivores: } \\
\text { species } \\
\text { richness }\end{array}$} & rel.var.imp & 1.00 & 1.00 & 1.00 & 1.00 & 0.24 & 0.25 & 1.00 & 1.00 & 0.24 & \\
\hline & n. models & 3 & 3 & 3 & 3 & 1 & 1 & 3 & 3 & 1 & 3 \\
\hline \multirow{2}{*}{$\begin{array}{l}\text { forest } \\
\text { insectivores: } \\
\text { abundance }\end{array}$} & rel.var.imp & 1 & 1 & 1 & 1 & - & 1 & 1 & 1 & - & \\
\hline & n. models & 1 & 1 & 1 & 1 & - & 1 & 1 & 1 & - & 1 \\
\hline
\end{tabular}

Abbreviations: $*=$ interaction term. 
Table 2: Anova results for the best models (those including all important explanatory variables) predicting total abundance and species richness per plot, for all birds, forest birds and insectivorous forest birds, respectively. Significant variables except the intercept are indicated in bold. Abbreviations: numDF= numerator degrees of freedom, denDF $=$ denumerator degrees of freedom.

\begin{tabular}{|c|c|c|c|c|c|}
\hline Response Variable & Explanatory Variable & numDF & denDF & F-value & $p$ \\
\hline \multirow{2}{*}{$\begin{array}{l}\text { all bird } \\
\text { species richness }\end{array}$} & intercept & 1 & 146 & 1121.34 & $<0.0001$ \\
\hline & daytime & 1 & 146 & 7.6875 & 0.0063 \\
\hline \multirow{2}{*}{$\begin{array}{l}\text { all bird } \\
\text { abundance }\end{array}$} & intercept & 1 & 146 & 13395.22 & $<0.0001$ \\
\hline & daytime & 1 & 146 & 49.54 & 0.0276 \\
\hline \multirow{7}{*}{$\begin{array}{l}\text { forest bird } \\
\text { species richness }\end{array}$} & intercept & 1 & 141 & 850.97 & $<0.0001$ \\
\hline & forest type & 2 & 141 & 19.43 & $<0.0001$ \\
\hline & edge distance & 1 & 141 & 9.55 & 0.0024 \\
\hline & area & 1 & 47 & 1.91 & 0.1725 \\
\hline & old forest $\%$ & 1 & 141 & 0.20 & 0.6506 \\
\hline & daytime & 1 & 141 & 9.49 & 0.0025 \\
\hline & area $*$ old forest $\%$ & 1 & 141 & 7.03 & 0.0089 \\
\hline \multirow{4}{*}{$\begin{array}{l}\text { forest bird } \\
\text { abundance }\end{array}$} & intercept & 1 & 143 & 670.61 & $<0.0001$ \\
\hline & forest type & 2 & 143 & 20.16 & $<0.0001$ \\
\hline & edge distance & 1 & 143 & 7.92 & 0.0056 \\
\hline & daytime & 1 & 143 & 9.21 & 0.0029 \\
\hline \multirow{7}{*}{$\begin{array}{l}\text { forest insectivore } \\
\text { species richness }\end{array}$} & intercept & 1 & 141 & 582.07 & $<0.0001$ \\
\hline & forest type & 2 & 141 & 152.84 & $<0.0001$ \\
\hline & edge distance & 1 & 141 & 146.55 & 0.0002 \\
\hline & area & 1 & 47 & 0.09 & 0.7651 \\
\hline & old forest $\%$ & 1 & 141 & 0.88 & 0.3481 \\
\hline & daytime & 1 & 141 & 82.45 & 0.0047 \\
\hline & area $*$ old forest $\%$ & 1 & 141 & 110.22 & 0.0011 \\
\hline \multirow{8}{*}{$\begin{array}{l}\text { forest insectivore } \\
\text { abundance }\end{array}$} & intercept & 1 & 140 & 531.16 & $<0.0001$ \\
\hline & forest type & 2 & 140 & 19.18 & $<0.0001$ \\
\hline & edge distance & 1 & 140 & 13.08 & 0.0004 \\
\hline & area $[\log 10 \mathrm{ha}]$ & 1 & 47 & 0.26 & 0.6118 \\
\hline & old forest $\%$ & 1 & 140 & 5.02 & 0.0266 \\
\hline & altitude & 1 & 140 & 4.49 & 0.0357 \\
\hline & daytime & 1 & 140 & 8.58 & 0.0040 \\
\hline & area $*$ old forest $\%$ & 1 & 140 & 10.17 & 0.0018 \\
\hline
\end{tabular}

Abbreviations: $*=$ interaction term. 


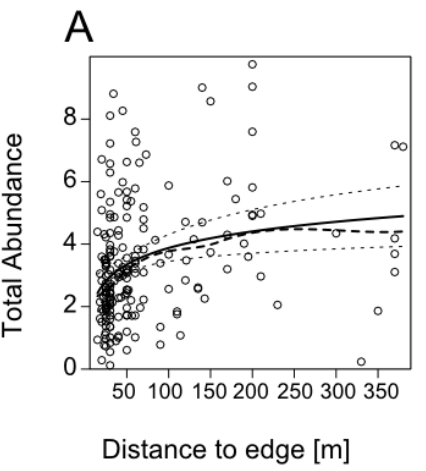

B

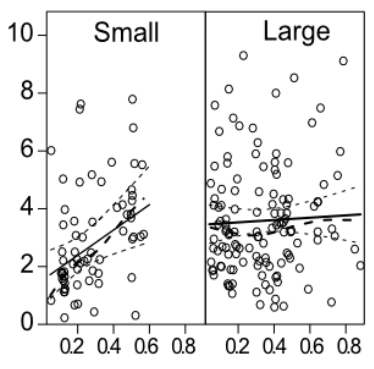

Proportion Old Forest $1000 \mathrm{~m}$

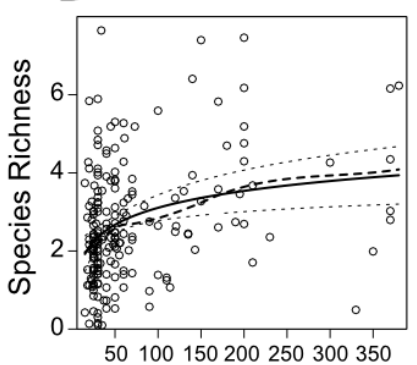

Distance to edge $[\mathrm{m}]$
$\mathrm{E}$

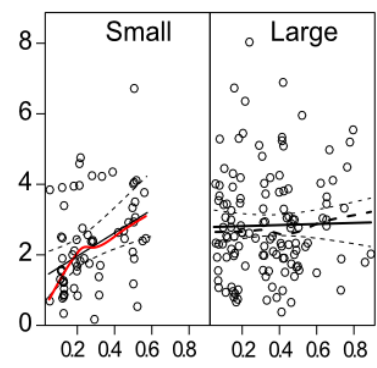

Proportion Old Forest $1000 \mathrm{~m}$

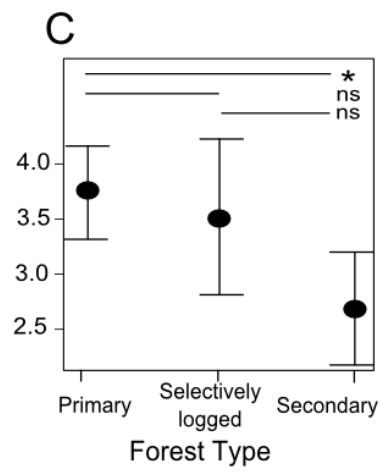

$\mathrm{F}$

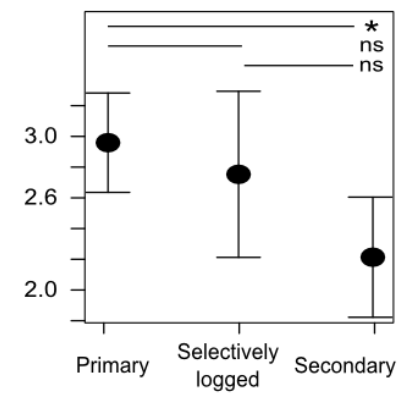

Forest Type

Fig. 3: Response of avian forest insectivores to four key parameters at the plot scale. Note that the entire forest bird community responded similarly. Shown is the response of total abundance (above) and total species richness (below) to edge distance (A \& D), fragment size and amount of old growth forest within $1000 \mathrm{~m}$ radius $(\mathrm{B} \& \mathrm{E})$ and forest type within the plot (C \& F). Shown are predictions (black solid line / filled black dots) and 95\% confidence intervals (thin dashed line / whiskers) for the best model. Circles represent partial residuals, the thick dashed line a loess smoother. The red line is a loess smoother, indicating the abrupt collapse of species richness below $22.3 \%$ cover (see text for details). In B \& E, small and large refers to predictions for patches of 2.5 and 100 ha size, respectively. Effects in A,B, D \&E are all significant at $\alpha=$ 0.05. Significance for pairwise comparisons of forest types ( $\mathrm{C}$ and $\mathrm{F}$ ) are based on two-sided Tukeys post-hoc test; $*$ indicates $\mathrm{p}<0.05$.

Importantly, the proportion of all forest was a poor predictor of abundance and richness at the plot level, Model selection run without ALLFOR versus without OLDFOR additionally suggested that this was not only due the high correlation with old forest and subsequently down-biased variable importance; variable importance of ALLFOR never exceeded 0.5 in any model during model selection without OLDFOR. Further, the best model starting without OLDFOR always performed worse than those without ALLFOR ( $\triangle$ AICc always $>2$ for all responses).

\section{$\beta$-diversity}


The analysis of multivariate dispersion indicated that the four groups significantly differed in $\beta$-diversity (anova: df $=3, \mathrm{~F}=6.747, p<0.001$ ). Generally, large connected fragments showed the highest $\beta$-diversity, followed by large isolated, small connected and finally small isolated fragments. Small isolated fragments had significantly lower community dispersion than the other categories (Fig. 4A, Table 3), indicating very low turnover between small isolated fragments. However, $\beta$-diversity did not only significantly differ for pairwise comparisons between the other three categories.

A

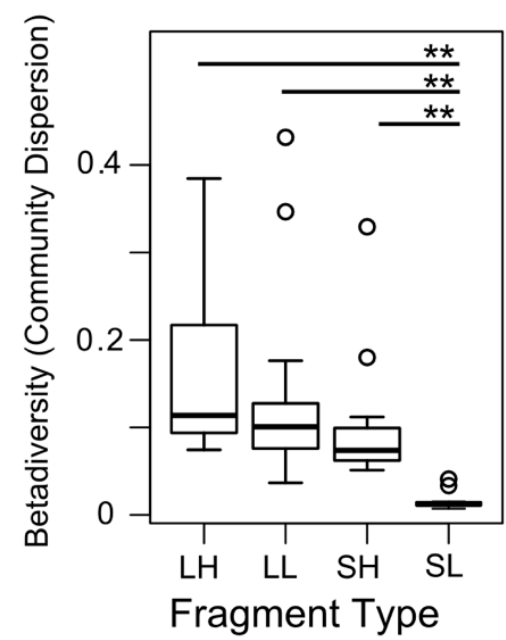

B

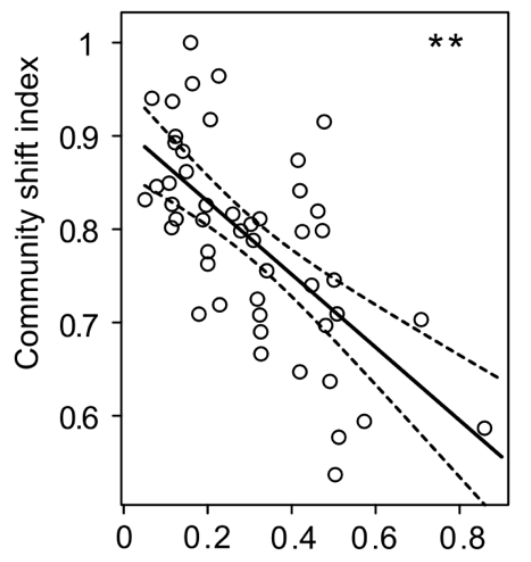

Proportion Old Forest $1000 \mathrm{~m}$

Fig. 4: $\beta$-Diversity and community shift of the entire bird community. A) Boxplots of $\beta$-diversity (community dispersion based on Raup-Crick-dissimilarities) for four groups of forest fragments: Large and high amount of old growth forest (LH), large and low amount of old growth forest (LL), small and high amount of old growth forest (SH), and small low amount of old growth forest (SL). B) Avian community shift in forest fragments compared to pristine forest as a function of the amount of old forest within $1000 \mathrm{~m}$. Shown are predictions (black solid line), the 95\% confidence interval (dashed), and partial residuals (circles) for the best model. High values represent a strong shift, low values high similarity to pristine forest. ** indicates significance at $\alpha=0.01$. 
Table 3: Effect of fragment type on $\beta$-diversity, measured as community dispersion based on Raup-Crick distances. Shown are permutational $p$-values (9999 permutations) for pairwise comparisons between small isolated, small connected, large isolated and large connected fragments. Isolated refers to fragments with less than $25 \%$ of old forest at the landscape scale, connected to fragments with more than $25 \%$ of old forest at the landscape scale. Small fragments were smaller than 5 ha, large fragments larger than 35ha. Significant values are indicated in bold.

\begin{tabular}{l|ccc} 
& Large isolated & Small connected & Small isolated \\
\hline Large connected & 0.5326 & 0.1161 & $\mathbf{0 . 0 0 0 1}$ \\
Large isolated & & 0.4471 & $\mathbf{0 . 0 0 0 8}$ \\
Small connected & & & $\mathbf{0 . 0 0 0 3}$
\end{tabular}

\section{Community shift}

The only important variable influencing community shift was the proportion of old-growth forest (variable weight $=1$ ). The CSI significantly decreased with increasing proportion of old-growth forest (anova: Chisq $=36.209, \mathrm{df}=1, p<0.001$ ), indicating that bird communities were highly similar to pristine forest at high proportions of old-growth forest, irrespective of their size (Fig. 4B). Similar results were achieved with CSI based on Raup-Crick dissimilarities and with generalized additive models using a spatial smooth term.

\section{DisCUSSION}

We found three key results: First, the entire bird community remained surprisingly stable at the plot scale. In contrast, forest bird richness, in particular insectivores, collapsed in small patches, but only at low levels $(<23 \%)$ of old growth forest within the landscape. This shows that negative effects of small patch size were counterbalanced by positive landscape effects. Second, $\beta$-Diversity for the entire bird community imploded in small fragments, but again, only at low amounts of old growth forest in the landscape. This implies homogenized bird communities small, isolated fragments. Third, the amount of old growth forest, but not fragment size, was the main factor affecting the similarity of avian communities found in fragments compared to near-primary forests. This demonstrates that landscape wide habitat composition is instrumental in shaping the trajectory of forest fragment inhabiting bird communities after land conversion.

\section{Plot scale: Effects of landscape characteristics}


We show that the amount of old growth forest within human modified landscapes altered the capability of small forest fragments to harbour forest birds. Importantly, and in accordance with our first hypothesis, landscape-scale amount of old growth forest mitigated the detrimental effect of small patch size on plot-scale species richness and abundance; small patches exhibited significantly lower abundance and species richness than large ones, but only at low amount of old growth forest. This was particularly true for forest insectivores, which face drastic community collapses in anthropogenically fragmented landscapes (Stouffer \& Bierregaard 1995, Sekercioglu et al.2002) and are thus assumed to be among the most threatened tropical bird guilds (Bregmanet al. 2014). The observed pattern suggests that small fragments depend on the pool of immigrants from the "old growth forest" metacommunity to maintain high levels of forest species diversity. This species pool, in turn, increases with habitat amount (Tscharntke et al. 2012, Hadley \& Betts 2012), leading to the positive effect we observed. In contrast, the small isolated fragments of this study appear to profit little from such a rescue effect. Negative effects of small fragments size and low habitat amount or connectivity have been reported previously (Stouffer \& Bierregaard 1995, Lens et al.2002, Lees \& Peres 2006). However, only few authors have explicitly addressed the interaction between fragment size and habitat amount within the landscape: Similar to our results, Roesch et al.(2013) found communities of habitat restricted insects to collapse in small isolated, but not small connected temperate zone grassland habitat fragments. Further, habitat restricted birds required a minimal patch size, but only so when patches were isolated (Betts et al.2006). In conclusion, this suggests that the minimal local area required guaranteeing the persistence of a local population is modified (downsized) in improved landscapes.

In stark contrast to forest species, total abundance and species richness of the entire bird community was not significantly affected by any of the landscape metrics we examined. This is in accordance with a previous study in our region finding that total bird capture rates varied little between small and large forest fragments (Sekercioglu et al. 2002). Work from temperate regions suggests that the conversion of native habitat does not necessarily lead to decreased species richness or abundance in intensively humandominated areas, even if community shifts toward species with high mobility and low habitat specificity occur (Dormann et al. 2007). Indeed, 61\% of the bird species we observed were not restricted to forest and have been found to use the agricultural countryside for foraging (Hughes et al. 2002). The observed stability was therefore largely driven by non-forest species. 
Further, we found no positive landscape effect of secondary forest. This is surprising, given that secondary forests can facilitate colonization of forest fragments in several tropical forest birds (Stouffer \& Bierregaard 1995, Antongiovanni \& Metzger 2005). Regardless, our results suggest that secondary forests on their own are unlikely to sustain avian biodiversity and at most play a subordinate role in shaping forest bird communities.

\section{Plot scale: Effects of local site characteristics}

The capability of fragments to sustain bird communities also depended on forest type and edge proximity. Secondary forest plots supported significantly lower species richness and abundance of forest birds than old forest. This is consistent with Antongiovanni \& Metzger (2005) and Barlow (2007), who reported that secondary forests support only a subset of biota found within older forest. Secondary forests lack many microhabitat elements such as dead trees or sparse understory vegetation that are of elementary importance for many forest birds, particularly insectivores (Sekecioglu et al.2002, Laurance 2008). This is critical, given that over 50\% of the remaining humid tropical forest in human modified landscapes is secondary forest (Melo et al.2013). On the other hand, young stages of forest regrowth adjacent to old growth forest can mitigate edge-avoidance in forest-interior birds, and thus extend the undisturbed core area (Stouffer \& Bierregaard 1995, Lauranceet al. 2004). Overall, our results show that assuming that these secondary forests support equivalent levels of biodiversity to old growth remnants could be risky.

Selective logging did not appear to affect the bird community, which can be expected given the relatively low intensity of selective tree removal in the Coto Brus region. In a recent global meta-analysis, Burivalova et al. (2014) found that bird species richness was even slightly elevated under selective logging. But importantly, this increase was driven by an influx of habitat generalist species, while forest specialist species richness decreased at higher levels of logging intensity. Logging can not only influence bird communities by local changes in habitat quality, but also further alter landscape-wide movement of birds (Graham 2001). Although a certain dietary flexibility may help some (insectivorous) forestbirds to compensate altered food availability caused by selective logging (Edwards et al. 2013), heavy forest perturbation can induce elevated, physiologically relevant stress levels (Lens 1999). Thus, increased tree removal seen in other regions is likely to have larger effects on the bird community than we observed (Burivalova et al. 2014).

Forest bird richness and abundance, in particular insectivores, decreased by $\sim 50 \%$ in edge proximity compared to the interior (Fig 3). Fragment edges can have elevated predator and brood parasites levels (Gates \& Gysel, 1978; Wilcove 1985). In combination 
with our results, this suggests that increasing the core area of remaining forest fragments in human modified landscape is likely to have a positive effect. Further, this also suggests that increasing the width of common linear landscape elements, a dominant feature in tropical countrysides (Harvey et al.2005), may be important to increase their functionality in facilitating movements and functional connectivity between forest fragments (Gillies \&Clair 2008).

\section{$\beta$ - diversity and community shift}

Contrasting with the plot scale, our results demonstrate that habitat amount and fragment size can determine $\beta$-diversity of the entire bird community: The variation of species identities among fragments (community dispersion), appeared to decrease with increasing degree of forest degradation: Large, connected fragments varied most, followed by large isolated, small connected and small isolated. Importantly, small fragments showed significantly reduced levels of species variation between fragments, at low amounts of old forest within the landscape, but not at high amounts. This indicates that only a depauperated set of species occurred again and again in small, isolated fragment, whereas high levels of old growth forest mitigated community homogenization. Indeed, many typical forest restricted species such as the insectivorous Formicarius analis and the endemic hummingbird Lampornis castaneoventris did not occur at all in small isolated patches. Many rare species including insectivores and frugivores (e.g. Anabacerthia variegaticeps, Campylorbamphus pusillus, Chlorophonia callophrys) occurred only in a few large and connected fragments. Typical for many tropical organism groups, intact tropical bird communities generally contain a high proportion of rare species (Terborgh 1990, Robinson et al. 2000), many of them bound to a specific set of environmental factors (Laurance 2008). These rare species bound to large connected patches also explain the at first counterintuitive high $\beta$-diversity among the most intact fragments: many rare species were either only present in a few fragments or potentially present in many, but only detected in few surveys.Overall, this result suggests that bird communities in small, isolated patches undergo a broadly predefined trajectory of species loss, resulting in a homogenized subset of the original community (Lobo 2011). However, we show that this erosion of $\beta$-diversity can be partly mitigated by a high landscape wide retention of old growth forest.

We know of few previous studies that disentangled the effect of habitat amount and configuration on $\beta$-diversity: Similar to our results, Arroyo-Rodriguez et al. (2008) found that small forest fragments could cumulatively harbour much of the native plant diversity through high levels of $\beta$-diversity, but only with high forest cover remaining in the 
landscape. Interestingly, our analysis based on the community shift index suggests, that the trajectory of avian communities in forest fragments strongly depends on the amount of old growth forest in the landscape. Thus, bird communities in forest fragments appear to be shaped most by the landscape wide species pool, which determines the number and the identity of potential immigrants. Importantly, this implies that also small forest remnants, which are among the most abundant tropical landscape elements, can harbour bird species found in pristine forests - given a high landscape-level percentage of old growth forest.

\section{A note on landscape thresholds}

Our results strongly suggest disturbance thresholds beyond which human modified landscapes rapidly support lower levels of native avian biodiversity. Reducing the amount of old forest on the landscape to less than $\sim 23 \%$ appears to rapidly increase negative effects on forest insectivore birds. Further, $\beta$ - diversity (species variation between sites), even calculated with a measure independent of $\alpha$ - diversity, appeared to implode at low levels of old growth forest cover. This implies, that fragment size is most important within landscapes of low forest amount, but less so in areas with high forest amount, and not only for $\alpha$-, but also for $\beta$ - diversity. Several studies have suggested a similar 'fragmentation threshold' for habitat amount in human modified landscapes, below which habitat configuration may become significant (Andren 1994; Betts et al. 2006; Tscharntke et al. 2012; Villard \& Metzger 2014). However, to our knowledge this study is among the first to report interactive effects of habitat amount and configuration on multiple diversity dimensions simultaneously. Species area-relationships are often used in literature to predict species loss of habitat specialists after habitat loss (Lindenmayer \& Fischer 2006). Our study suggests that ignoring the landscape context in such studies might lead to limited insights.

\section{CONCLUSIONS}

Our results caution against potentially misleading expectations that moderately human modified landscape may represent a panacea for the conservation of tropical biodiversity. We found that there are specific characteristics of human modified landscapes that affect their ability to sustain avian biodiversity. In particular our results emphasize previous calls (Gibson et al. 2011, Laurance et al.2012) on the importance of old growth forest for biodiversity conservation in tropical landscapes. Not only does old forest support higher levels of forest bird diversity, its benefits extend to mitigating fragmentation effects 
in surrounding small fragments. Our study shows that the minimal local area (fragment size) required to maintain high levels of $\alpha$ - and $\beta$ - diversity decreases if landscape-level amount old forest remains above a critical threshold $(\sim 25 \%)$. However, if too much old forest is lost, biodiversity in small patches will collapse and converge among fragments. Secondary forest supported lower levels of species richness and abundance and failed to offer the same capacity as old forest to mitigate fragmentation effects in small forest remnants. Additionally we found high levels of edge avoidance suggesting that increasing core areas may be valuable for conservation forest bird diversity within human modified landscapes. In general our results suggest that while human modified landscapes are a suitable option for conserving avian diversity in tropical landscapes care needs to be taken to insure that disturbance thresholds are not crossed.

\section{Acknowledgements}

We would like to thank Jeisson Figueroa for field work, Guillermo Duran and Zak Zahavi for GIS support, Jim Zook and Danny Karp for helpful initial discussions and all landowners for access to their properties. This research was funded by the DFG Research Training Group 1644 Scaling Problems in Statistics (UGK), NSF-DEB-1050954 (MGB, WDR, ASH) and NSERC-PDF (ASH). 


\section{REFERENCES}

Anderson, M. J., et al. (2011) Navigating the multiple meanings of $\beta$ diversity: a roadmap for the practicing ecologist. Ecology Letters, 14(1), 19-28.

Anderson, M. J., Ellingsen, K. E., \& McArdle, B. H. (2006) Multivariate dispersion as a measure of beta diversity. Ecology Letters, 9(6), 683-693.

Andren, H. (1994) Effects of habitat fragmentation on birds and mammals in landscapes with different proportions of suitable habitat: a review. Oikos, 355-366.

Antongiovanni, M., \& Metzger, J. P. (2005) Influence of matrix habitats on the occurrence of insectivorous bird species in Amazonian forest fragments. Biological Conservation, $122(3), 441-451$.

Arroyo-Rodríguez, V., Pineda, E., Escobar,F., \& Benitez-Malvido., J. (2008) Value of Small Patches in the Conservation of Plant-Species Diversity in Highly Fragmented Rainforest. Conservation Biology, 23(3), 729-739.

Barlow, J., Mestre, L. A., Gardner, T. A., \& Peres, C. A. (2007) The value of primary, secondary and plantation forests for Amazonian birds. Biological Conservation, 136(2), 212-231.

Barton, K. (2014) MuMIn: Multi-model inference. R package version 1.10.5. http://CRAN.Rproject.org $/$ package $=$ MuMIn .

Betts, M. G., Forbes, G. J., Diamond, A. W., \& Taylor, P. D. (2006) Independent effects of fragmentation on forest songbirds: an organism-based approach. Ecological Applications, 16(3), 1076-1089.

Bregman, T. P., Sekercioglu, C. H., \& Tobias, J. A. (2014) Global patterns and predictors of bird species responses to forest fragmentation: Implications for ecosystem function and conservation. Biological Conservation, 169, 372-383.

Burivalova, Z., Şekercioğlu, Ç. H., \& Koh, L. P. (2014) Thresholds of Logging Intensity to Maintain Tropical Forest Biodiversity. Current Biology, 24 (16),1893-1898.

Chazdon, R. L., et al. (2009) The Potential for Species Conservation in Tropical Secondary Forests. Conservation Biology, 23,1406-1417.

Clough, Y., Dwi Putra, D., Pitopang, R., \& Tscharntke, T. (2009) Local and landscape factors determine functional bird diversity in Indonesian cacao agroforestry. Biological Conservation, 142(5), 1032-1041.

Dirzo, R., et al. (2014) Defaunation in the Anthropocene. Science, 345(6195), 401-406. 
Dormann, C. F., et al. (2007) Effects of landscape structure and land-use intensity on similarity of plant and animal communities. Global Ecology and Biogeography, 16(6), 774-787.

Edwards, D.P. et al. (2013) Trophic flexibility and the persistence of understory birds in intensively logged rainforest. Conservation Biology, 27(5), 1079-86.

Fahrig, L. (2003) Effects of habitat fragmentation on biodiversity. Annual review of ecology, evolution, and systematics, 34, 487-515.

FAO \& JRC. (2012)Global forest land-use change 1990-2005, by E.J. Lindquist, R. D’Annunzio, A. Gerrand, K. MacDicken, F. Achard, R. Beuchle, A. Brink, H.D. Eva, P. Mayaux, J. San-Miguel-Ayanz \& H-J. Stibig. FAO Forestry Paper No. 169. Food and Agriculture Organization of the United Nations and European Commission Joint Research Centre. Rome, FAO.

Fischer, J., \& Lindenmayer, D. B. (2002) Small patches can be valuable for biodiversity conservation: two case studies on birds in southeastern Australia. Biological Conservation, 106(1), 129-136.

Fischer, J., et al. (2014) Land Sparing Versus Land Sharing: Moving Forward. Conservation Letters 7(3), 149-157.

Fischer, J., et al. (2011) Conservation, Limits of Land Sparing. Science, 334 (6056), 593-593.

Foley, J. A., et al. (2005) Global consequences of land use. Science, 309(5734), 570-574.

Fox J. (2014) Effects Package, 3.0-1. http://cran.r-project.org/package=effects.

Frishkoff, L. O., et al. (2014) Loss of avian phylogenetic diversity in neotropical agricultural systems. Science, 345(6202), 1343-1346.

Gardner, T. A., J. Barlow, N. S. Sodhi, \& Peres, C. A. (2010) A multi-region assessment of tropical forest biodiversity in a human-modified world. Biological Conservation, 143,2293-2300.

Gates, J.E., \& Gysel, L.W. (1978) Avian nest dispersion and fledgling outcome in fieldforest edges. Ecology 59(1), 871-883.

Gibson, L., et al. (2011) Primary forests are irreplaceable for sustaining tropical biodiversity. Nature, 478(7369), 378-381.

Gillies, C.S \& Clair, C.C.S. (2008) Riparian corridors enhance movement of a forest specialist bird in fragmented tropical forest. Proceedings of the National Academy of Sciences of the United States of America,105(50): 19774-19779. 
Graham, C. H. (2001) Factors Influencing Movement Patterns of Keel-Billed Toucans in a Fragmented Tropical Landscape in Southern Mexico. Conservation Biology, 15(6), 1789-1798.

Hadley, A. S., \& Betts, M. G. (2009). Tropical deforestation alters hummingbird movement patterns. Biology letters, rsbl.2008.0691.

Hadley, A. S., \& Betts, M. G. (2012) The effects of landscape fragmentation on pollination dynamics: absence of evidence not evidence of absence. Biological Reviews, 87(3), 526-544.

Hadley, A.S., Frey, S.J., Robinson, W.D., Kress, W.J. \& Betts, M.G. (2014) Tropical forest fragmentation limits pollination of a keystone understory herb. Ecology, 95(8): 22022212.

Harvey, C.A. et al. (2005) Contribution of live fences to the ecological integrity of agricultural landscapes. Agriculture, Ecosystems \& Environment, 111(1): 200-230.

Herzog, S. K., Kessler, M., \& Cahill, T. M. (2002) Estimating species richness of tropical bird communities from rapid assessment data. The Auk, 119(3), 749-769.

Hothorn, T., Bretz, F., \& Westfall, P. (2008)Simultaneous Inference in General Parametric Models. Biometrical Journal 50(3), 346-363.

Hothorn, T., Buehlmann, P., Kneib, T., Schmid, M.,\& Hofner, B. (2014)mboost: Model-Based Boosting, R package version 2.3-0. http://CRAN.R-project.org/package=mboost.

Hughes,J.B., Daily, G.C.,\& Ehrlich, P.R. (2002) Conservation of tropical forest birds in countryside habitats. Ecology Letters, 5(1): 121-129.

Karp, D. S., et al. (2013) Forest bolsters bird abundance, pest control and coffee yield. Ecology Letters, 16(11), 1339-1347.

Karp, D. S., et al. (2012) Intensive agriculture erodes $\beta$-diversity at large scales. Ecology Letters, 15(9), 963-970.

Laurance, S. G., Stouffer, P. C., \& Laurance, W. F. (2004) Effects of road clearings on movement patterns of understory rainforest birds in central Amazonia. Conservation Biology, 18(4), 1099-1109.

Laurance, W. F. (2008) Theory meets reality: how habitat fragmentation research has transcended island biogeographic theory. Biological Conservation, 141(7), 1731-1744.

Laurance, W. F., et al. (2012) Averting biodiversity collapse in tropical forest protected areas. Nature, 489(7415), 290-294.

Laurance, W. F. (2013) Does research help to safeguard protected areas?. Trends in ecology \& evolution, 28(5), 261-266. 
Laurance, W. F., Sayer, J., \& Cassman, K. G. (2014) Agricultural expansion and its impacts on tropical nature. Trends in ecology \& evolution, 29(2), 107-116.

Lees, A. C., \& Peres, C. A. (2006) Rapid avifaunal collapse along the Amazonian deforestation frontier. Biological Conservation, 133(2), 198-211.

Lees, A. C., \& Peres, C. A. (2009) Gap-crossing movements predict species occupancy in Amazonian forest fragments. Oikos, 118(2), 280-290.

Lens, L., van Dongen, S., Wilder, C. M., Brooks, T. M., \& Matthysen, E. (1999) Fluctuating asymmetry increases with habitat disturbance in seven bird species of a fragmented afrotropical forest. Proceedings of the Royal Society of London. Series B: Biological Sciences, 266(1425), 1241-1246.

Lindenmayer, D. B., \& Fischer, J. (2006) Habitat fragmentation and landscape change: an ecological and conservation synthesis. Island Press.

Lôbo, D., Leão, T., Melo, F. P., Santos, A. M., \& Tabarelli, M. (2011) Forest fragmentation drives Atlantic forest of northeastern Brazil to biotic homogenization. Diversity ※Distributions, 17(2), 287-296.

Maas, B., Clough, Y., \& Tscharntke, T. (2013) Bats and birds increase crop yield in tropical agroforestry landscapes. Ecology letters, 16(12), 1480-1487.

Melo, F. P. L., Arroyo-Rodriguez, V., Fahrig, L., Martinez-Ramos, M., \& Tabarelli, M.(2013) On the hope for biodiversity-friendly tropical landscapes. Trends in Ecology \& Evolution, 28(8):462-468.

Mendenhall, C. D., Karp, D. S., Meyer, C. F., Hadly, E. A., \& Daily, G. C. (2014) Predicting biodiversity change and averting collapse in agricultural landscapes. Nature, 509(7499), 213-217.

Millennium Ecosystem Assessment (2005) Millennium Ecosystem Assessment Ecosystems and Human Well-being: Synthesis, Island Press.

Lens, L., Van Dongen, S., Norris, K., Githiru, M., \& Matthysen, E. (2002) Avian persistence in fragmented rainforest. Science, 298(5596), 1236-1238.

Myers, N., Mittermeier, R. A., Mittermeier, C. G., Da Fonseca, G. A., \& Kent, J. (2000) Biodiversity hotspots for conservation priorities. Nature, 403(6772), 853-858.

Oksanen, J., et al. (2013) vegan: Community Ecology Package. R package version 2.0-10. http:/ /CRAN.R-project.org/package= vegan

Paradis, E., Claude, J., \& Strimmer, K. (2004) APE: analyses of phylogenetics and evolution in R language. Bioinformatics, 20, 289-290. 
Perfecto, I. \& Vandermeer,J. (2008) Biodiversity conservation in tropical agroecosystems A new conservation paradigm. Year in Ecology and Conservation Biology,2008(1134), 173-200.

Perfecto, I. \& Vandermeer, J.(2010) The agroecological matrix as alternative to the landsparing/agriculture intensification model. Proceedings of the National Academy of Sciences of the United States of America, 107(13), 5786-5791.

Phalan, B., M. Onial, A. Balmford, \& Green, R. E.(2011) Reconciling Food Production and Biodiversity Conservation: Land Sharing and Land Sparing Compared. Science, 333 (6047),1289-1291.

Pinheiro, J., Bates, D., DebRoy, S., Sarkar, D. \& R Core Team (2014)nlme: Linear and Nonlinear Mixed Effects Models. R package version 3.1-117, <URL: http://CRAN.Rproject.org $/$ package $=$ nlme $>$

R Core Team (2014)R: A language and environment for statistical computing. R Foundation for Statistical Computing, Vienna. Austria. URL http://www.R-project.org/.

Robinson, S. K., \& Terborgh, J. (1995) Interspecific aggression and habitat selection by Amazonian birds. Journal of Animal Ecology, 1-11.

Robinson, W. D. (1999) Long-term changes in the avifauna of Barro Colorado Island, Panama, a tropical forest isolate. Conservation Biology, 13(1), 85-97.

Robinson, W. D., Robinson, T. R., Robinson, S. K., \& Brawn, J. D. (2000) Nesting success of understory forest birds in central Panama. Journal of Avian Biology, 31(2), 151-164.

Rösch, V., Tscharntke, T., Scherber, C., \& Batary, P. (2013) Landscape composition, connectivity and fragment size drive effects of grassland fragmentation on insect communities. Journal of Applied Ecology, 50(2), 387-394.

Sekercioglu, C. H. (2003) Conservation through commodification. Birding,35 (4), 394-402.

Sekercioglu, C. H. (2006) Increasing awareness of avian ecological function. Trends in Ecology \& Evolution, 21(8), 464-471.

Şekercioglu, Ç. H., Daily, G. C., \& Ehrlich, P. R. (2004) Ecosystem consequences of bird declines. Proceedings of the National Academy of Sciences, 101(52), 18042-18047.

Şekercioglu, Ç. H., et al. (2002) Disappearance of insectivorous birds from tropical forest fragments. Proceedings of the National Academy of Sciences, 99(1), 263-267.

Slud, P. (1976) Geographic and climatic relationships of avifaunas with species reference to comparative distribution in the Neotropics. Smithsonian, Washington, DC. 
Steffan-Dewenter, I. et al. (2007) Tradeoffs between income, biodiversity, and ecosystem functioning during tropical rainforest conversion and agroforestry intensification. Proceedings of the National Academy of Sciences, 104(12), 4973-4978.

Stier, A. C., Geange, S. W., Hanson, K. M., \& Bolker, B. M. (2013) Predator density and timing of arrival affect reef fish community assembly. Ecology, 94(5), 1057-1068.

Stiles, F.G. \& Skutch, A.F. (1989)A Guide to the Birds of Costa Rica. Cornell University, Ithica, New York.

Stouffer, P. C.,\& Bierregaard Jr, R. O. (1995) Use of Amazonian forest fragments by understory insectivorous birds. Ecology, 76(8), 2429-2445.

Terborgh, J. (1990)An overview of research at Cocha Cashu biological station. Four neotropical rainforests. Yale University Press, New Haven, 48-59.

Tabarelli, M., A. V. Aguiar, M. C. Ribeiro, J. P. Metzger, \& Peres, C. A. (2010) Prospects for biodiversity conservation in the Atlantic Forest: Lessons from aging humanmodified landscapes. Biological Conservation, 143, 2328-2340.

Tilman, D., C. Balzer, J. Hill, \& Befort,B. L. (2011) Global food demand and the sustainable intensification of agriculture. Proceedings of the National Academy ofSciences, 108(59),20260-20264.

Tscharntke, T., et al. (2012) Landscape moderation of biodiversity patterns and processes eight hypotheses. Biological Reviews, 87(3), 661- 685.

Turner, I. M., \& Corlett, R. (1996) The conservation value of small, isolated fragments of lowland tropical rain forest. Trends in Ecology \& Evolution, 11(8), 330-333.

Tylianakis, J. M., Klein, A. M., \& Tscharntke, T. (2005) Spatiotemporal variation in the diversity of Hymenoptera across a tropical habitat gradient. Ecology, 86(12), 32963302.

Venables, W.N. \& Ripley, B.D. (2002) Modern Applied Statistics with S. Springer, New York.

Villard, M. A., \& Metzger, J. P. (2014) Review: Beyond the fragmentation debate: a conceptual model to predict when habitat configuration really matters. Journal of Applied Ecology, 51(2), 309-318.

Wade, T. G., Riitters, K. H., Wickham, J. D., \& Jones, K. B. (2003) Distribution and causes of global forest fragmentation. Conservation Ecology, 7(2), 7.

Watson, D. M. (2010) Optimizing inventories of diverse sites: Insights from Barro Colorado island birds. Methods in Ecology and Evolution, 1(3), 280-291.

Whittaker, R.H. (1960) Vegetation of the Siskiyou Mountains, Oregon and California. Ecological Monographs, 30(3), 279-338. 
Wilcove, D.S.(1985) Nest predation in forest tracts and the decline of migratory songbirds. Ecology, 66(4), 1212-1214.

Wood, S.N. (2006) Generalized Additive Models: An Introduction with R. Chapman and Hall/CRC.

Wright, S. J. (2010) The future of tropical forests. Annals of the New York Academy of Sciences, 1195(1), 1-27. 


\section{SUPPORTING INFORMATION}

Table S1: Correlation coefficients of explanatory variables used in the study (Pearson's r) and their significances, calculated at the plot level.

\begin{tabular}{|c|c|c|c|c|c|c|}
\hline $\begin{array}{l}\text { Pearson } \\
\text { correlation } \\
\text { coefficient }\end{array}$ & $\begin{array}{l}\text { Edge } \\
\text { Distance }\end{array}$ & $\begin{array}{l}\log 10(\text { Area }[ \\
\text { ha]) }\end{array}$ & $\begin{array}{l}\text { Total } \\
\text { Forest }\end{array}$ & $\begin{array}{l}\text { Old Growth } \\
\text { Forest }\end{array}$ & Altitude & Daytime \\
\hline Edge Distance & 1.00 & 0.52 & 0.42 & 0.26 & 0.04 & 0.29 \\
\hline Area $(\log 10[\mathrm{ha}])$ & 0.52 & 1.00 & 0.43 & 0.13 & 0.07 & 0.44 \\
\hline Total Forest & 0.42 & 0.43 & 1.00 & 0.69 & 0.19 & 0.25 \\
\hline Old Growth Forest & 0.26 & 0.13 & 0.69 & 1.00 & 0.50 & 0.05 \\
\hline Altitude & 0.04 & 0.07 & 0.19 & 0.50 & 1.00 & 0.00 \\
\hline Time of Day & 0.29 & 0.44 & 0.25 & 0.05 & 0.00 & 1.00 \\
\hline$p$-values & $\begin{array}{l}\text { Edge } \\
\text { Distance }\end{array}$ & $\begin{array}{l}\log 10 \text { (Area[ } \\
\text { ha]) }\end{array}$ & $\begin{array}{l}\text { Total } \\
\text { Forest }\end{array}$ & $\begin{array}{l}\text { Old Growth } \\
\text { Forest }\end{array}$ & Altitude & Daytime \\
\hline Edge Distance & & 0.0000 & 0.0000 & 0.0003 & 0.5981 & 0.0000 \\
\hline Area $(\log 10[\mathrm{ha}])$ & 0.0000 & & 0.0000 & 0.0762 & 0.3148 & 0.0000 \\
\hline Total Forest & 0.0000 & 0.0000 & & 0.0000 & 0.0068 & 0.0004 \\
\hline Old Growth Forest & 0.0003 & 0.0762 & 0.0000 & & 0.0000 & 0.5084 \\
\hline Altitude & 0.5981 & 0.3148 & 0.0068 & 0.0000 & & 0.9868 \\
\hline Time of Day & 0.0000 & 0.0000 & 0.0004 & 0.5084 & 0.9868 & \\
\hline
\end{tabular}

Table S2: Threshold analysis for the effect of proportion of old forest on insectivore species richness small patches. Analysis is based on nonlinear, saturating Michaelis-Menten models.

\begin{tabular}{lllll}
\hline Variable & Estimate & Std. Error & $\mathrm{t}$ - value & $\boldsymbol{p}$ \\
\hline Maximum Species Richness & 3.728 & 1.095 & 3.403 & 0.001 \\
Threshold Old Forest cover & 0.227 & 0.153 & 1.482 & 0.143 \\
\hline
\end{tabular}


Tables S3: Details on model selection based on model averaging, for abundance and species richness in all birds and forest insectivores. Shown are models in a $\triangle$ AICc range of 2.

Abundance of all birds

\begin{tabular}{llllll}
\hline Model components $^{1}$ & df & logLik & AICc & $\Delta$ AICc & Weight \\
\hline $\mathbf{5 6}$ & 6 & -526.03 & 1064.51 & 0.00 & 0.14 \\
$\mathbf{2 6}$ & 6 & -526.27 & 1064.99 & 0.48 & 0.11 \\
$\mathbf{2 3 6}$ & 8 & -524.22 & 1065.21 & 0.70 & 0.10 \\
$\mathbf{3 5 6}$ & 8 & -524.28 & 1065.32 & 0.81 & 0.10 \\
$\mathbf{3 6}$ & 7 & -525.43 & 1065.46 & 0.96 & 0.09 \\
$\mathbf{2 4 6}$ & 7 & -525.50 & 1065.59 & 1.08 & 0.08 \\
$\mathbf{6}$ & 5 & -527.65 & 1065.61 & 1.10 & 0.08 \\
$\mathbf{1 5 6}$ & 7 & -525.54 & 1065.68 & 1.18 & 0.08 \\
$\mathbf{2 5 6}$ & 7 & -525.56 & 1065.71 & 1.20 & 0.08 \\
$\mathbf{4 6}$ & 6 & -526.76 & 1065.96 & 1.45 & 0.07 \\
\hline
\end{tabular}

\begin{tabular}{clllll}
\hline 1Term codes: & & & & & \\
ALLPER & ALTI & FORTYPE & AREA & OLDPER & TIME \\
1 & 2 & 3 & 4 & 5 & 6
\end{tabular}

Species richness of all birds

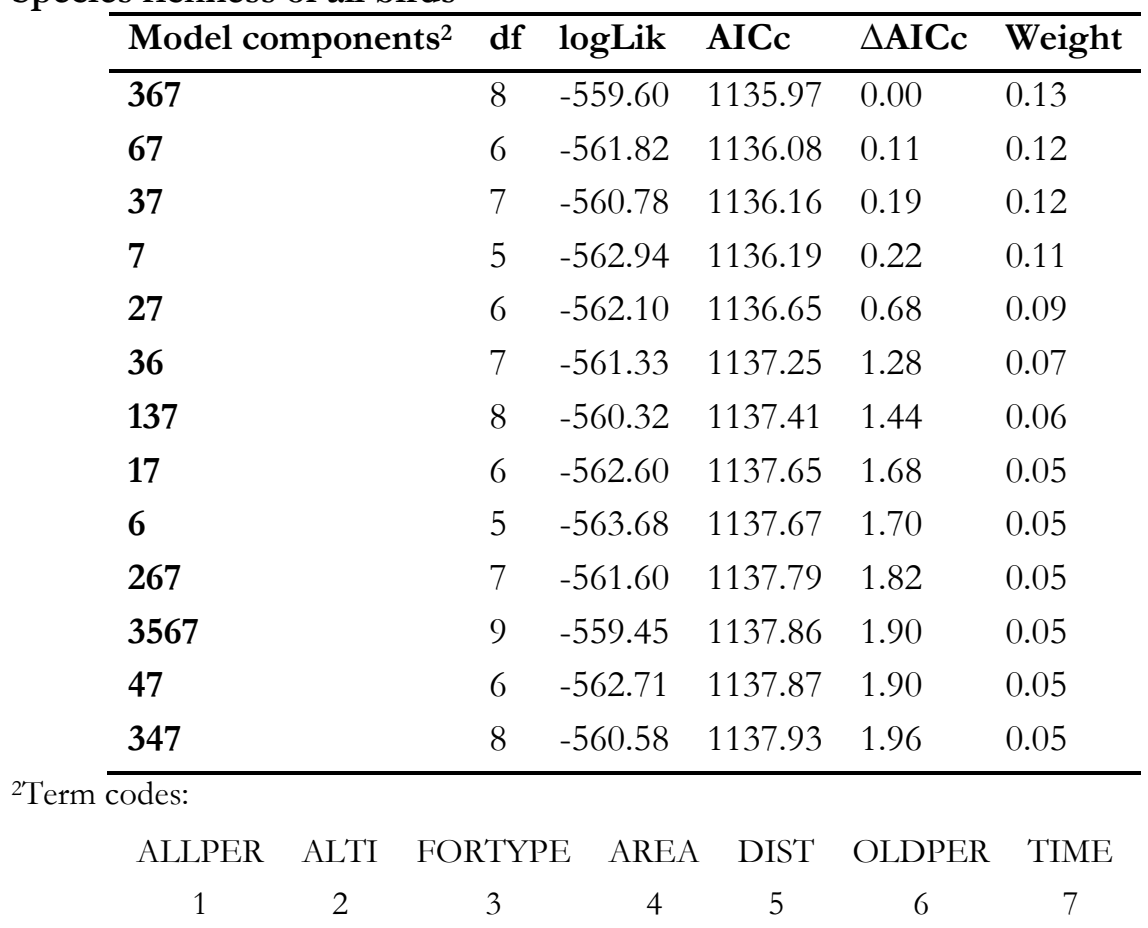


Tables S3 (continued): Details on model selection based on model averaging, for abundance and species richness in all birds and forest insectivores. Shown are models in a $\triangle$ AICc range of 2.

Species richness of forest insectivores

\begin{tabular}{llllll}
\hline $\begin{array}{l}\text { Model } \\
\text { components }^{3}\end{array}$ & df & logLik & AICc & $\Delta$ AICc & Weight \\
\hline $\mathbf{3 4 5 6 7 9}$ & 11 & -349.72 & 722.88 & 0.00 & 0.51 \\
$\mathbf{2 3 4 5 6 7 9}$ & 12 & -349.29 & 724.29 & 1.41 & 0.25 \\
$\mathbf{1 3 4 5 6 7 8 9}$ & 13 & -348.17 & 724.34 & 1.46 & 0.24 \\
\hline
\end{tabular}

3Term codes:

ALLPER ALTI FORTYPE AREA DIST OLDPER TIME ALLREP:AREA OLDPER:AREA

$\begin{array}{llllllllll}1 & 2 & 3 & 4 & 5 & 6 & 7 & 8 & 9\end{array}$

Abundance of forest insectivores

\begin{tabular}{rlllll}
\hline $\begin{array}{l}\text { Model } \\
\text { components }^{4}\end{array}$ & df & logLik & AICc & $\Delta$ AICc & Weight \\
\hline $\mathbf{1 2 3 4 5 6 7}$ & 12 & -402.14 & 829.99 & 0.00 & 1.00 \\
\hline
\end{tabular}

4Term codes:

ALTI FORTYPE AREA DIST OLDPER TIME OLDPER:AREA

$\begin{array}{lllllll}1 & 2 & 3 & 4 & 5 & 6 & 7\end{array}$




\section{Table S4}

Table S4: Pairwise comparisons for the effect of forest type on species richness and abundance based on the best linear mixed effects models. Results are based on Tukey's post hoc tests. Forest types: $\mathrm{p}=$ old growth forest, $\mathrm{i}=$ selectively logged forest (bosque intervenido), $\mathrm{s}=$ secondary forest. Significant differences are indicated in bold.

\begin{tabular}{lllllll}
\hline Response & $\begin{array}{l}\text { Forest } \\
\text { Types }\end{array}$ & Estimate & $\begin{array}{l}\text { Lower } \\
\mathbf{9 5 \%} \text { CI }\end{array}$ & $\begin{array}{l}\text { Upper } \\
\mathbf{9 5 \%} \text { CI }\end{array}$ & z value & $p$ \\
\hline All forest birds & $\mathrm{p}-\mathrm{i}$ & 0.834 & -0.122 & 1.789 & 2.042 & 0.101 \\
Species Richness & $\mathrm{s}-\mathrm{i}$ & -0.636 & -1.581 & 0.308 & -1.577 & 0.254 \\
& $\mathrm{~s}-\mathbf{p}$ & $\mathbf{- 1 . 4 7 0}$ & $\mathbf{- 2 . 2 6 4}$ & $\mathbf{- 0 . 6 7 6}$ & $\mathbf{- 4 . 3 3 4}$ & $<\mathbf{0 . 0 0 1}$ \\
\cline { 2 - 7 } All forest birds & $\mathrm{p}-\mathrm{i}$ & 1.270 & -0.022 & 2.562 & 2.298 & 0.055 \\
Abundance & $\mathrm{s}-\mathrm{i}$ & -0.898 & -2.232 & 0.435 & -1.575 & 0.254 \\
& $\mathrm{~s}-\mathbf{p}$ & $\mathbf{- 2 . 1 6 8}$ & $\mathbf{- 3 . 2 0 6}$ & $\mathbf{- 1 . 1 3 1}$ & $\mathbf{- 4 . 8 8 5}$ & $<\mathbf{0 . 0 0 1}$ \\
\hline Forest insectivore & $\mathrm{p}-\mathrm{i}$ & 0.206 & -0.557 & 0.969 & 0.631 & 0.802 \\
Species Richness & $\mathrm{s}-\mathrm{i}$ & $\mathbf{- 0 . 5 4 0}$ & $\mathbf{- 1 . 2 9 4}$ & 0.215 & -1.673 & 0.214 \\
& $\mathrm{~s}-\mathbf{p}$ & $\mathbf{- 0 . 7 4 6}$ & $\mathbf{- 1 . 3 8 0}$ & $\mathbf{- 0 . 1 1 1}$ & $\mathbf{- 2 . 7 5 1}$ & $\mathbf{0 . 0 1 6}$ \\
\cline { 2 - 7 } Forest insectivore & $\mathrm{p}-\mathrm{i}$ & 0.220 & -0.778 & 1.218 & 0.516 & 0.863 \\
Abundance & $\mathrm{s}-\mathrm{i}$ & -0.832 & $\mathbf{- 1 . 8 1 9}$ & 0.155 & -1.973 & 0.118 \\
& $\mathrm{~s}-\mathbf{p}$ & $\mathbf{- 1 . 0 5 2}$ & $\mathbf{- 1 . 8 8 4}$ & $\mathbf{- 0 . 2 2 0}$ & $\mathbf{- 2 . 9 5 8}$ & $\mathbf{0 . 0 0 9}$ \\
\hline
\end{tabular}




\section{ACKNOWLEDGEMENTS}

During the last 4 years, a whole lot of people supported me for this thesis.

I owe a great debt to my two supervisors, Teja Tscharntke and Christoph Scherber, for giving me the opportunity to conduct this thesis in the Agroecology research group. Although my final thesis does not overlap 100\% with the original project (more $0.5 \% \mathrm{I}$ would say), this never seemed to be big of a deal to them. Importantly, you supported me substantially and throughout to change the scope of this thesis from temperate systems (where our first project faced an abrupt gridlock) to a wonderful tropical system. Teja, thanks for (mostly) having your office door open, especially in the evening, and for your patience when pondering about problems. Christoph, 1000 thanks for showing me the beauty of R (finally I started to enjoy the mindbombing R session), the beauty of thinking beyond paradigms, and most, for believing in scientific integrity.

Martin Schlather was instrumental to get the RTG1644 "Scaling problems in statistics". Also, thanks for showing us the Disco-distribution. Thomas Kneib accepted to inherit the duty of being the RTG chair, and did without doubt a brilliant job. Thanks.

The most important person during the first field season was Verena Rösch. Vreni, thanks for your approximately 7 gigatons of excellent, outstanding food with which you kept the level of motivation high, be it in the field or later on.Peter Batary helped in the field and with coordination. Field work would not have been possible without Filipe Nogueira (we can survive!), Nora German, Felix Weiss, Celilia Cantor, Rüdiger Hoffmann and Annika Hass.Mathias Weithemeier, Fachdienst Umwelt Göttingen and Reinhard Urner, Biol. Schutzgemeinschaft Göttingen helped with field site selection.

I am extremely grateful to Adam Hadley and Matt Betts, who initiated the pollination study in Costa Rica. Adam, it was a great thing to meet you by coincidence - in the Swiss Alps! I thank you for your involvement and help in shaping the corridor and the avian community projects, critical thinking, transport, help during the writing process. Chapter four profited considerably from input of Doug Robinson. Jeisson Figueroa, Dajan Ramirez, Hanna Eberlein and Manuel Larbig provided field assistance and did a great job. I really appreciated the hard work you carried out, and the friendly atmosphere you provided. The team of the Las Cruces Field station provided an outstanding environment 
for research. Further, Noelia Volpe, Randy Figuero, Evan Jackson, Sarah Frey, Mauricio Paniagua, Guillermo Duran, Zak Zahavi and Felix Klaus were instrumental at various stages related to chapter three and four of this thesis. They assisted with site selection, GIS, transport, lab analysis, on site coordination and many other tasks. Importantly, Nadja Klein spent endless hours explaining, programming and customizing BayesX with the least possible delay. Amazing!

I would highlight the tremendous help that Barbara Strauss, Dörte Dede and Jutta Gilles provided to cope with the sometimes absurd officialism of Göttingen University. You did an excellent job so that I could largely focus on my $\mathrm{PhD}$.

The RTG1644 provided a great platform that encouraged to think outside the statistical standard box often used in our field. Special thanks to Philip Mundhenk and Jule Manitz for helping with initial analytical problems.

Further, the Agroecology group provided a splendid environment during the last 4 years. Thanks to the whole team, especially Susanne Jahn und Brigitte Jühnemann for keeping the engine running. Especially, I would like to thank Chrissi Venjakob, Claudia Norman, Georg Everwand, Pierre Gras, Jochen Fründ, Maraja Riehers, Björn Klatt and Carina Burmeister for fooling around, running, barbecuing,generally for having wonderful hours. In addition, 1001 gracias to my office mates (alphabetic order): Queen Sarcasm I Tatiane Beduschi, Lydia Betz (my table is your table), Hella Schlinkert (outstanding mental support) and Julia Uschi Tiede. It was an excellent time with you, girls! Laura Sutcliffe (thanks 1000) and Kristy Udi helped with linguistic improvements.

I would like to thank my friends and family who supported me here in Göttingen and or from more distant places. Thank youLaura, Anja, Julie, Björn and Daniel for providing a good atmosphere at home.

Towards the end of this research project, Iris Motzke became increasingly important, for the thesis and for me. Thanks for climbing, yoga, endless layouting sessions, hiking, generally for being there. I am looking forward to what comes next.

Last but not least, thanks to my parents, who supported me ever since I was there. I would not be there without you (...).

This research was sponsored by the Deutsche Forschungsgemeinschaft, who provided financial support during the first three years of this project. 


\section{Curriculum vitae}

\section{Urs Gabriel Kormann}

\section{Personal information}

Affiliation

Agroecology/ RTG 1644

Dept. of Crop Sciences

Georg-August-University

Grisebachstrasse 6

37077 GöttingenGermany

004915161035873

oso@hotmail.ch

Nationality

Swiss

Language skills Swiss German - fluent (mother tongue)

English - fluent

French - fluent

Spanish - basic skills

\section{Education}

2010 -

PhD cand in Agroecology. Supervisors: Teja Tscharntke \& Christoph Scherber, RTG „Scaling Problems in Statistics“, Georg August University Göttingen, Germany

$2008-09$

Msc in Ecology and Evolution, University of Bern, Switzerland Supervisors: Laurent Excoffier and Felix Gugerli

„Landscape genetics in capercaillie (Tetrao urogallus L.): Combining direct and indirect methods to quantify dispersal and functional connectivity in a mountain landscape"

2003-05 \& 06-07 Undergraduate studies in Zoology. Institute of Ecology and Evolution, University of Bern, Switzerland

„Effects of habitat amount and isolation on bird communities in fragmented traditional orchards" 
$1998-2002$

Matura (High School)

Major: Biology \& Chemistry, Minor: Philosophy. Mathematics and

Sciences School, Gymnasium Bern-Neufeld, Switzerland

Reviewer for:

Community Ecology, PlosOne, Zoology and Ecology, Basic and Applied Ecology, Der Ornithologische Beobachter.

\section{Acquired grants and awards:}

Scientific grants:

2014 DFG Start Up Grant: Sum 12`000 Euros

2013 Volkswagenstiftung: Workshop Organisation "East meets West:

Transferring conservation approaches between Eastern and Western European landscapes“, Coapplicant, sum: 30’600 Euros

2009

Travel Grant Swiss Society for Wildlife Biology. Sum: 500 CHF

Non-scientific grants:

2008: $\quad$ Species Recovery Programme Little Owl, BirdLife Switzerland. Sum: 1000 $\mathrm{CHF}$

2009-12 Evaluation management optimization, Heidenweg: Swiss Ornithological Society, Coapplicant. Sum 30’000 CHF

Awards:

2001, $2002 \quad 1^{\text {st }}$ and $3^{\text {rd }}$ place Swiss Biology Olympiad $(2001,2002)$

2002 Matura Award Gymnasium Bern-Neufeld for outstanding Senior thesis (Maturaarbeit): Prosper or perish: Success of reintroduction programs for endangered plants in the Seeland region. Sum: $500 \mathrm{CHF}$

\section{Teaching experience}

Courses:

2011 \& 12 Assistance "Introduction to Hymenoptera" University Göttingen, 4 hours

2008-09 "Ornithology and bird ecology", Birdlife Zurich, 10 evenings plus excursions

2005 - 08 "Introduction to Evolutionary Biology, Ethology and Taxonomy" for high school students participating in the Swiss Biology Olympiad, 8 hours per 
course

2005-06 "Introduction to Ecology" for high school students participating in the Swiss Biology Olympiad, 3 hours per course

2004 "Plant Systematics" for high school students participating in the Swiss Biology Olympiad, 8 hours per course

2003 - 2009 Substitute teacher at secondary school Ins, Switzerland (maths, german, natural history, handicrafts, gymnastics) app. 100 hours

Supervised students

2013 - 2014 Hanna Eberlein (University of Tübingen). Effects of habitat configuration and composition on wasps and bees in Costa Rica (MSc thesis)

2013 Manuel Larbig (University of Darmstadt): Hecken als Korridore für Kolibris (BSc thesis)

2013 Felix Klaus, Birte Müller, Lisa Marholt, Johanna Julia (Projektpraktikum): Barrier effects of hedgerows and roads on pollinator movement infered by fluorescent dye and fruit set

2013

Florian Hackmann (Projektpraktikum): Habitat heterogeneity influences beta diversity of leafhoppers and sampling efficiency in calcarous grasslands (Co-supervised with Verena Rösch)

2012 Carina Burmeister (Projektpraktikum): Effect of Oil Seed Rape on Calcarous grasslands by spillover of invertebrate predators

2012 Rüdiger Hoffmann (Projektpraktikum): Effekt von Raps auf die Bestäubung einer spezialisierten Kalkmagerrasenpflanze

\section{Community outreach}

$2009-$

$2003-2008$

$2000-2009$
Member of the board for management optimization „IBA Heidenweg“"

Vice Head Swiss Biology Olympiad

Member of the managing board Bernese Society for Ornithology 


\section{Publications}

\section{Peer - reviewed journals (accepted)}

Klaus, F., Klatt, B., Müller, B., Bass,J., Kormann, U. (2015): Hedgerows have a barrier effect and channel pollinator movement in the agricultural landscape. Journal of Landscape Ecology 6(1).

Kormann, U. *, Rösch, V*., Batary, P., Tscharntke, T., Orci, KM., Samu, F., Scherber, C. (2015): Local and landscape management affects trait-mediated biodiversity of nine taxa on small grassland fragments. Diversity \& Distributions 1(14) (* equal contribution)

Sutcliffe, L.M.E., Batáry, P., Kormann, U., participants of the East-West workshop 2013, Tscharntke, T. (2015): Harnessing the biodiversity value of Central and Eastern European farmland. Diversity \& Distributions 21(6) 722 - 730.

Pfeifer, M., Lefebvre, V., Baeten, L., Banks-Leite, C., Barlow, J., Betts, MG., Brunet, J., Cerezo, A., Cisneros, LM., Collard, S., D’Cruze, N., da Silva Motta, C., Duguay, S., Eggermont, H., Eigenbrod, F., Gardner, TA., Hadley, AS., Hanson, TR., Hawes, JE., Heartsill, T., Klingbeil, BT., Kolb, A., Kormann, U., [...], Ewers, R. (2013) BIOFRAG - A new database for analysing BIOdiversity responses to forest FRAGmentation. Ecology and Evolution 4(9), 1524 - 1537.

Kormann, U., Sturmberger, B. (2013)A Sabine's Gull Xema sabini in Montenegro - first record in the North-Eastern Mediterranean and a short review the species'status in the region. Acrocephalus, 34 (156/157): 79-82.

Meichtry-Stier, S., Korner-Nievergelt, F., Kormann, U., Spiess, M., Mosimann-Kampe, P., Strebel, S., Zollinger, JL., Spaar R. (2013Habitat selection of the Common Whitethroat Sylvia communis in the western part of Switzerland: implications for species conservation. Ornithologischer Beobachter 110, 1-16.

Herrmann, J. D., Kormann, U., Schüepp, C., Stocker, Y., Herzog, F., Entling, M. H. (2012) Effects of habitat isolation and predation pressure on an arboreal food-web. Community Ecology, 13(1), 82-87.

Kormann, U., Gugerli, F., Ray, N., Excoffier, L., Bollmann, K. (2012) Parsimony-based pedigree analysis and individual-based landscape genetics suggest topography to 
restrict dispersal and connectivity in the endangered capercaillie. Biological Conservation, 152, 241-252.

Bailey, D., Schmidt-Entling, M. H., Eberhart, P., Herrmann, J. D., Hofer, G., Kormann, U., Herzog, F. (2010) Effects of habitat amount and isolation on biodiversity in fragmented traditional orchards. Journal of Applied Ecology, 47(5), 1003-1013

Mühlner, S., Kormann, U., Schmidt-Entling, M., Herzog, F., Bailey, D. (2010). Structural Versus Functional Habitat Connectivity Measures to Explain Bird Diversity in Fragmented Orchards. Journal of Landscape Ecology, 3(1), 52-64.

\section{Submitted or in preparation}

Zahavi, R.Z., Duran, G.M., Kormann, U.: Sixty-seven years of land-use change in southern Costa Rica. PLoS One (resubmitted with minor revisions)

Beduschi, T., Tscharntke, T., Kormann, U., Scherber C.: Semi-natural habitats increase spatial similarity of pollinator communities within agricultural mosaic landscapes. Resubmitted to Oikos. (manuscript available)

Kormann, U., Scherber, C., Tscharntke, T., Klein. N., Larbig, M., Valente, J., Hadley, AS. Betts, MG.: Corridors restore animal-mediated pollination in fragmented tropical forest landscapes. To be submitted to Proceedings of the Royal Society B(manuscript available)

Madeira, F.N., Elek, Z., Kormann, U., Pons, X., Rösch, V., Samu, F., Scherber, C., Tscharntke, T. (2013) Spillover of predatory and non-predatory arthropods between calcareous grassland, wheat fields and meadows (invited for resubmisssion to Agriculture, Ecosystems \& Environment)

Braaker, S., Obrist, M.K., Kormann, U., Bontadina., F: Landscape genetic structure of urban hedgehogs. To be submitted to Landscape Ecology (manuscript available)

Kormann, U., Tscharntke, T., Betts, MG., Robinson, WD., Hadley, AS., Scherber, C.: Old growth forest mitigates the erosion of tropical bird communities in human modified landscapes. In preparation (manuscript available) 
Non-scientific publications:

Kormann, U. (2008) Turmfalken-Hilfe konkret. ORNIS 3/08.

Kormann, U. (2010, book chapter) Insel Helgoland. In: Aebischer A (eds)(2010): Vögel beobachten in Europa - Die besten Plätze vom Mittelmeer bis zum Nordkap. Haupt Verlag, Bern.

Kormann, U.(2014) Weissrussland - Vergessene Wildnis- ORNIS 1/14

Kormann, U. (2015) Silberreiher: Schmucker Immigrant ORNIS 3/15

Eberlein, H.\& Kormann, U.(2013) Being a „Bee Mother“ in the Tropics. Amigos Newsletter 80. 


\section{Thesis declaration}

I hereby confirm that this thesis was performed and written in accordance with the required standard that the bureaucracy of the Georg August University Göttingen demands. In particular, neither have I used any sources unmentioned in the text (no plagiarism), nor have I used any unauthorized assistance.

Zürich, September 2015 